Raquel Quimas Molina da Costa

\title{
Avaliação da orientação espacial em um ambiente de realidade virtual em pacientes com comprometimento cognitivo leve
}

Tese apresentada à Faculdade de Medicina da Universidade de São Paulo para obtenção do título de Doutor em Ciências

Programa de Neurologia

Orientadora: Dra. Sonia Maria Dozzi Brucki Coorientador: Dr. José Eduardo Pompeu

São Paulo 


\section{Dados Internacionais de Catalogação na Publicaçăo (CIP)}

Preparada pela Biblioteca da

Faculdade de Medicina da Universidade de Săo Paulo

Creproduçāo autorizada pelo autor

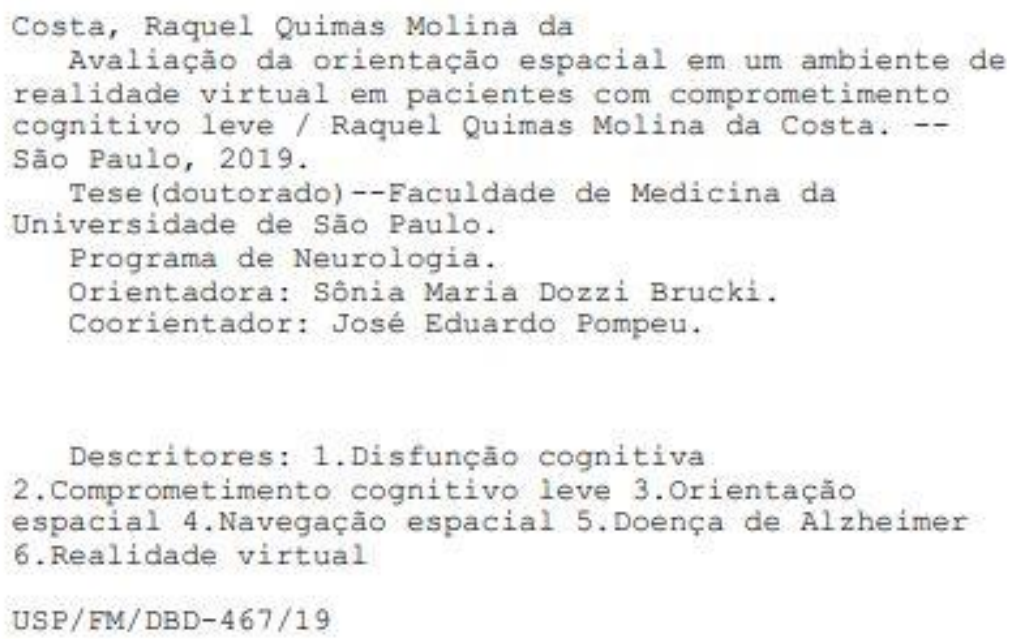

Responsável: Erinalva da Conceiçāo Batista, CRB-8 6755 
Aos meus pais que sempre estiveram ao meu lado e despertaram em mim o amor pelos estudos e pelo conhecimento. É deles o exemplo que me acompanha e me guia.

Ao meu companheiro Leonardo, que me apoiou e me levantou todas as vezes durante essa jornada. Com ele ao meu lado todo o peso se tornou mais leve.

Aos mestres que me inspiraram e acreditaram em mim. 


\section{AGRADECIMENTOS}

Primeiramente agradeço à minha orientadora, Profa. Dra. Sonia Maria Dozzi Brucki, por ter me aceitado como sua aluna, ter acreditado na minha capacidade e ter me incentivado incansavelmente durante todo esse período. Nos momentos em que não me vi capaz, sua certeza me inspirou e me deu coragem. Seus conselhos e direcionamentos certamente moldaram a pesquisadora que me tornei.

Ao meu coorientador, Prof. Dr. José Eduardo Pompeu, que abriu meus olhos para um mundo novo da tecnologia, me guiou por esse mundo e fez com que me apaixonasse por esse trabalho. Seu apoio e orientação foram de grande valor para mim e de valor ainda maior para o fortalecimento deste projeto.

Ao Dr. Rogério Paysano Marrocos e ao colega Dr. Fábio Henrique de Gobbi Porto que me incentivaram, me encorajaram e ajudaram este sonho a se tornar realidade.

Às colegas fisioterapeutas Michelle Didone dos Santos, Fernanda Zillig Rodrigues e Juliana Magalhães Silva que estiveram ao meu lado e me ajudaram de forma fundamental na execução desse trabalho. Sem elas não teria sido possível.

Ao Prof. Dr. Ricardo Nitrini e aos colegas do Grupo de Neurologia Cognitiva e do Comportamento da Faculdade de Medicina de São Paulo que acompanharam o desenvolvimento deste trabalho, contribuindo sempre para meu crescimento e fornecendo todo apoio necessário. À secretária do Centro de Referência em Distúrbios Cognitivos (CEREDIC), Simone Rebouças, que proporcionou o apoio logístico, a ajuda e acima da tudo a parceria que foram de grande importância para mim e para o sucesso deste trabalho. Aos colegas da Escola Politécnica da Universidade de São Paulo, em especial na figura do engenheiro Emerson Moretto, pela dedicação, atenção e apoio, bem como por nos 
cederem o espaço, os equipamentos e o conhecimento técnico. Que a parceria criada entre as equipes multidisciplinares gere ainda muitos frutos com impacto positivo na saúde das pessoas.

Aos colegas da Escola de Educação Física e Esporte da Universidade de São Paulo pelo espaço cedido, pelo apoio dos colegas e por receberem a nossa equipe de braços abertos. À FAPESP pelo financiamento: processo: 16/04984-3. Chamada e-science e ao Conselho Nacional de Desenvolvimento Científico e Tecnológico (CNPq) pela concessão de Bolsa de Doutorado, processo 140534/2018-0.

Por fim, mas não menos importante, aos queridos voluntários que participaram desse estudo, que foram compreensíveis com todas as etapas deles requeridas e que contribuíram não só para o conhecimento científico gerado por este trabalho, mas também para o meu crescimento pessoal e profissional. São eles que nos inspiram a criar e estudar mais para contribuir de alguma forma nesse mundo. 


\section{NORMATIZAÇÃO ADOTADA}

Esta tese está de acordo com as seguintes normas, em vigor no momento desta publicação:

Referências: adaptado de International Committee of Medical Journals Editors (Vancouver). Universidade de São Paulo. Faculdade de Medicina. Divisão de Biblioteca e Documentação. Guia de apresentação de dissertações, teses e monografias. Elaborado por Anneliese Carneiro da Cunha, Maria Julia de A. L. Freddi, Maria F. Crestana, Marinalva de Souza Aragão, Suely Campos Cardoso, Valéria Vilhena. 3a ed. São Paulo: Divisão de Biblioteca e Documentação; 2011.

Abreviaturas dos títulos dos periódicos de acordo com List of Journals Indexed no Index Medicus. 


\section{SUMÁRIO}

Lista de Abreviaturas e siglas

Lista de figuras

Lista de tabelas

Resumo

Abstract

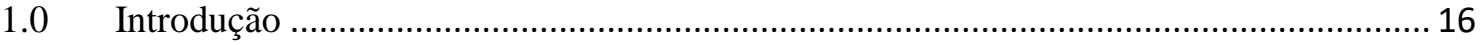

1.1 Comprometimento Cognitivo Leve: Definição e prevalência......................................... 16

1.2 Avaliação cognitiva na identificação de risco em CCL ................................................ 21

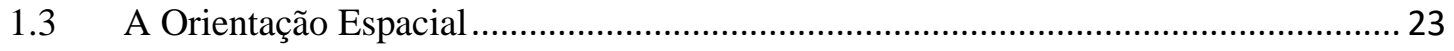

1.4 Avaliações ecológicas e o uso da Realidade Virtual .................................................... 29

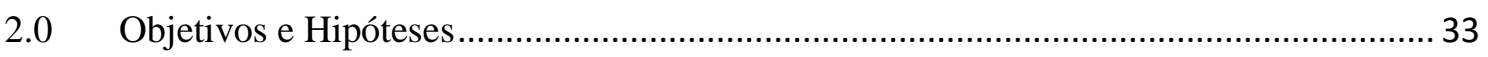

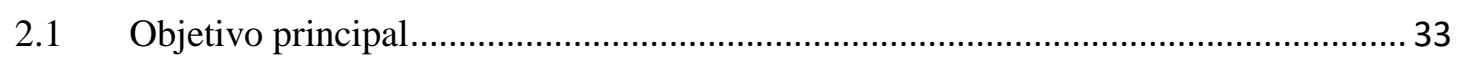

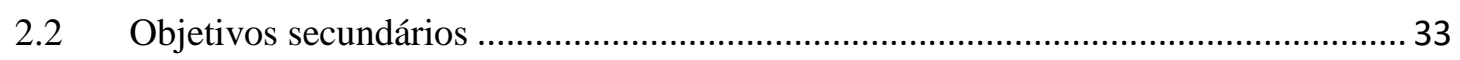

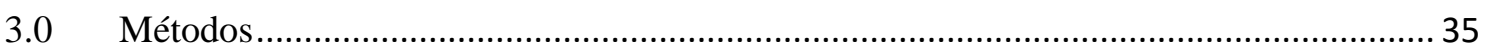

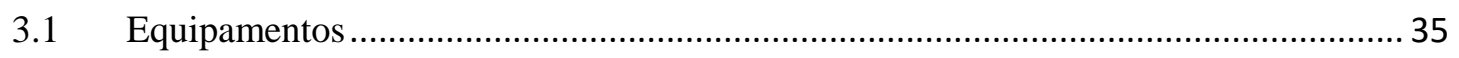

3.2 Tarefas de orientação espacial (Spatial orientation in immersive virtual environment

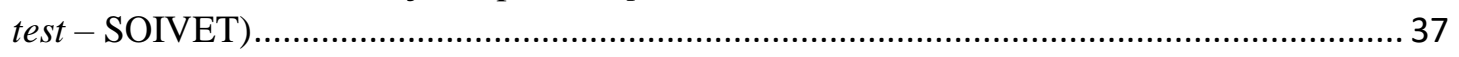

3.2.1 Desenvolvimento do sistema e adaptação das tarefas ............................................ 37

3.2.2. Tarefa SOIVET-Maze (Transposição da perspectiva alocêntrica para egocêntrica)38

3.2.2.1 Avaliação do desempenho dos participantes na tarefa SOIVET-Maze ........................ 41

3.2.3. Tarefa 2: SOIVET-Route (Rota com marcos topográficos) .................................... 41

3.2.3.1. Avaliação do desempenho dos participantes na tarefa SOIVET-Route ............... 43

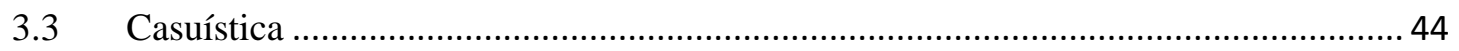

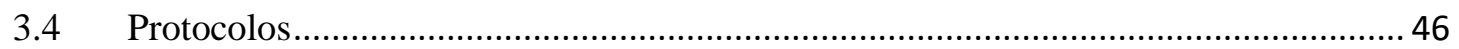

3.4.1. Projeto Piloto- Avaliação da tolerabilidade, sensação de presença e imersão e facilidade de uso ("usabilidade") do sistema SOIVET e tarefas ............................................... 46

3.4.1.1. Medidas de desfecho para Tolerabilidade, Sensação de Presença e Usabilidade ..... 46

3.4.1.2. Análise estatística do projeto piloto ....................................................................... 48

3.4.2. Avaliação com idosos: Validade de construto das tarefas de realidade virtual, comparação de grupos e acurácia das tarefas

3.4.2.1 Análise estatística para validade de construto, comparação de grupos e sensibilidade e especificidade na identificação do grupo CCL em comparação ao grupo controle ................. 51

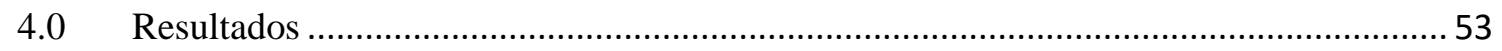

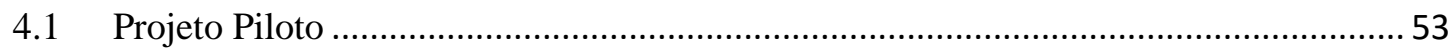

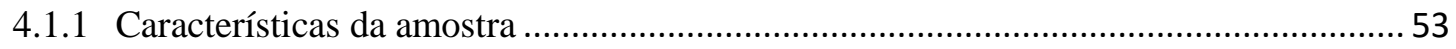

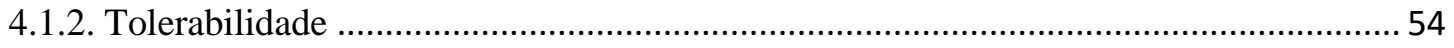


4.1.2 Sensação de Presença e Imersão ......................................................................... 55

4.1.3 Usabilidade - Compreensão das instruções das tarefas e interação com o sistema 56

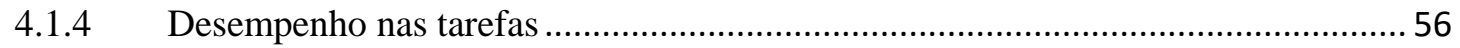

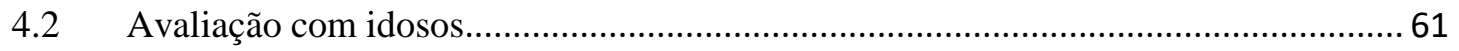

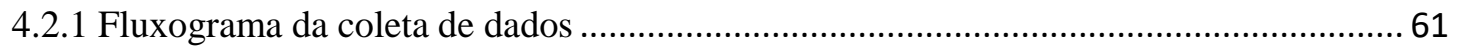

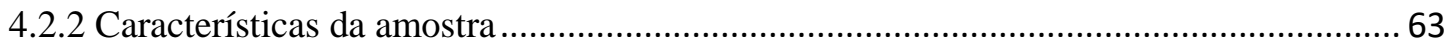

4.2.3 Correlação com testes neuropsicológicos tradicionais .................................................... 64

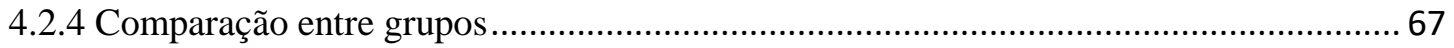

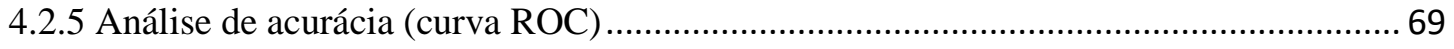

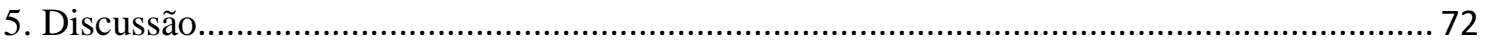

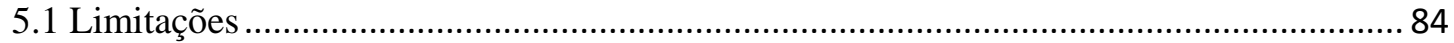

5.2 Implicações clínicas e considerações para estudos futuros ............................................... 85

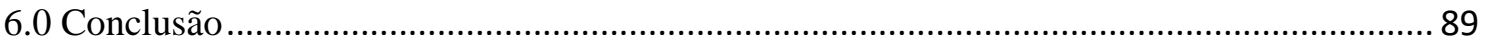

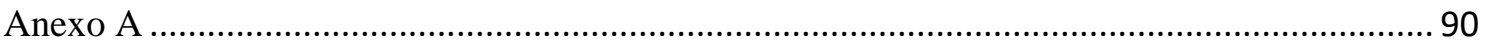

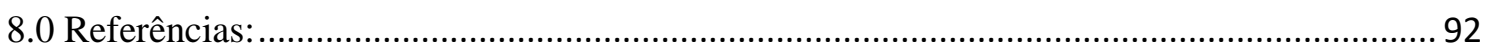

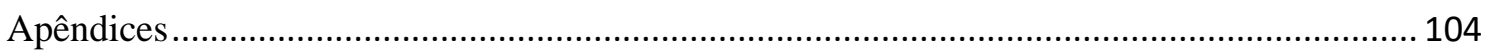




\section{LISTA DE ABREVIATURAS OU SIGLAS}

$3 \mathrm{D}-$

$\varepsilon 4-$

ACE-R -

APOE -

AUC -

$\mathrm{A} \beta-$

Três dimensões, tridimensional

Alelo $\varepsilon 4$ da apolipoproteína $\mathrm{E}$

Caminho HC I - Rota percorrida no Instituto central do HCFMUSP, evocação imediata

Caminho HC T - Rota percorrida no Instituto central do HCFMUSP, evocação tardia

CAPPesq - C Comissão de Ética para Análise de Projetos de Pesquisa da

Universidade de São Paulo

CCL - $\quad$ Comprometimento cognitivo leve

CCLa - Comprometimento cognitivo leve amnéstico

CCLna - Comprometimento cognitivo leve não amnéstico

CEREDIC - Centro de referência de distúrbios cognitivos

CSV - $\quad$ Comma separated values, ou dados separados por vírgula

DA - Doença de Alzheimer

DP - Desvio padrão

GNCC - Grupo de neurologia cognitiva e do comportamento

HCFMUSP - Hospital das Clínicas da Faculdade de Medicina da Universidade de

São Paulo

HMD - Head-mounted display, ou dispositivo acoplado à cabeça

IC - $\quad$ Intervalo de confiança

ICC - $\quad$ Índice de comorbidades de Charlson

IMU - $\quad$ Unidade de medição inercial

IQR - Intervalo interquartil

LED - $\quad$ Diodo emissor de luz

Linhas de Benton - Teste de orientação das linhas de Benton

M - Média 
MMSE - $\quad$ Mini Exame do Estado Mental

MoCA - Avaliação cognitiva de Montreal

MRMT - $\quad$ Money Road Map Test

OLED - $\quad$ Diodo orgânico emissor de luz

p-tau - Proteína tau hiperfosforilada

PET - Tomografia computadorizada por emissão de pósitrons

Rift - $\quad$ Equipamento Oculus Rift

ROC - Receiver operating characteristics, ou Curva de características

operacionais

Route I - $\quad$ Tarefa SOIVET Route evocação imediata

Route T - $\quad$ Tarefa SOIVET Route evocação tardia

RV - $\quad$ Realidade virtual

SBSOD - $\quad$ Escala de Orientação de Santa Barbara

SOIVET - $\quad$ Sistema Spatial Orientation in Immersive Virtual Environment Test

TCMR - $\quad$ Teste comportamental de memória de Rivermead

t-tau - Proteína tau total

USB - $\quad$ Universal serial bus, tipo de entrada em computadores

VR - $\quad$ Virtual reality, ou realidade virtual 


\section{LISTA DE FIGURAS}

Figura 1 - Samsung Gear VR

Figura 2 - Oculus Rift versão 3: HMD e controles

Figura 3 - Trecho do original Money Road Map Test. A linha pontilhada indica o caminho a ser descrito oralmente pelo participante.

Figura 4 - Fase de treino da tarefa Maze no sistema de realidade virtual. O ponto verde indica o último ponto de virada do participante.

Figura 5 - Sequência de marcos topográficos da tarefa SOIVET-Route .42

Figura 6 - Fase de Instruções da tarefa SOIVET-Route: Sequência do caminho demonstrada pelo personagem virtual e acompanhada pelo participante.

Figura 7 - Fluxograma do projeto piloto. 54

Figura 8 - Desempenho dos participantes $(\mathrm{n}=30)$ na tarefa SOIVET-Maze.

Figura 9 - Desempenho dos participantes na tarefa SOIVET-Maze separado por sexo...58

Figura 10 - Distribuição da pontuação na tarefa SOIVET-Route imediata entre os voluntários do projeto piloto

Figura 11 - Fluxograma de coleta das tarefas virtuais, com dropouts por grupo.

Figura 12 - Média de acertos nas tarefas MRMT e SOIVET-Maze por grupo. .68

Figura 13 - Média de acertos nas tarefas SOIVET-Route imediata e tardia, por grupo...69

Figura 14 - Curvas ROC das tarefas SOIVET-Maze, SOIVET-Route imediata e SOIVETRoute tardia. .70 


\section{LISTA DE TABELAS}

Tabela 1 - Características da amostra do projeto piloto

Tabela 2 - Correlação de Spearman entre o número de acertos na tarefa SOIVET-Maze e na tarefa tradicional MRMT e a pontuação em cada item da escala SBSOD e pontuação total

Tabela 3 - Médias e medianas nas tarefas SOIVET-Maze, SOIVET-Route imediata e SOIVET-Route tardia separadas por sexo e comparação de grupos

Tabela 4 - Características da amostra da etapa de avaliação com idosos

Tabela 5 - Matriz de correlação entre a tarefa SOIVET-Maze e os testes neuropsicológicos tradicionais.

Tabela 6 - Matriz de correlação entre a tarefa SOIVET-Route imediata e tardia, o caminho percorrido no mundo real (reprodução imediata e tardia) e os testes neuropsicológicos tradicionais. .65

Tabela 7 - Desempenho dos participantes, separado por grupo (controle e CCL) nas tarefas virtuais e nos testes neuropsicológicos tradicionais

Tabela 8 - Médias e medianas obtidas nas tarefas SOIVET-Maze, SOIVET-Route imediata e tardia e "Caminho" imediato e tardio e comparação de grupos.

Tabela 9 - Resultados da análise de sensibilidade e especificidade para as tarefas SOIVET-Maze, SOIVET-Route imediata e SOIVET-Route tardia..... .71

Tabela 10 - Pontos de corte propostos para as tarefas SOIVET-Maze, SOIVET-Route imediata e tardia e os diferentes valores de sensibilidade e especificidade. .71 


\section{RESUMO}

Costa RQM. Avaliação da orientação espacial em um ambiente de realidade virtual em pacientes com comprometimento cognitivo leve [tese]. São Paulo: Faculdade de Medicina, Universidade de São Paulo; 2019.

Introdução: A orientação espacial é um domínio cognitivo frequentemente acometido na Doença de Alzheimer (DA), sendo muitas vezes um dos primeiros sintomas. Estudos em pacientes com Comprometimento Cognitivo Leve (CCL) também identificaram a desorientação espacial nestes pacientes, em especial naqueles com maior risco de progressão para a DA. A falta de um padrão-ouro na avaliação da orientação espacial e a necessidade de avaliá-la de forma mais ecológica justificam o desenvolvimento de tarefas novas e mais realistas, como nos ambientes de realidade virtual. Objetivos: 1) desenvolver o sistema Spatial Orientation in Immersive Virtual Environment Test (SOIVET) e adaptar duas tarefas de orientação espacial para um ambiente de realidade virtual imersiva; 2) identificar aspectos de tolerabilidade, usabilidade, sensação de presença e imersão do sistema proposto; 3) analisar a correlação entre o desempenho nas tarefas virtuais e os testes neuropsicológicos tradicionais; 4) comparar o desempenho dos grupos controle e CCL nas tarefas virtuais, bem como verificar a acurácia destas para o diagnóstico de CCL. Métodos: Trinta e dois adultos participaram da etapa de verificação dos aspectos de tolerabilidade, usabilidade e sensação de presença e imersão do sistema proposto. Em seguida, 29 idosos cognitivamente saudáveis e 19 idosos com CCL, participaram da análise de correlação com testes neuropsicológicos tradicionais, acurácia para o diagnóstico de CCL e comparação de desempenho por grupo. As tarefas virtuais foram a SOIVET-Maze, desenvolvida com o objetivo de avaliar a transposição de informações espaciais alocêntricas para uma perspectiva egocêntrica, através de um 
caminho a ser percorrido num labirinto sem marcos topográficos e a tarefa SOIVETRoute, com enfoque na orientação alocêntrica e memória espacial, através da reprodução imediata e tardia de uma rota com marcos topográficos bem estabelecidos. Resultados: Os aspectos de usabilidade e sensação de presença e imersão se mostraram favoráveis para ambas tarefas, com resultados de tolerabilidade da tarefa SOIVET-Route levemente superiores aos da SOIVET-Maze. A tarefa SOIVET-Maze apresentou correlação com os testes: Torre de Londres, Orientação das Linhas de Benton, Money Road Map Test e com as categorias visuoespacial e memória do Exame Cognitivo de Addenbrooke -Versão Revisada (ACE-R). Esta tarefa não sofreu influência da idade, escolaridade nem perfil de uso de tecnologia dos participantes. A tarefa SOIVET-Route imediata mostrou correlação com o Money Road Map Test, com as categorias memória e visuoespacial do ACE-R e sofreu influência apenas da escolaridade. Ambas tarefas foram capazes de diferenciar significativamente o grupo controle do grupo CCL e apresentaram áreas sob a curva de 0,725 e 0,701 respectivamente para o diagnóstico de CCL. Conclusão: O sistema SOIVET se mostrou viável para aplicação em adultos e idosos e as tarefas SOIVET-Maze e SOIVET-Route se correlacionaram com testes tradicionais e foram capazes de diferenciar grupos, com acurácia moderada para o diagnóstico de CCL. Esses resultados apoiam a inclusão de tarefas ecológicas de orientação espacial na avaliação cognitiva de idosos, com destaque para o uso da realidade virtual imersiva.

Descritores: Disfunção Cognitiva, Comprometimento Cognitivo Leve, Orientação Espacial, Navegação Espacial, Doença de Alzheimer, Realidade Virtual 


\begin{abstract}
Costa RQM. Spatial orientation assessment in a virtual reality environment in mild cognitive impairment patients [thesis]. São Paulo: "Faculdade de Medicina, Universidade de São Paulo"; 2019.
\end{abstract}

Background: Spatial orientation is a cognitive domain frequently impaired in Alzheimer's disease (AD), and is often one of its earliest symptoms. Studies with Mild Cognitive Impairment (MCI) have also identified spatial disorientation in these patients, especially in those at higher risk of progression to AD. The lack of a gold standard for the assessment of spatial orientation and the need for ecological forms of evaluation justify the development of new and more realistic tasks, like the ones using virtual reality environments. Objectives: 1) to develop the Spatial Orientation in Immersive Virtual Environment Test (SOIVET) system and to adapt two spatial orientation tasks to an immersive virtual reality environment; 2) to identify aspects of tolerability, usability, sense of presence and immersion of the proposed system; 3) to analyze the correlation between the virtual tasks and traditional neuropsychological evaluation; 4) to compare the performance of the control and MCI groups in the virtual tasks, and to determine the accuracy of the virtual tasks for the diagnosis of MCI. Methods: Thirty-two adults participated in the initial phase of the study to investigate tolerability, usability, and sense of presence and immersion of the proposed system. Afterward, 29 cognitively healthy elderly and 19 MCI participated in this study for correlation analysis with traditional neuropsychological tests, accuracy for the MCI diagnosis and group comparison. Virtual reality tasks were the SOIVET-Maze, developed to evaluate the transposition of allocentric spatial information to an egocentric perspective, using a maze without topographical landmarks and the SOIVET-Route, which focused on allocentric 
orientation and spatial memory, using the immediate and delayed performance of a route with well-established topographical landmarks. Results: Usability and sense of presence and immersion results indicated favorable aspects for both tasks. Tolerability results were slightly higher for SOIVET-Route than SOIVET-Maze. SOIVET-Maze correlated with the Tower of London test, the Benton Judgment of Line Orientation test, the Money Road Map test, and with visuospatial and memory categories of the Addenbrooke Cognitive Examination - Revised (ACE-R). This task was not influenced by age, education or technology use profile. The SOIVET-Route immediate task correlated with the Money Road Map Test, the ACE-R memory and visuospatial categories, and was influenced only by educational level. Both tasks were able to differentiate the control group from the MCI group significantly. Areas under the curve of 0.725 and 0.701 were found for SOIVETMaze and SOIVET-Route immediate tasks respectively. Conclusion: The SOIVET system proved to be applicable to adults and elders, and the SOIVET-Maze and SOIVETRoute tasks correlated with traditional neuropsychological tests and were able to differentiate groups with a moderate accuracy for the MCI diagnosis. These results support the inclusion of ecological forms of evaluation of spatial orientation in the cognitive assessment of elders. In particular, the use of immersive virtual reality seems suitable for this purpose.

Descriptors: Cognitive dysfunction; Mild cognitive impairment; Spatial orientation; Spatial navigation; Alzheimer disease; Virtual reality 


\subsection{Introdução}

\subsection{Comprometimento Cognitivo Leve: Definição e prevalência}

O comprometimento cognitivo leve (CCL) é uma entidade clínica heterogênea muito estudada atualmente com o objetivo de identificar estágios pré-clínicos da Doença de Alzheimer (DA) e outras demências (1,2). A identificação de indivíduos em estágios préclínicos permitiria a implementação de pesquisas com foco em intervenções passíveis de alterar o curso natural da doença (2). Visando a padronização do conceito de CCL, Ronald Petersen estabeleceu em 2004 os critérios para este diagnóstico, amplamente utilizados desde então. Segundo estes critérios, o diagnóstico de CCL requer 1) a presença de uma queixa cognitiva, seja própria ou trazida por familiares, associada à 2) evidência objetiva de comprometimento cognitivo em relação à idade e escolaridade em testagem neuropsicológica, porém 3) sem o comprometimento do funcionamento na vida diária (e portanto, sem critério para diagnóstico de demência) (1,3). Para uma maior caracterização do tipo de declínio cognitivo observado, o diagnóstico de CCL pode ainda ser subdividido em CCL amnéstico (CCLa) quando há o comprometimento objetivo da memória ou em CCL não amnéstico (CCLna), quando o comprometimento cognitivo envolve outras áreas que não a memória (como linguagem ou funções executivas) (3). Além da classificação em CCLa e CCLna, é possível também especificar se há comprometimento em apenas um domínio cognitivo ou em múltiplos domínios cognitivos. Esta estratificação tem como objetivo a predição etiológica do possível processo degenerativo em andamento, de forma que o diagnóstico de CCLa teria maior relação com a patologia da DA, enquanto o CCLna 
teria maior relação com a Demência Fronto-temporal ou com a Demência com corpos de Lewy, por exemplo (1).

De acordo com uma revisão realizada em 2013, a prevalência de CCL no Brasil variou entre 3 e $42 \%$ nas amostras estudadas, sendo os valores mais altos encontrados em estudos com população acima de 70 anos (4). No Brasil, há poucos estudos de prevalência e incidência de CCL na população. Godinho et al. encontraram uma prevalência de $6,1 \%$ na cidade de Porto Alegre (5). No estudo de Chaves et al. também realizado em Porto Alegre, foi encontrada uma incidência de CCL de 13,2\% a cada 1000 habitantes por ano (6). Outros estudos encontraram uma incidência de 1,5\%, considerando-se o comprometimento cognitivo sem demência numa amostra de 1.563 idosos selecionados randomicamente na comunidade (7) e uma prevalência de $19,5 \%$ de comprometimento cognitivo sem demência na cidade de Tremembé em São Paulo (8). Já um estudo que considerou o comprometimento cognitivo e funcional sem a exclusão de demência encontrou uma prevalência de 18,9\% na cidade de Ribeirão Preto (9). Estes estudos, entretanto, concentraram-se na região sul e sudeste do país e a real prevalência e incidência de CCL no Brasil ainda é desconhecida.

A identificação de CCL na população se mostra relevante pelo risco aumentado que estes indivíduos apresentam de evoluir para a DA e para outras demências, em comparação com a população idosa em geral (10). Um estudo comparativo das taxas de progressão de CCL para demência entre indivíduos provenientes de ambientes clínico e hospitalar e provenientes da comunidade, encontrou taxas de progressão de CCL para DA entre 10 a 15\% ao ano no ambiente clínico e taxas de progressão menores, entre 3,8 até 6,3\% ao ano na comunidade (11). Uma recente metanálise dos diversos estudos que investigaram taxas de progressão de CCL para DA, reportaram uma taxa ajustada de 
progressão de $13 \%$ em amostras provenientes da comunidade e de $31 \%$ de amostras provenientes de ambiente clínico-hospitalar. Por outro lado, este mesmo estudo reportou uma taxa ajustada de reversão de CCL para normalidade cognitiva de até $26 \%$ entre indivíduos provenientes da comunidade (12).

As variações nas taxas de progressão encontradas e a significativa parcela de reversão para o estado de normalidade demonstram a diversidade de condições clínicas e possivelmente de processos patológicos subjacentes ao diagnóstico clínico de CCL (13). A percepção de que nem todos os indivíduos CCL de fato evoluem para DA ou outras demências colocou em foco a discrepância entre a identificação do diagnóstico clínico e o processo patológico de base. Por esse motivo, diversos estudos ao redor do mundo têm concentrado esforços para determinar quais fatores estariam então relacionados à maior taxa de progressão para DA ou outras demências e, dessa forma, quais os grupos de maior risco dentre aqueles que receberam o abrangente diagnóstico de CCL $(10,11,14,15)$.

Entre os fatores de risco até então identificados encontram-se os marcadores de patologia compatível com a DA, como o aumento de tau total (t-tau) e tau hiperfosforilada (p-tau) no líquor, indicadores da presença de emaranhados neurofibrilares no tecido cerebral; a redução do peptídeo beta amiloide $(A \beta)$ no líquor, indicador indireto da presença das placas amiloides no cérebro e a identificação do alelo APOE $\varepsilon 4$ no sangue, relacionado ao maior risco de desenvolvimento da DA (16-18). A avaliação da perfusão, metabolismo ou estrutura cerebrais reduzidas em áreas críticas para o desenvolvimento da DA, mensurado através de exames de imagem, também foram replicadas em diversos estudos: a hipoperfusão ou o hipometabolismo das estruturas temporo-parietais, precuneus e cíngulo posterior se mostraram de grande importância para a avaliação de risco no CCL, uma vez que as modificações anatomopatológicas 
relacionadas à DA podem se iniciar anos antes dos sintomas clínicos se manifestarem (10,19-21). A relação da atrofia hipocampal e o maior risco de progressão para DA é um achado consistente na literatura $(14,22,23)$. Estudos longitudinais, por sua vez, confirmaram que a atrofia do hipocampo constitui forte preditor de conversão de CCL para DA (24).

Achados como estes levaram duas entidades americanas que norteiam as pesquisas nessa área, o National Institute on Aging e a Alzheimer's Association, a estabelecerem em 2011 novos critérios para o uso de biomarcadores periféricos e de imagem em CCL. Estas entidades convocaram um grupo de trabalho internacional para revisar as evidências científicas até o momento e desenvolver recomendações para o uso de biomarcadores no entendimento do CCL e da DA. Os critérios recomendados visaram a padronização do uso em pesquisa dos biomarcadores como indicadores prognósticos, como determinantes da probabilidade da patologia da DA e para o estadiamento da DA pré-clínica e da progressão para a DA. Entre os biomarcadores incluídos nos critérios estão o $A \beta$, a $t$-tau e a p-tau liquóricos, o hipometabolismo ou a hipoperfusão temporoparietal ou do precuneus e a atrofia temporal mesial (regiões hipocampais) (25). Outros biomarcadores, entretanto, foram descritos desde então e vêm sendo estudados, o que mostra o amplo campo de pesquisa de CCL e da sua relação com a DA.

Ao final do ano de 2017 foram rediscutidos vários aspectos da DA e uma nova estrutura de categorização da doença foi sugerida. Esta nova categorização baseou-se na presença de biomarcadores e levou em consideração a existência de um continuum entre estes em algumas pessoas $(26,27)$. Estes critérios tem como objetivo definir e estagiar a doença em todo o seu espectro e de servir como um guia para pesquisas e não como 
critério diagnóstico ou diretriz de tratamento. Seu uso é indicado especialmente para estudos de coorte observacional e para ensaios clínicos de intervenção.

Anteriormente, apenas o diagnóstico clínico era utilizado para inclusão de pacientes em ensaios clínicos, mas com o advento do exame de tomografia computadorizada por emissão de pósitrons (PET) com marcador de proteína amiloide observou-se que 20 a $30 \%$ dos pacientes com diagnóstico clínico não apresentavam marcação amiloide cerebral. Esses achados colocaram em evidência a forma de recrutamento de pacientes para ensaios clínicos de medicamentos dirigidos especificamente para a fisiopatologia da DA. Pacientes que não apresentassem exame PET amiloide positivo dificilmente se beneficiariam de tratamentos voltados para essa proteína (28).

Atualmente, os estudos com biomarcadores, em especial aqueles com PET amiloide trouxeram uma mudança no entendimento das alterações neuropatológicas que definem a DA. A possibilidade da identificação precoce de marcadores relacionados à fisiopatologia da DA colocou em evidencia as divergências entre o diagnóstico clínico e o diagnóstico fisiopatológico englobados pela mesma terminologia. Portanto, a definição da doença passou a abranger os biomarcadores indicativos da alteração neuropatológica da DA, independentemente da existência de sintomas clínicos (28). Para este fim, o National Institute on Aging e a Alzheimer's Association propuseram o sistema ATN, onde: "A" refere-se à presença de marcador $A \beta$ medido pelo PET com ligante para amiloide ou mensurado no líquor; " $\mathrm{T}$ " refere-se ao marcador da patologia tau medida pela p-tau no líquor ou pelo PET com ligante para novelos neurofibrilares parenquimatosos e "N" refere-se à neurodegeneração ou injúria/disfunção neuronal mensurada pela alteração de volume hipocampal, volume cortical ou espessura cortical. Neste sistema proposto, "A" e "T" são considerados específicos para o diagnóstico de 
$\mathrm{DA}$, ao contrário de "N" que é inespecífico, uma vez que injúria cerebral com alteração volumétrica pode ocorrer em outras patologias além da DA. Com a incorporação dos biomarcadores e dos estudos longitudinais de indivíduos com vários níveis de comprometimento cognitivo, foi possível abranger a DA desde a sua fase pré-clínica até a fase avançada $(26,27)$.

1.2 Avaliação cognitiva na identificação de risco em CCL

Apesar do crescente interesse na identificação de biomarcadores para a identificação da patologia da DA e para a estratificação de subgrupos de CCL de maior risco de progressão para DA ou outras demências, muitos estudos se concentraram na identificação de aspectos clínicos para esse objetivo, como a avaliação cognitiva (29-31). A avaliação cognitiva é utilizada para examinar os desfechos cognitivos de lesões cerebrais, doenças cerebrais e doenças mentais graves. Existem várias utilidades e usos específicos deste tipo de avaliação, como a coleta de informações para o diagnóstico e para diagnósticos diferenciais, a avaliação da resposta ao tratamento e a previsão do potencial funcional e prognóstico do indivíduo. A avaliação cognitiva se mostra menos custosa e é não-invasiva, o que aumenta sua aplicabilidade na prática clínica (32).

Em especial no que se refere ao estudo do CCL, a avaliação cognitiva se mostra essencial para o estabelecimento do próprio diagnóstico desta entidade clínica. Lembrando-se que o diagnóstico provém da evidência do declínio de uma ou mais funções cognitivas, com relativa preservação da funcionalidade (33). O declínio cognitivo é identificado através da avaliação objetiva de funções como memória, funções executivas, linguagem, atenção, velocidade de processamento, capacidade visuoconstrutiva, orientação espacial, entre outras. Embora o comprometimento da 
memória seja o mais comum entre os pacientes com CCL e tenha sido consistentemente associado a um maior risco de progressão para DA $(3,34)$, diferentes estudos têm demonstrado que os pacientes CCL, mesmo do tipo amnéstico, muitas vezes apresentam comprometimento de outras funções cognitivas, antes do declínio da memória aparecer $(35,36)$. Estudos demonstraram que as funções executivas, habilidades visuoconstrutivas e a orientação espacial, por exemplo, podem se manifestar antes do comprometimento da memória. Estes domínios têm sido estudados na identificação daqueles subgrupos de CCL com maior risco de progressão $(10,36,37)$.

A avaliação de idosos com suspeita de CCL inclui tanto a avaliação cognitiva inicial quanto o acompanhamento das funções cognitivas e funcionamento da vida diária, de modo a detectar um possível declínio ao longo do tempo (38). Entretanto, uma metanálise realizada na América do Norte sobre avaliação cognitiva de rastreio na atenção primária evidenciou que os diferentes instrumentos de rastreio disponíveis são sensíveis para a identificação de demência mas perdem sensibilidade para o diagnóstico de CCL (39).

Em 2015, uma revisão da Cochrane concluiu que o Mini Exame do Estado Mental (MMSE), instrumento de rastreio mais utilizado ao redor do mundo, não deveria ser utilizado para identificação de pacientes CCL com maior risco de conversão para DA (40).

Já em 2017, Belleville et al. realizaram uma metanálise sobre a acurácia da avaliação cognitiva na progressão de CCL para DA. Os autores avaliaram os resultados de vários testes de diferentes domínios cognitivos (memória episódica verbal e visual, linguagem, funções executivas, habilidades visuoperceptivas e visuoconstrutivas e capacidade cognitiva global). Além da reconhecida importância dos testes de memória episódica, em especial os de conteúdo verbal, o estudo mostrou que alguns testes de linguagem, 
habilidades visuoespaciais e capacidade cognitiva global também demonstraram bons resultados de acurácia. Os achados deste estudo levaram os autores a defender a importância da avaliação cognitiva na identificação de risco de progressão para DA e concluíram que a avaliação de diferentes domínios cognitivos, ao invés da eleição de um ou outro, constitui a melhor forma de verificar o risco de progressão (41). Dados como esses evidenciam a necessidade de formas mais amplas e detalhadas de avaliação das funções cognitivas, com pouca evidência de que haja um teste superior ao outro, ou mesmo de um domínio cognitivo em particular.

\subsection{A Orientação Espacial}

A orientação espacial pode ser definida como a capacidade de estabelecer relações entre a posição, direção e movimento de objetos e pontos no espaço, bem como da posição de seu próprio corpo em relação ao espaço. Este tipo de orientação também é chamada de orientação topográfica, sendo a desorientação topográfica o comprometimento da capacidade de navegação no espaço (42). Neste trabalho optamos por utilizar o termo mais amplo de orientação espacial no lugar de topográfica, pelo seu uso mais frequente na literatura.

O comprometimento da orientação espacial tem sido relatado na DA, frequentemente como um dos primeiros sintomas identificados (43-46). Vários estudos também demonstraram este comprometimento em indivíduos CCL, com uma prevalência descrita de até $41,4 \%$ em algumas amostras $(23,47-49)$. As regiões cerebrais envolvidas no processo de orientação espacial também se mostraram relacionadas à patologia da DA e consideradas preditoras de progressão de CCL para DA, o que tem aumentado o interesse dos pesquisadores por esse domínio cognitivo $(45,47,50,51)$. 
Para a avaliação da orientação espacial, é importante ter em mente que, além da percepção visual e espacial preservadas, bem como das funções executivas e de atenção, a capacidade de se orientar em ambientes familiares e não familiares abrange dois tipos diferentes de orientação espacial: egocêntrica e alocêntrica $(37,52,53)$.

A orientação egocêntrica utiliza o ponto de vista pessoal do indivíduo e as informações sensório-motoras provenientes dos movimentos do seu corpo em relação ao espaço $(37,54)$. Este processo cognitivo depende do funcionamento dos lobos parietais superiores e inferiores (50).

A orientação alocêntrica, por outro lado, é um processo que resulta da observação dos aspectos visuais do ambiente. Ela identifica a posição de marcos topográficos e sua relação com outros aspectos relevantes do entorno, bem como a direção desses marcos e as distâncias estimadas pelo observador $(37,44)$. Ao contrário da orientação egocêntrica, as representações alocêntricas são centradas no objeto e não no observador, e dependem da formação e do uso de um mapa cognitivo $(37,52)$. Estudos de imagem identificaram que as estruturas temporais mesiais são responsáveis pelo funcionamento da orientação alocêntrica, em particular o hipocampo (47,50). Para que um indivíduo se oriente com sucesso, ambas formas de orientação espacial devem estar preservadas $(37,54)$. O córtex retroesplenial, em especial, foi identificado como uma região importante para a integração destas duas funções, o que é essencial para um indivíduo se orientar no espaço de forma eficiente. Interessante salientar que este processo de integração parece estar particularmente comprometido na DA $(55,56)$.

As principais regiões cerebrais, afetadas precocemente pelo acúmulo patológico de placas e emaranhados neurofibrilares na DA, estão também envolvidas no processamento da orientação espacial e são consistentes com os déficits de navegação $(57,58)$. As regiões 
hipocampais são determinantes para o funcionamento da orientação alocêntrica e as estruturas parietais estão envolvidas na orientação egocêntrica $(50,59)$. Dessa forma, a identificação do comprometimento da orientação espacial, a partir da avaliação cognitiva deste domínio, poderia indicar o comprometimento dessas regiões e possivelmente o início de um processo patológico e degenerativo.

O hipocampo tem sido historicamente associado à capacidade de orientação espacial. Um estudo amplamente conhecido sobre este assunto e frequentemente citado, foi o estudo de Woollet \& Maguire, que avaliou o volume hipocampal de taxistas da cidade de Londres. Estes taxistas são conhecidos por passarem por um extenso treinamento para retirar sua licença de taxista, que envolve o aprendizado da localização de quase 25 mil ruas, diversos pontos turísticos e locais importantes. Foi identificado que estes taxistas tinham maior volume nas regiões hipocampais posteriores, em comparação com indivíduos da mesma idade. Além disso, quanto mais os taxistas se deslocavam pela cidade de Londres, maior era o seu volume hipocampal posterior. A partir desses achados, passou a ser discutida a capacidade de neuroplasticidade desta região em humanos adultos saudáveis de modo a acomodar a representação espacial de um ambiente complexo, o que antes era desconhecido $(60,61)$.

O envolvimento do hipocampo na orientação espacial em indivíduos CCL também foi evidenciado em diferentes estudos. Laczó et al. (2009) demonstraram que indivíduos CCLa com comprometimento do hipocampo apresentaram pior desempenho em uma tarefa de orientação espacial e pior capacidade de aprendizado nesta tarefa do que aqueles CCLa sem o comprometimento hipocampal (62). O estudo de Nedelska et al. (2012) identificou que a redução do volume do hipocampo direito em indivíduos CCL em comparação com indivíduos saudáveis estava relacionada ao pior desempenho em tarefas 
de navegação tanto no mundo real como num ambiente virtual (47). Recentemente, o estudo de Peter et al. (2018) identificou que as sub-regiões CA1/2 do hipocampo direito foram preditivas do desempenho de participantes CCL e controles em uma tarefa ecológica de aprendizagem de rotas, enquanto a cauda do hipocampo direito esteve envolvida apenas em participantes CCLa (51).

Pacientes CCLa demonstram comprometimento significativo da orientação espacial, não somente nas modalidades alocêntricas, dependentes do hipocampo, mas também nas egocêntricas. O desempenho destes indivíduos em tarefas de orientação espacial parece se situar entre o desempenho de idosos saudáveis e de idosos com DA leve (63-65). O estudo de Laczó et al. (2011) identificou também que pacientes CCLa que possuíam o alelo $\varepsilon 4$ da APOE (reconhecido por indicar um subgrupo de pacientes com maior risco de progressão para DA (66)) desempenhavam pior nas tarefas de orientação espacial do que pacientes CCLa sem este genótipo (67). Em 2014 o mesmo grupo conseguiu demonstrar que os pacientes CCLa com dois alelos $\varepsilon 4$ tinham pior desempenho nestas tarefas do que aqueles com apenas um alelo $\varepsilon 4$ e esses por sua vez tinham pior desempenho do que os participantes sem nenhum alelo $\varepsilon 4$ (68).

Pacientes CCLna, por outro lado, tiveram um desempenho semelhante a idosos cognitivamente saudáveis em tarefas de orientação espacial $(62,69,70)$.

Embora a importância da avaliação da orientação espacial no CCL e na DA tenha se mostrado cada vez mais evidente, ainda encontramos barreiras para sua implementação na avaliação cognitiva regular. A grande diversidade de formas de avaliação deste domínio cognitivo, a falta de um padrão-ouro e a dificuldade para encontrar tarefas representativas das dificuldades de orientação no mundo real são algumas dessas barreiras. Há muitas formas de se avaliar a orientação espacial, seja a egocêntrica, a 
alocêntrica, ou ambas sem distinção entre estes processos. Autores têm empregado metodologias distintas como: questionários, avaliações tradicionais em papel e caneta, avaliações ecológicas em ambientes reais e também em ambiente virtuais (71-73). Muitos pesquisadores criaram suas próprias tarefas para avaliação da orientação espacial em CCL e um crescente estímulo às avaliações ecológicas tem se mostrado na literatura $(68,72,74,75)$.

Laczó et al. (2009) propuseram uma versão humana do Labirinto Aquático de Morris, desenvolvido na década de 80 para avaliação da orientação alocêntrica e egocêntrica em camundongos (62). Na versão de Laczó et al. foi criada uma "arena de veludo" na qual os participantes entravam, se posicionavam de pé e deveriam memorizar a localização de um objeto oculto indicado por um laser pointer. A tarefa envolvia subtestes tanto para avaliação da orientação alocêntrica quanto da orientação egocêntrica, que dependiam do tipo de pista fornecida para facilitar a memorização da localização do objeto oculto pistas visuais presentes na arena ou posicionamento inicial do corpo em relação ao objeto, respectivamente $(62,69)$. Este grupo de pesquisa conseguiu demonstrar que as tarefas realizadas na versão humana do Labirinto Aquático de Morris foram capazes de distinguir idosos CCL, idosos com DA leve e idosos cognitivamente saudáveis $(62,69,72)$.

Rusconi et al. (2015) desenvolveram uma cidade em miniatura feita de Lego, com diferentes marcos topográficos. Utilizando esta representação, os participantes eram solicitados a realizar diferentes tarefas, como aprendizagem de rotas, desenho de um mapa, memorização de marcos topográficos e suas localizações, entre outras. Essas tarefas se mostraram capazes de avaliar a orientação topográfica em idosos saudáveis e pacientes com CCL e diferenciar estes dois grupos (76). 
O Money Road Map Test (MRMT) foi desenvolvido em 1965 para a avaliação da orientação espacial e discriminação direita-esquerda (77). Neste teste, o participante deve descrever um caminho pontilhado presente num mapa de papel e informar oralmente, em cada ponto de curva, se é necessário virar à direita ou à esquerda para seguir o caminho apresentado. O participante deve fazer isso sem manusear ou rodar o papel, sendo necessário a imaginação do posicionamento do seu corpo em cada ponto da curva. Suas respostas são classificadas como "certas" ou "erradas" e recebe-se um ponto para cada resposta certa, num total de 32 pontos (77). A transposição do clássico MRMT em papel para um ambiente computadorizado (dentro de um labirinto) e com funcionalidade interativa em $3 D$ foi proposta por Morganti et al. em 2013 e se mostrou eficaz para a avaliação da orientação espacial em pacientes com DA leve (56). Esta adaptação permitiu a avaliação da transferência da perspectiva alocêntrica do tipo survey (ou em planta baixa do labirinto no papel) para a orientação egocêntrica, recrutada ao se caminhar dentro do labirinto computadorizado. O desempenho nesta tarefa computadorizada se mostrou comprometido em pacientes com DA leve, em comparação com idosos saudáveis $(56,78)$.

O Teste Comportamental de Memória de Rivermead (TCMR) utiliza tarefas da vida diária e foi desenvolvido para avaliar o declínio cognitivo, em especial o da memória. Esta bateria cognitiva foi validada e adaptada para a realidade brasileira por Oliveira \& Schmidt e a validação das características psicométricas para o diagnóstico de DA e de CCL foi estabelecida por Yassuda et al. em 2010 (79,80). O TCMR consiste de 12 itens, que incluem tarefas de reconhecimento visual, linguagem e orientação espacial. No oitavo item, denominado "Caminho", o paciente deve refazer uma rota que foi previamente demonstrada pelo investigador. Este leva consigo um envelope e um livro e percorre um caminho que contém 5 locais dentro da sala de atendimento: ao começar por uma porta, em seguida uma cadeira (onde deixa o envelope), depois para outra cadeira, para uma 
mesa (onde deixa o livro) e por fim para a janela. O paciente deve refazer exatamente o mesmo caminho apresentado, na mesma ordem. Após 20 minutos é solicitado novamente ao paciente que refaça o caminho, sem que o aplicador demonstre a rota uma segunda vez. No estudo de Yassuda et al. com idosos no Brasil, foi identificado que estes subitens "caminho imediato" e "caminho após intervalo" contribuíram significativamente para diferenciar o grupo de pacientes CCL do grupo de idosos controles (80). Estes mesmos subitens foram utilizado por Weniger et al. na validação de uma tarefa ecológica virtual para avaliação da orientação espacial (73).

As avaliações ecológicas parecem recrutar de maneira mais fidedigna os processos cognitivos e consequentemente o funcionamento cerebral essencialmente envolvido na orientação do indivíduo no ambiente que o cerca. Dessa forma, as avaliações ecológicas se mostram vantajosas para a investigação da orientação espacial, em contraponto às avaliações tradicionais em "papel e caneta", muitas vezes voltadas apenas para as funções visuoconstrutivas ou de memória visuoespacial $(74,81)$. $\mathrm{O}$ advento da tecnologia permitiu um novo olhar sobre a avaliação da orientação espacial e os ambientes virtuais têm se mostrado úteis na criação de tarefas ecológicas de orientação espacial.

\subsection{Avaliações ecológicas e o uso da Realidade Virtual}

A falta de um consenso sobre quais testes ou tarefas devam ser empregados na avaliação da orientação espacial e a vantagem de uma avaliação ecológica tornam importante o desenvolvimento de novos testes, de forma mais próxima à vida real. Em 2006, Hegarty et al. investigaram a correlação entre os clássicos testes em "papel e caneta" para a avaliação da orientação espacial e da habilidade visuoespacial e os testes 
em ampla escala, realizados em ambientes reais de forma ecológica. Os pesquisadores identificaram uma baixa correlação entre essas avaliações e defenderam que as habilidades cognitivas recrutadas nas avaliações da orientação espacial em ampla escala diferem significativamente daquelas recrutadas nas avaliações tradicionais, em pequena escala. Concluíram portanto, que a baixa validade ecológica das avaliações em "papel e caneta" reforça a importância e a utilidade de se avaliar a orientação espacial em um ambiente em ampla escala, seja real ou virtual (82). Em especial, a realidade virtual imersiva pode ser considerada como uma tecnologia "personificada" (ou embodied technology em inglês), pela capacidade de percepção do próprio corpo por quem a utiliza. Isso permite que o participante tenha consciência da posição de seu corpo no ambiente virtual. A coordenação do movimento da cabeça (detectado pelo equipamento de RV) com a posição do ambiente permite um alto nível de feedback sensório-motor e a reprodução da perspectiva em primeira pessoa (orientação egocêntrica) $(83,84)$. Esta reprodução dificilmente seria alcançada de forma fidedigna em avaliações tradicionais em pequena escala.

Seguindo este entendimento, diferentes grupos de pesquisa propuseram tarefas ecológicas para a avaliação da orientação espacial nos últimos anos, seja em ambiente real, seja em ambiente virtual. Tais estudos foram utilizados para avaliação da orientação egocêntrica, alocêntrica, ou a integração das duas, e investigaram pacientes idosos saudáveis, CCL e com DA leve. As diferentes formas de avaliação ecológica da orientação espacial se mostraram eficientes na identificação e diferenciação entre esses grupos $(62,72,74,85)$. Alguns estudos também encontraram correlação entre o desempenho de pacientes CCL nas tarefas de orientação espacial e o perfil de atrofia cerebral e a presença de biomarcadores preditores de progressão para DA $(47,67,71)$. O uso dos ambientes virtuais tem se mostrado uma alternativa interessante para esse tipo de 
avaliação e a tecnologia tem sido utilizada com sucesso na população idosa com e sem declínio cognitivo $(56,85,86)$.

Em uma recente revisão sistemática, Cogné et al. investigaram a contribuição das avaliações em realidade virtual para o diagnóstico da desorientação espacial. Os autores concluíram que o uso de avaliações em realidade virtual tem se tornado uma ferramenta valiosa e em rápida expansão. Em particular, para a investigação da orientação espacial, a realidade virtual permite a avaliação de pacientes em situações dinâmicas, bem próximas de um ambiente real, que a torna vantajosa em relação às abordagens tradicionais, em pequena escala. Essa forma de avaliação também fornece uma melhor compreensão dos processos cognitivos recrutados na orientação de um indivíduo. Por fím, além da investigação diagnóstica da desorientação, a realidade virtual também permite uma melhor compreensão de possíveis soluções que tenham por objetivo reabilitar a capacidade de orientação dos pacientes, de forma a impactar diretamente no seu cotidiano (87). Como demonstrado por Woollet \& Maguire (2011), a exposição e o treinamento espacial de indivíduos adultos em ambientes complexos promove a neuroplasticidade hipocampal, o que torna intervenções deste tipo muito interessantes na patologia da DA.

Embora promissor, o uso rotineiro da realidade virtual para avaliação cognitiva ainda encontra algumas limitações. $\mathrm{O}$ alto custo de alguns equipamentos de realidade virtual, a necessidade de pessoal capacitado para programação, desenvolvimento das tarefas e manutenção do sistema e as dificuldades de tolerabilidade que algumas pessoas vivenciam ao utilizar essa tecnologia ainda limitam sua ampla utilização na prática clínica $(88,89)$. Particularmente, a população idosa, que tem menor exposição à tecnologia de um modo geral poderia ter pior aceitação desta forma de avaliação e poucos estudos investigaram esse aspecto $(90,91)$. 
Tendo em vista a importância da investigação da orientação espacial em pacientes CCL e as vantagens do uso da realidade virtual para uma avaliação ecológica deste domínio cognitivo, foram identificadas na literatura duas tarefas que se mostram potencialmente interessantes para uma adaptação para o ambiente de realidade virtual imersivo: o Money Road Map Test (MRMT) e o subitem "Caminhos" do Teste Comportamental de Memória de Rivermead (TCMR). A adaptação destas tarefas para um sistema de realidade virtual imersiva possibilitaria a avaliação da orientação espacial em idosos cognitivamente saudáveis e idosos CCL, bem como contribuiria para o crescente campo de estudo do uso da realidade virtual como forma de avaliação cognitiva ecológica em idosos.

Este trabalho visou propor duas tarefas ecológicas para a avaliação da orientação espacial em um ambiente virtual imersivo. As tarefas investigaram a integração entre a orientação alocêntrica e a egocêntrica (através de uma rota feita com um mapa, sem a disponibilização de marcos topográficos - tarefa $M a z e$ ) e a orientação alocêntrica (em um ambiente com marcos topográficos bem definidos - tarefa Route). Estas tarefas virtuais foram baseadas nos testes originais MRMT e "Caminhos" do TCMR respectivamente. Inicialmente, as tarefas foram realizadas por adultos jovens, para investigação da aplicabilidade do sistema. A seguir, foram aplicadas em idosos cognitivamente saudáveis e idosos CCL de modo a permitir a investigação da validade de construto, bem como a comparação entre o envelhecimento normal e o patológico. Através da testagem de idosos CCL e a comparação de seus resultados com os de idosos cognitivamente saudáveis foi possível determinar também a acurácia destas tarefas de orientação espacial para o diagnóstico de CCL. 


\subsection{Objetivos e Hipóteses}

\subsection{Objetivo principal}

Desenvolver um sistema de realidade virtual imersiva que permita a avaliação ecológica da orientação espacial em idosos: o sistema Spatial Orientation in Immersive Virtual Environment Test (SOIVET) e adaptar duas tarefas de orientação espacial para o ambiente virtual, as tarefas SOIVET-Maze e SOIVET-Route.

\subsection{Objetivos secundários}

1. Avaliar a aplicabilidade do sistema SOIVET em adultos, por meio da verificação da facilidade de uso ("usabilidade"), sensação de presença e imersão e a tolerabilidade.

2. Investigar a validade de construto das tarefas SOIVET-Maze e SOIVET-Route por meio da correlação com testes neuropsicológicos tradicionais.

3. Investigar a capacidade das tarefas SOIVET-Maze e SOIVET-Route em diferenciar o grupo de idosos controle do grupo CCL, bem como verificar a acurácia destas tarefas para o diagnóstico de CCL. 


\subsection{Hipóteses}

Foram formuladas as hipóteses que 1) seria possível desenvolver um sistema de realidade virtual imersivo para avaliação ecológica da orientação espacial; 2) as tarefas SOIVETMaze e SOIVET-Route se mostrariam viáveis para a aplicação em adultos e idosos; 3) demonstrariam validade de construto quanto ao domínio cognitivo avaliado (orientação espacial) apresentando correlação com testes neuropsicológicos tradicionais e 4) se mostrariam capazes de diferenciar significativamente o grupo de idosos CCL do grupo de idosos cognitivamente saudáveis, revelando acurácia moderada a alta para o diagnóstico de CCL. 


\subsection{Métodos}

\subsection{Equipamentos}

Durante a fase piloto, foi utilizado o aparelho Samsung Galaxy S6 para armazenar e reproduzir o software desenvolvido e o equipamento Samsung Gear VR para a imersão. Samsung Gear VR são "óculos" de realidade virtual desenvolvidos pela Samsung Electronics, em colaboração com a empresa Oculus e produzidos pela Samsung. Estes “óculos", chamados de head-mounted display (HMD) são compatíveis com os aparelhos de smartphone Galaxy Note 5, Galaxy S6/S6 Edge, Galaxy S7/S7 Edge, que funcionam como processador e tela do Gear VR (Figura 1). Este último funciona como o controlador, que contém o campo de visão de grande alcance, bem como uma unidade de medição inercial (IMU) para rastreamento rotativo, que se conecta ao smartphone via micro-USB. Para o controle dos comandos de movimento e seleção no menu das tarefas, foi utilizado um controle Bluetooth compatível com os aparelhos smartphones da Samsung.
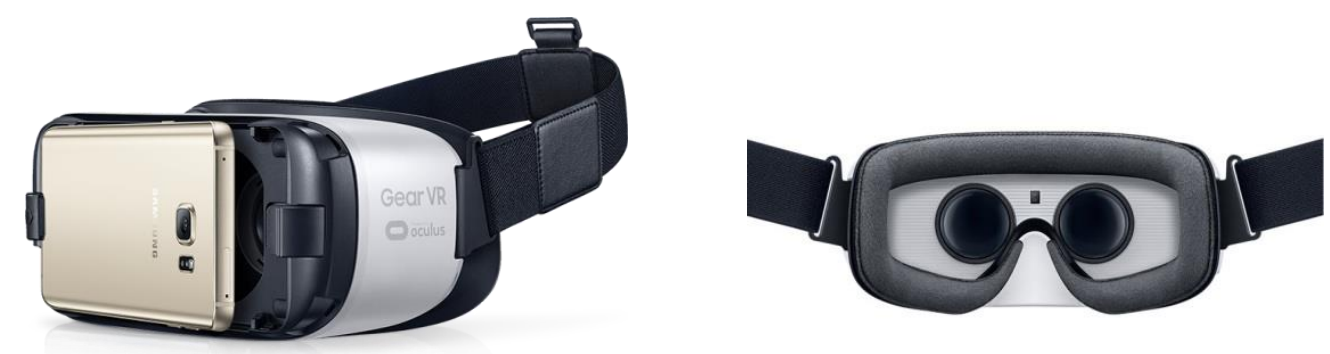

Figura 1: Samsung Gear VR 
Após o desenvolvimento do sistema e a realização e conclusão do projeto piloto, foi demonstrada a limitação dos equipamentos da Samsung (Samsung Galaxy S6 para processamento e Samsung Gear VR como HMD) com relação à tolerabilidade (descrita adiante no item "Resultados"). A análise dos resultados do projeto piloto determinou a mudança de equipamento para a etapa seguinte, com idosos. Esta mudança teve como objetivo reduzir os efeitos adversos causados pela tecnologia virtual imersiva (cybersickness), potencializados pelas limitações dos equipamentos da Samsung. Foi determinada então a troca para o equipamento Oculus Rift versão 3, que se mostrou mais bem tolerado e, portanto, mais adequado para a população idosa. $\mathrm{O}$ equipamento Oculus Rift consiste em um HMD desenvolvido e fabricado pela Oculus. O Rift apresenta duas telas OLED (diodo orgânico emissor de luz), uma para cada olho, com resolução 1080x 1200 pixels cada e taxa de atualização de imagens de 90Hz. Possui giroscópios que permitem localizar a posição da cabeça, bem como um par de fones de ouvido para detecção de áudio em 3D. A versão 3 inclui também dois controles touch e dois sensores que rastreiam constelações de LEDs infravermelhos para traduzir o movimento do participante, esteja ele sentado ou em pé. Para atuar como processador, o Rift necessita de um computador com sistema operacional Windows 10 e outras especificações de compatibilidade como placa gráfica NVIDIA GTX 1060 e saídas USB 3.0. 


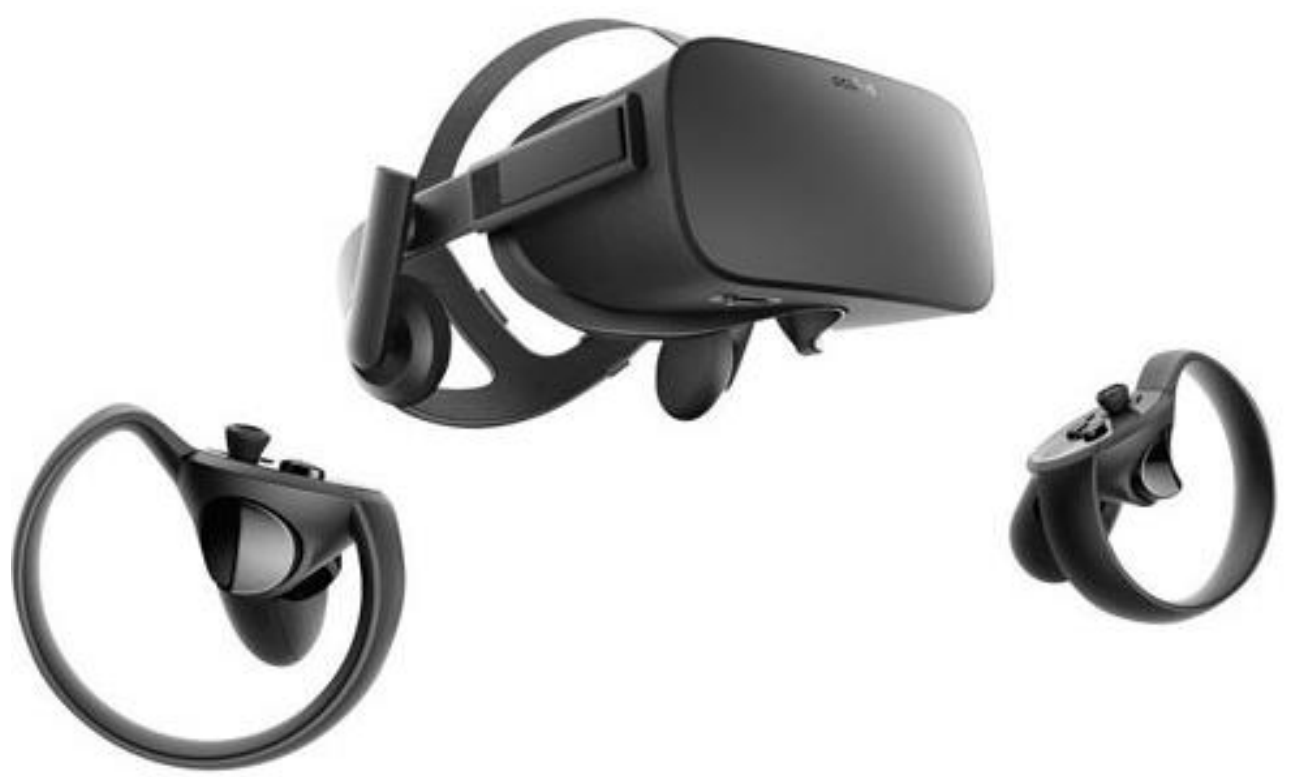

Figura 2. Oculus Rift versão 3: HMD e controles.

3.2 Tarefas de orientação espacial (Spatial orientation in immersive virtual environment test - SOIVET)

3.2.1 Desenvolvimento do sistema e adaptação das tarefas

As tarefas SOIVET-Maze e SOIVET-Route foram elaboradas inicialmente através de discussões em reuniões com os pesquisadores envolvidos neste projeto (Dra. Sonia Brucki, neurologista e orientadora deste projeto de doutorado; Dr. José Eduardo Pompeu, fisioterapeuta e coorientador deste projeto e Raquel Molina, médica e aluna de doutorado), que idealizaram e projetaram como seria a adaptação das clássicas tarefas do MRMT e "Caminhos" do TCMR para o ambiente virtual imersivo.

Posteriormente, o desenvolvimento do sistema e a programação na plataforma Unity® foi realizada pelos programadores Emerson Moretto e Daniel Mello da empresa startup NeuroWay. O custo deste serviço foi previsto no orçamento do financiamento concedido pela FAPESP (Processo: 16/04984-3). Durante seis meses foram realizadas reuniões para 
discussão dos aspectos do sistema em desenvolvimento, com os pesquisadores envolvidos no projeto e os programadores. Estas discussões resultaram em melhorias e refinamentos do sistema de modo a torná-lo de fácil compreensão e interação.

Houve também a colaboração da pesquisadora Prof. Francesca Morganti, da Universidade de Bergamo, idealizadora da transposição do MRMT para um ambiente computadorizado interativo, conforme sua publicação em 2013 (56). A Prof. Morganti foi convidada por este grupo de pesquisa a visitar o departamento de Neurologia do Hospital das Clínicas da Faculdade de Medicina da Universidade de São Paulo (HCFMUSP) e contribuir para a elaboração da tarefa SOIVET-Maze.

Ao término das discussões foi dado início à etapa do projeto piloto, para verificação de aspectos do sistema e ajustes finais antes da aplicação na população idosa.

\subsubsection{Tarefa SOIVET-Maze (Transposição da perspectiva alocêntrica para} egocêntrica)

Como mencionado, a tarefa Maze foi inspirada no estudo de Morganti et al. (2013) que desenvolveu uma tarefa computadorizada, em perspectiva 3D, baseada no MRMT e aplicada à população idosa saudável e com DA leve $(56,78)$. O MRMT original, por se tratar de um teste no modelo tradicional em "papel e caneta", oferece apenas uma perspectiva alocêntrica, como um mapa visto de cima (Figura 3). 


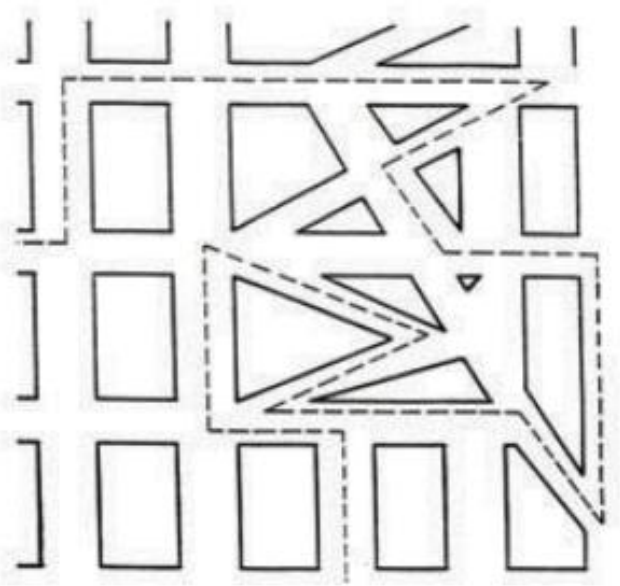

Figura 3. Trecho do original Money Road Map Test. A linha pontilhada indica o caminho a ser descrito oralmente pelo participante.

Na tarefa SOIVET-Maze, os participantes realizaram inicialmente o teste original MRMT no papel e depois foram convidados a realizar o mesmo caminho dentro da realidade virtual imersiva, usando o Samsung Gear VR no projeto piloto e o Oculus Rift na avaliação com idosos. Antes de começar o labirinto virtual completo, todos os participantes puderam realizar uma etapa de treino com uma versão menor do caminho, disponibilizada também na tarefa MRMT original. A tarefa Maze na realidade virtual permite a transposição do mapa do MRMT em perspectiva alocêntrica para a perspectiva egocêntrica: o participante era posicionado dentro do labirinto virtual e podia vivenciar as suas decisões de viradas à direita ou à esquerda e observar a adaptação do entorno a cada virada, como acontece no mundo real. As delimitações do labirinto e o caminho foram os mesmos do MRMT original no projeto piloto e uma versão reduzida do mapa (com máximo de 18 pontos de virada) na avaliação com idosos, devido à dificuldade do teste detectada no projeto piloto (descrita em mais detalhes adiante). Em ambas versões da tarefa (completa e reduzida), o participante visualizava a todo momento o mapa dentro da realidade imersiva enquanto se locomovia. 
Para percorrer o labirinto, os participantes utilizaram um controle joystick Bluetooth compatível com o sistema Samsung Gear VR no projeto piloto e os controles touch do Oculus Rift na avaliação com idosos. O participante era capaz de visualizar na parte inferior do seu campo de visão a imagem do mapa do MRMT com o caminho de linha pontilhada a ser seguido. O participante deveria utilizar esse caminho delimitado no mapa para se orientar dentro do labirinto. À medida que avançavam eles eram capazes de acompanhar sua progressão no caminho da mapa através da posição de um ponto verde. O ponto verde sempre indicava a última virada do participante no labirinto. Além disso, para se orientar era necessária a observação das perspectivas resultantes de seus movimentos no labirinto (por exemplo a mudança na posição dos prédios ou ruas após uma virada à direita ou à esquerda) (Figura 4). Esta observação da mudança da perspectiva a cada virada representava a integração entre a perspectiva egocêntrica (da virada do corpo) com a perspectiva alocêntrica (do posicionamento dos prédios e ruas e progressão do caminho no mapa).

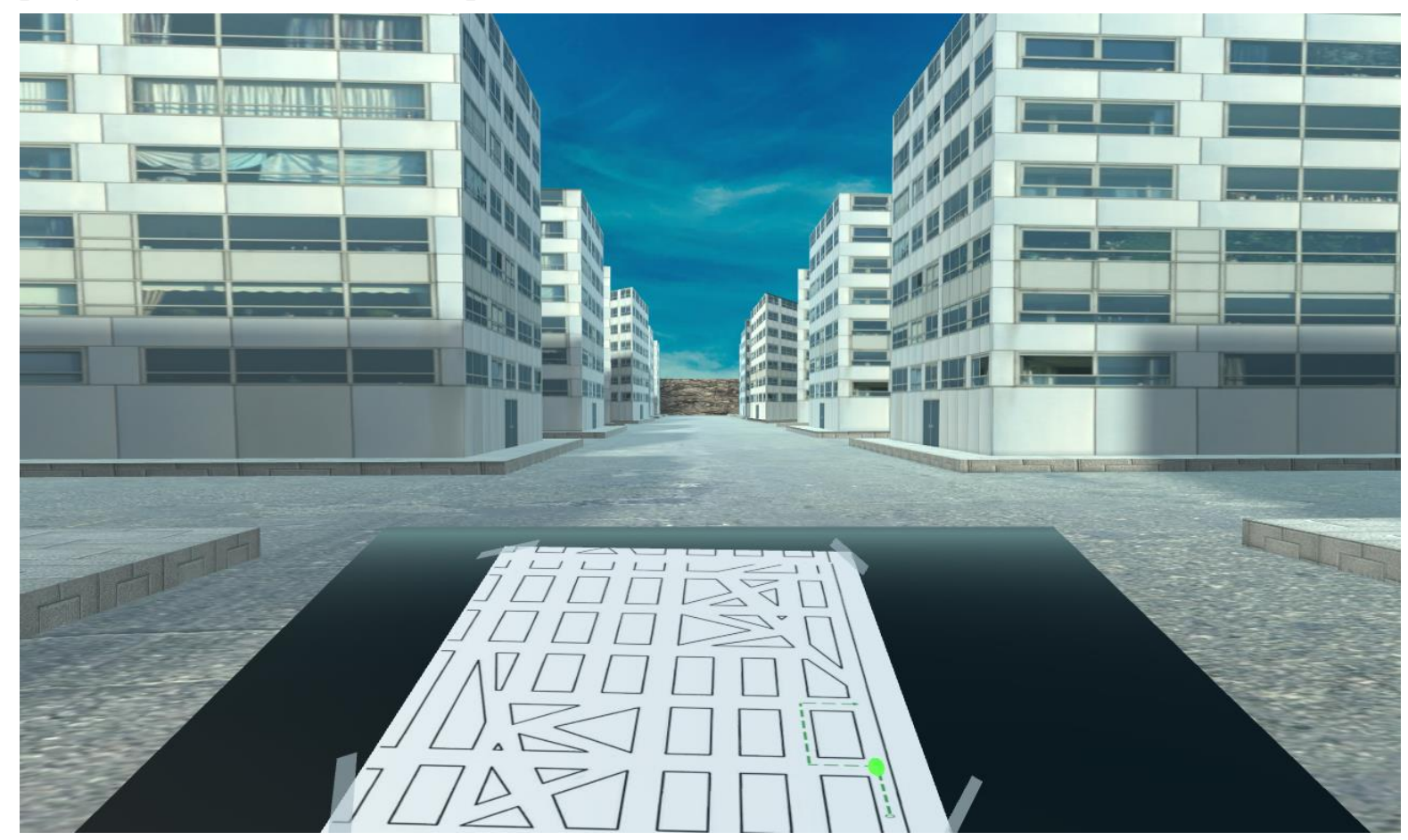

Figura 4: Fase de treino da tarefa Maze no sistema de realidade virtual. O ponto verde indica o último ponto de virada do participante 
3.2.2.1 Avaliação do desempenho dos participantes na tarefa SOIVET-Maze

No projeto piloto, o caminho incluiu os mesmos 32 pontos de virada e decisão "direitaesquerda" do teste original. Como os participantes da etapa piloto mencionaram a dificuldade na realização da tarefa e a média de acertos se distanciou do número máximo de acertos permitidos pela tarefa (32 pontos), foi decidida a redução do mapa visualmente pela metade. Consequentemente, o número máximo de acertos passou para 18 na etapa seguinte. Esta adaptação para a fase de coleta em idosos objetivou a redução do impacto visual e da complexidade da tarefa, com consequente redução da ansiedade destes participantes.

A forma de pontuação foi a mesma utilizada no original MRMT, ou seja, atribui-se 1 ponto para cada virada realizada corretamente. Diferente do original, na tarefa Maze o participante poderia errar até três vezes o local das viradas e após esse número de erros o teste era encerrado. Isso resultou numa pontuação baseada somente em acertos na tarefa Maze, uma vez que o número máximo de erros era três para todos os participantes. Os dados do desempenho do participante foram extraídos automaticamente no formato de planilha em um arquivo .csv (dados separados por vírgulas), que podia ser armazenado e organizado em uma planilha do tipo Excel (Microsoft Excel versão 2013). Os dados extraídos de cada participante incluíram 1) tempo total, 2) número de acertos e 3) número de erros, bem como o local de cada erro no mapa.

\subsubsection{Tarefa 2: SOIVET-Route (Rota com marcos topográficos)}

Ao contrário da tarefa Maze, em que o participante necessita utilizar a sua orientação egocêntrica para se situar em um ambiente sem diferenciação entre marcos topográficos, 
a tarefa Route visou a utilização de uma sequência de lugares diferenciados, inspirados em um ambiente público do Hospital das Clínicas de São Paulo.

Na tarefa SOIVET-Route, os participantes eram capazes de "andar" em primeira pessoa, em um ambiente virtual imersivo baseado no quinto andar do edifício do Instituto Central. Nas imediações deste local são exibidos um balcão de recepção, uma cafeteria, a entrada do Centro de Estudos, uma mesa e uma banca de jornais do lado de fora da entrada principal (Figura 5). Inicialmente, os participantes "seguiam" um personagem virtual que passava pelos 5 locais diferentes descritos acima (Figura 6), em uma sequência pré-determinada, para em seguida repetirem este caminho sozinhos (Tarefa SOIVETRoute evocação imediata). Após um período de 20 minutos fora do ambiente virtual, os participantes eram convidados a recriar a mesma sequência do caminho que percorreram com o personagem virtual, sem que o personagem virtual lhes mostrasse o caminho novamente (Tarefa SOIVET-Route evocação tardia). Assim como determinado no TCMR original, além dos cinco locais visitados, foi também reproduzido o posicionamento de um envelope no segundo local visitado e um livro no quarto local visitado.

1) Balcão da recepção

2) Banca de jornal

3) Cafeteria

4) Mesa

5) Centro de estudos

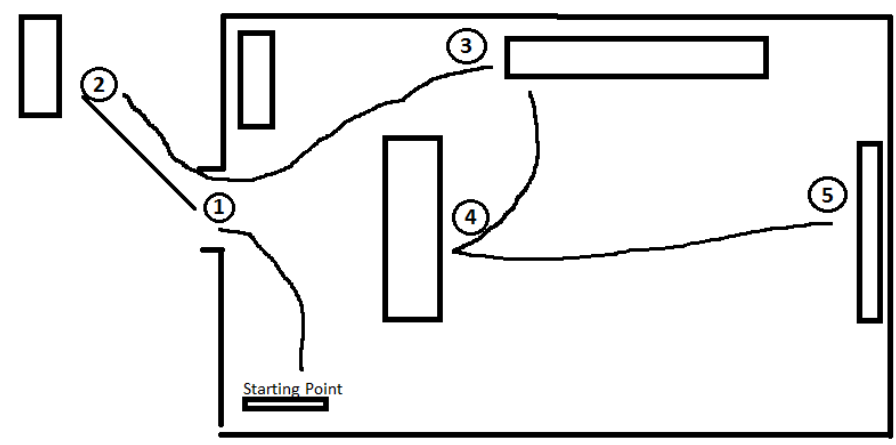

Figura 5: Sequência de marcos topográficos da tarefa SOIVET-Route 


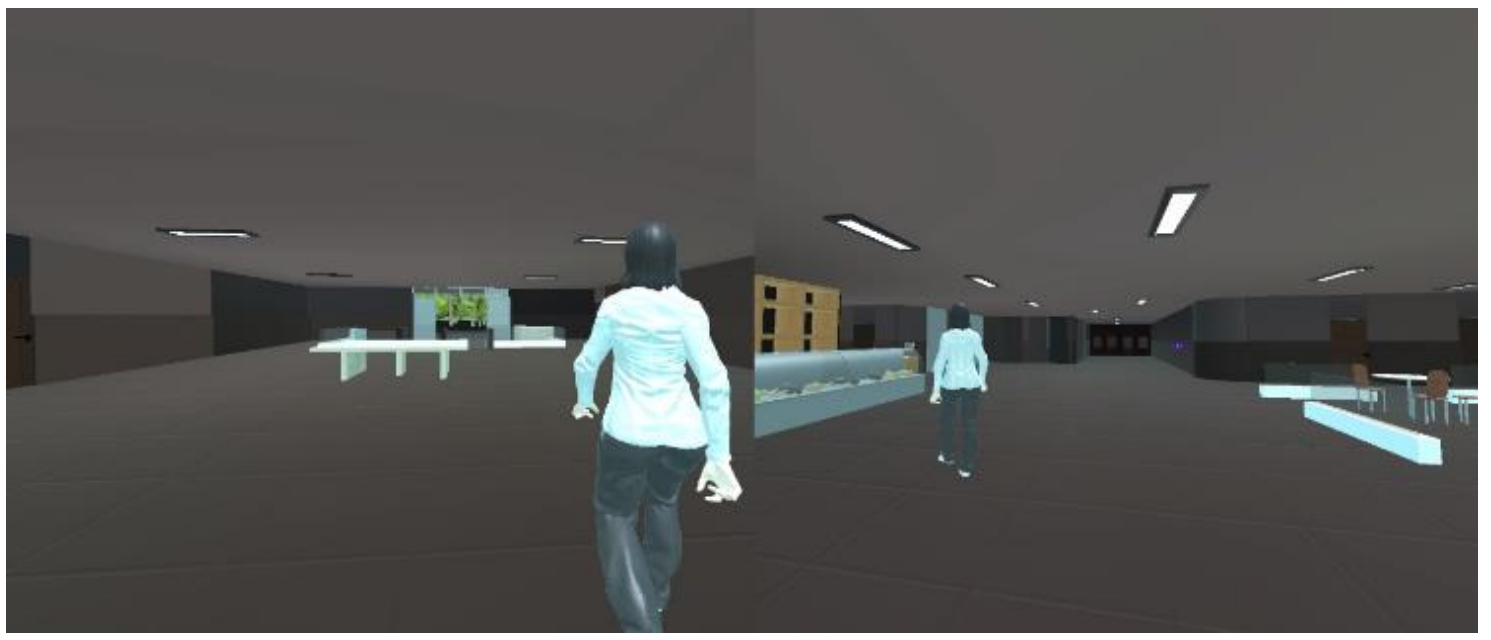

Figura 6. Fase de Instruções da tarefa SOIVET-Route: Sequência do caminho demonstrada pelo personagem virtual e acompanhada pelo participante.

\subsubsection{Avaliação do desempenho dos participantes na tarefa SOIVET-Route}

O desempenho dos participantes nesta tarefa seguiu a mesma pontuação proposta para o subitem "Caminho" do TCMR. Foram extraídos automaticamente do sistema de realidade virtual, em forma .csv: 1) tempo total, 2) número de locais visitados na ordem correta da sequência (acertos), 3) número de locais visitados fora da ordem (erros). A tarefa era encerrada automaticamente quando o participante alcançava os cinco locais ou quando o participante considerava ter terminado de percorrer o caminho (no caso de não visitar os cinco locais). A extração automática de dados foi a mesma descrita para a tarefa Maze. A mensagem e o livro deixados pelo personagem foram utilizados somente para destacar o segundo e quarto locais como determina o TCMR e nenhuma ação por parte dos participantes era necessária subsequentemente. 


\subsection{Casuística}

Este estudo obteve a aprovação da Comissão de Ética para Análise de Projetos de Pesquisa da Universidade de São Paulo (CAPPesq processo 12491/2014). Todos os participantes deste estudo foram voluntários e forneceram consentimento livre e esclarecido por escrito para sua participação e inclusão.

- Projeto piloto: Foram incluídos nesta etapa do estudo apenas participantes adultos, entre 18 e 59 anos, com diferentes perfis de uso de tecnologia e sem queixa cognitiva. Estes participantes foram recrutados entre estudantes da Universidade de São Paulo e familiares ou conhecidos dos envolvidos neste projeto.

- Idosos cognitivamente saudáveis: Foram incluídos no grupo controle participantes acima de 60 anos de idade, sem queixa nem comprovação objetiva de comprometimento cognitivo verificada através de testagem neuropsicológica de rastreio com o Exame Cognitivo de Addenbrooke, versão revisada (ACE-R) (92) (Apêndice 1) e pontuação acima dos limites normativos de 82 pontos considerados para declínio cognitivo sem demência, de acordo com a escolaridade $(93,94)$. Os participantes deste grupo foram provenientes da comunidade local e de programas de educação continuada ou exercício físico para idosos que acontecem na Universidade de São Paulo e no HCFMUSP.

- Idosos com CCL: Foram incluídos no grupo CCL idosos acima de 60 anos, provenientes do ambulatório do Grupo de Neurologia Cognitiva e do Comportamento (GNCC) no HCFMUSP e do Centro de Referência de Distúrbios Cognitivos (CEREDIC) do HCFMUSP, após avaliação neuropsicológica realizada nestes setores e diagnóstico final estabelecido segundo os critérios de Petersen e/ou Jak \& Bondi 
$(3,95)$. A avaliação neuropsicológica, a avaliação médica e o rastreio para transtornos psiquiátricos foram realizados de forma rotineira nos ambulatórios do GNCC e atendimentos no CEREDIC previamente à inclusão neste estudo. Nesta avaliação há também o detalhamento do comprometimento cognitivo e registro de pacientes que apresentam comorbidades clínicas e sintomas clinicamente significativos de depressão, ansiedade ou outra patologia psiquiátrica em atividade.

Critérios de inclusão: Os critérios de inclusão gerais para todos os participantes (do projeto piloto e da avaliação com idosos) foram: acuidade visual e auditiva preservada ou corrigida; sem histórico de labirintopatias ou vertigem. Foram excluídos aqueles que não conseguiram realizar as tarefas por questões de tolerabilidade (cybersickness) ou que não retornaram para dar seguimento ao protocolo do estudo (dropout).

Os critérios de inclusão específicos do grupo CCL foram: idade superior a 60 anos, diagnóstico de CCL amnéstico de acordo com os critérios de Petersen e/ou Jak \& Bondi $(3,95)$ e ausência de diagnóstico atual de quadro psiquiátrico (ansiedade ou depressão maior). Os critério de exclusão específico deste grupo foram 1) a mudança de diagnóstico ao longo do período de avaliação (pacientes que tenham evoluído para demência ou retornado ao estado de normalidade) de acordo com a avaliação rotineira realizada no CEREDIC durante a vigência deste projeto e 2) aqueles que não conseguiram realizar as tarefas ou não retornaram para conclusão do protocolo do estudo (dropout). 


\subsection{Protocolos}

3.4.1. Projeto Piloto-Avaliação da tolerabilidade, sensação de presença e imersão e facilidade de uso ("usabilidade") do sistema SOIVET e tarefas

O projeto piloto foi conduzido no Centro de Referência de Distúrbios Cognitivos do Hospital das Clínicas da Universidade de São Paulo (CEREDIC). Para melhor caracterização da amostra, os participantes foram solicitados a preencher questionários sobre perfil de uso de tecnologia e histórico de sensibilidade à cinetose, ambos desenvolvidos pelo nosso grupo de pesquisa, o questionário auto preenchido da Escala de Orientação de Santa Bárbara (Santa Barbara Sense of Direction Scale - SBSOD) sobre a habilidade de orientação e senso de direção (96) (Apêndice 2), bem como o Índice de Comorbidades de Charlson (ICC) (97). Estas informações não foram utilizadas como critérios de exclusão. Além destes questionários, os participantes foram solicitados a realizar as tarefas SOIVET-Maze, SOIVET-Route e o MRMT em papel e caneta. Nenhum dos participantes havia realizado as tarefas previamente. Foram coletadas as impressões, dificuldades e sugestões (feedback) dos participantes frente às tarefas virtuais. A coleta de dados do projeto piloto ocorreu em um único dia, com duração de aproximadamente 1 hora e 30 minutos.

3.4.1.1. Medidas de desfecho para Tolerabilidade, Sensação de Presença e Usabilidade

Medidas de tolerabilidade foram coletadas com um questionário de cybersickness de autorrelato, baseado na versão brasileira do Simulator Sickness Questionnaire $(98,99)$, 
que incluiu 16 efeitos adversos relacionados à cinetose e ao desconforto com realidade virtual - como náusea, dor de cabeça, visão borrada, vertigem - numa escala Likert de 4 pontos de intensidade (nem um pouco - um pouco - bastante e muito) (Apêndice 3) (100). Os participantes responderam a este questionário após cada tarefa. Para investigar a possibilidade de uma susceptibilidade individual ao cybersickness, os participantes também preencheram um questionário de desconforto e rastreio de cinetose, antes de realizar as tarefas (Apêndice 4) (100). O questionário de rastreio foi desenvolvido pelo nosso grupo de pesquisa e incluiu seis perguntas sobre situações que comumente induzem cinetose: "Você costuma sentir enjoo ou tontura enquanto lê num carro em movimento?" ou "Você prefere ser o motorista, ao invés do passageiro, porque senão você sente tontura ou enjoo?"

A sensação de presença e imersão foi avaliada com o Questionário de Presença de Witmer e Singer (101) (Apêndice 5). Dentre alguns questionários disponíveis para a avaliação de presença e imersão em realidade virtual $(102,103)$, este detalhado questionário, proposto em 1998 por Bob G. Witmer e Michael J. Singer, possui 24 itens no total e sua pontuação pode ser subdividida de acordo com os fatores de: controle, sensorial, distração e realismo. Segundo os autores, estes fatores contribuem substancialmente para a sensação de pertencimento de um indivíduo a um ambiente virtual (101). Os participantes responderam este questionário de forma autorrelatada imediatamente após cada tarefa.

Para avaliar a usabilidade do sistema, foram coletados comentários espontâneos dos participantes relacionados à compreensão das instruções das tarefas e interação com o sistema, bem como anotações das observações feitas pelos pesquisadores. Ademais, o perfil de uso de tecnologia entre os participantes foi investigado utilizando o questionário 
de Uso e Familiaridade com Tecnologia (Apêndice 6), desenvolvido pelo nosso grupo de pesquisa (100). Este questionário inclui 10 questões relativas ao uso rotineiro de dispositivos e programas de tecnologia, como smartphones, computadores e videogames. Os participantes responderam a este questionário antes da realização das tarefas, a fim de investigar uma possível influência da familiaridade tecnológica na compreensão e operação de cada tarefa. Não foi utilizado como critério de inclusão ou exclusão para a seleção da amostra.

\subsubsection{Análise estatística do projeto piloto}

Para analisar os dados da etapa piloto, foi realizada uma análise de distribuição de normalidade, utilizando valores de skewness e kurtosis, bem como análise visual de histograma. Para uma análise adicional, um teste de normalidade de KolmogorovSmirnov também foi realizado (104). Após a identificação do tipo de distribuição dos dados, foram reportadas as médias (M) e desvios padrão (DP) para dados de distribuição normal e as médias, desvios padrão, medianas e intervalos interquartis (IQR) para dados de distribuição não normal. Em seguida, foi realizado um teste $t$ para amostras independentes para comparação de dados paramétricos e um teste de classificação de Wilcoxon para comparação de dados não paramétricos de única amostra (105). Para melhor caracterização dos fatores influenciadores sobre o desempenho na tarefa, foram realizadas análises de correlação entre o desempenho nas tarefas e os fatores idade, escolaridade, perfil do uso de tecnologia e a pontuação na SBSOD. Para investigar a correlação entre dados, foi utilizado um teste de correlação de Spearman (para dados de distribuição não normal) (106). 
3.4.2. Avaliação com idosos: Validade de construto das tarefas de realidade virtual, comparação de grupos e acurácia das tarefas

Após a conclusão do projeto piloto e implementadas as modificações necessárias para a versão final do sistema SOIVET e das tarefas SOIVET-Maze e SOIVET-Route, deu-se início à coleta de dados com idosos para a validade de construto e para a comparação de grupos (idosos saudáveis vs. CCL).

O conceito de validade de construto em Psicologia difere do conceito utilizado tradicionalmente em Psicometria. Nesta última, a validação de um instrumento pode ser dividida em três grandes classes: validade de construto, validade de critério e validade de conteúdo. A validade de construto seria verificada pela análise fatorial dos itens do instrumento proposto, de forma a verificar os construtos previamente operacionalizados no instrumento (107). Entretanto, quando nos referimos ao campo da Psicologia, em especial ao da avaliação cognitiva, a validade de construto assume um significado mais amplo, dada a importância primordial de verificar se o instrumento proposto de fato mede aquilo que se propõe a medir. Desta forma, em 1999, a Associação Americana de Psicologia modificou o conceito de validade de construto, ampliando-o. Este passou a englobar (1) a evidência com base no conteúdo, (2) a evidência com base no processo de resposta, (3) a evidência com base na estrutura interna, (4) a evidência com base na relação com variáveis externas e (5) evidências baseadas nas consequências da testagem (108). Estes componentes abordam as múltiplas questões que precisam ser respondidas para compreender e justificar a pontuação de um teste cognitivo e sua utilidade (109).

A pergunta inicial que este estudo se propunha investigar era se as tarefas SOIVETMaze e SOIVET-Route de fato avaliam o domínio cognitivo da orientação espacial. A 
validade de construto em foco se caracteriza pela correlação das tarefas propostas com outras tarefas já bem estabelecidas na literatura e que são reconhecidas por avaliar este mesmo domínio de interesse (110), ou seja, a evidência com base na relação com variáveis externas (108).

Uma vez que não há um padrão-ouro para avaliação da orientação egocêntrica e alocêntrica de forma semelhante à vida real, foram utilizados para validade de construto os testes de memória operacional visuoespacial: Teste dos Blocos de Corsi $(111,112)$, de capacidade visuoperceptiva e de rotação mental: Teste de Orientação das Linhas de Benton (113) e o Money Road Map Test (no qual a tarefa SOIVET-Maze se baseia) (56) e de planejamento: o Torre de Londres (114) (Para maiores informações sobre estes testes, veja o Anexo A). Além disso, medidas de capacidade cognitiva global (ACE-R e MMSE) também foram utilizadas para correlação com os resultados das tarefas e consequente interpretação dos resultados. As análises dos testes selecionados para validade de construto foram realizadas agrupando-se os participantes dos dois grupos (controle e CCL).

O desempenho dos participantes nas tarefas SOIVET-Maze e SOIVET-Route foi utilizado para comparação de grupos e investigação da acurácia. De acordo com a hipótese deste estudo, era esperado que as tarefas de orientação espacial em ambiente virtual fossem capazes de discriminar o grupo saudável (controle) do grupo com declínio cognitivo. Além disso, foram obtudas as áreas sob a curva de cada teste para a identificação do grupo CCL em comparação ao grupo controle, bem como os pontos de corte de cada tarefa virtual que ofereçam a melhor combinação entre sensibilidade e especificidade. 
3.4.2.1 Análise estatística para validade de construto, comparação de grupos e sensibilidade e especificidade na identificação do grupo CCL em comparação ao grupo controle

Para verificação da validade de construto (relação com variáveis externas) a pontuação de cada tarefa virtual foi correlacionada com as pontuações nos testes: Teste dos Blocos de Corsi (ordem direta e inversa), Teste de Orientação das Linhas de Benton, Money Road Map Test, Torre de Londres e os subitens do ACE-R: memória, atenção e orientação e visuoespacial. A pontuação das tarefas virtuais incluiu: o número total de acertos na tarefa SOIVET-Maze, o número total de acertos na tarefa SOIVET-Route evocação imediata, SOIVET-Route evocação tardia. As pontuações na tarefa SOIVET-Route também foram correlacionadas com a pontuação do caminho em ambiente real (realizada no quinto andar do Instituto Central do HCFMUSP com os mesmo locais da tarefa virtual). O método de correlação empregado (teste de Pearson ou Spearman) foi escolhido de acordo com a distribuição normal ou não normal dos dados, que foi verificada antes da aplicação das correlações.

Adicionalmente, as pontuações de cada tarefa virtual foram também correlacionadas com a idade, escolaridade, capacidade cognitiva global (medida pelas pontuações totais no ACE-R e MMSE) e perfil de uso de tecnologia dos participantes, de modo a investigar a possível influência de outras variáveis no desempenho dos participantes. Para isso foi utilizada a correlação de Spearman para dados de distribuição não normal.

Para comparação de grupos, as médias e medianas das pontuações em cada tarefa foram separadas por grupo (controle e CCL) e depois aplicados os testes de comparação de grupos. Estes testes foram escolhidos de acordo com a distribuição (normal ou não 
normal) dos dados de desempenho: teste $t$ para amostras independentes para comparação de dados paramétricos e o teste de Wilcoxon-Mann-Whitney para comparação de dados não paramétricos para amostras independentes (também conhecido como Mann-Whitney $U$ test) (105). Para a comparação entre proporções de uma variável em cada grupo (como por exemplo a porcentagem de voluntários do sexo masculino em cada grupo) foi utilizado o teste do Qui-quadrado de homogeneidade (115). A hipótese nula seria considerada como rejeitada se um $\mathrm{p}<0.05$ fosse encontrado (hipótese estabelecida $a$ priori) para todos os testes de comparação de grupos.

Para a avaliação da sensibilidade e especificidade das pontuações dos itens individualmente ou da pontuação total, tanto na tarefa SOIVET-Maze como na SOIVETRoute, para o diagnóstico categórico de CCL, foi realizada a Curva de Característica de Operacionais (Curva ROC - Receiver Operating Characteristic) (116). A pontuação de cada tarefa foi selecionada como variável teste e o diagnóstico categórico de CCL como variável de estado. O cálculo da área sob a curva (AUC) permitiu a verificação da acurácia de cada tarefa para o diagnóstico correto de CCL. De acordo com a hipótese formulada inicialmente, uma área sob a curva >0.7 demonstraria boa acurácia (moderada a alta) das tarefas propostas para diferenciação de grupos. Se esta acurácia fosse encontrada, seria então definido o ponto de corte de cada tarefa para um diagnóstico confiável de CCL. O ponto de corte ideal foi estabelecido de acordo com o índice de Youden, ou seja, o melhor ponto de corte foi aquele em que foi obtido o menor número de diagnósticos incorretos (falso negativo mais falso positivo). O índice de Youden é calculado deduzindo-se 1 a partir da soma da sensibilidade e especificidade do teste e não se expressa como porcentagem, mas como parte de um número inteiro: (sensibilidade + especificidade) 1. Para um teste com uma má precisão do diagnóstico, índice de Youden é igual a zero, e em um teste perfeito, o índice de Youden é igual a 1 (117). 


\subsection{Resultados}

\subsection{Projeto Piloto}

\subsubsection{Características da amostra}

Todos os participantes do projeto piloto preencheram os critérios de inclusão e nenhum foi excluído antes da realização das tarefas. Foram incluídos neste estudo 32 participantes adultos (53.1\% eram mulheres), entre 18 e 59 anos de idade e escolaridade variando entre 12 a 18 anos, com diferentes perfis de uso de tecnologia e sem queixa cognitiva. Nenhum dos participantes apresentava deficiência auditiva e 61,3\% apresentavam deficiência visual corrigida (uso de óculos para miopia, hipermetropia ou astigmatismo). A maioria dos participantes $(93,54 \% \quad n=29)$ não apresentava comorbidades (ICC=0), dois participantes $(6,45 \%)$ apresentaram ICC $=1$ e apenas um participante $(3,22 \%)$ apresentou ICC $=2$. As pontuações no Questionário de Uso e Familiaridade com Tecnologia variaram entre 18 e 39 pontos, no qual 40 é a pontuação máxima possível (Tabela 1).

Tabela 1. Características da amostra do projeto piloto $(n=32)$

\begin{tabular}{|lccccc|}
\hline & Média & DP & Mediana & IQR & Variação \\
\hline Idade (anos) & 32,0 & 10,4 & 28,5 & 2,0 & $18-59$ \\
Escolaridade (anos) & 15,9 & 2,3 & 16,0 & 2,0 & $12-18$ \\
Uso de Tecnologia & 27,7 & 6,0 & 27,0 & 9,0 & $18-39$ \\
ICC & 0,1 & 0,4 & 0,0 & 0,0 & $0-2$ \\
Mulheres n (\%) & & & $17(53.1 \%)$ & & \\
& & & &
\end{tabular}

DP, Desvio padrão. IQR, intervalo interquartil. ICC, Índice de Comorbidade de Charlson. 


\subsubsection{Tolerabilidade}

Não foram encontradas diferenças de tolerabilidade estatisticamente significativas entre as tarefas SOIVET-Maze (média de 4.19 (DP 5.57)) pontos; mediana de 2,5 (IQR 5,8) e SOIVET-Route (média de 3.52 (DP 6.42)) pontos; mediana de 1,0 (IQR 4,0); Wilcoxon signed-rank test $(\mathrm{Z}=-0.901, \mathrm{p}=0.368)$. Entretanto, uma pequena vantagem numérica da tarefa SOIVET-Route - utilizando as pontuações do questionário de cybersickness após a realização de cada tarefa - pôde ser observada. Ademais, dois (6.25\%) participantes não conseguiram completar a tarefa SOIVET-Maze por questões de tolerabilidade (dropouts), enquanto todos os participantes conseguiram completar a tarefa SOIVET-Route. Conforme pode-se ver no fluxograma abaixo (Figura 7):

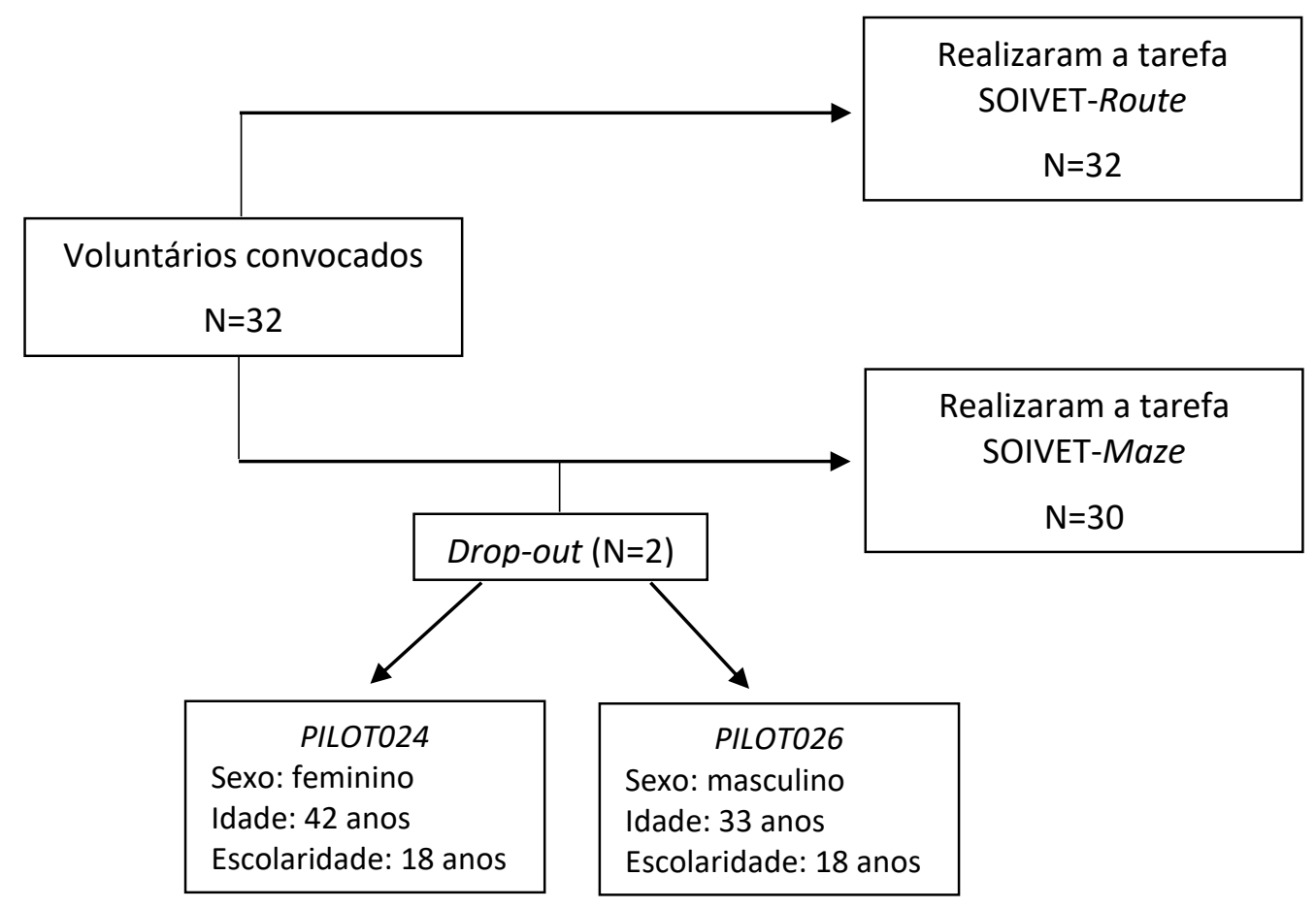

Figura 7. Fluxograma do projeto piloto. 
As pontuações do questionário de cybersickness em ambas tarefas parecem estar relacionadas a uma susceptibilidade individual à cinetose, pois uma correlação positiva e significativa foi encontrada entre as pontuações de cybersickness na SOIVET-Maze e SOIVET-Route $(\mathrm{r}=0.552, \mathrm{p}=0.001)$ e entre as pontuações de cybersickness e o questionário de rastreio para cinetose $(\mathrm{r}=0.533, \mathrm{p}=0.002$ e $\mathrm{r}=0.365, \mathrm{p}=0.043$ para SOIVET-Maze e SOIVET-Route respectivamente). As pontuações de cybersickness não diferiram quanto ao sexo e não apresentaram correlação com a idade ou perfil de uso de tecnologia, utilizando a correlação de Spearman.

\subsubsection{Sensação de Presença e Imersão}

Os resultados obtidos utilizando o Questionário de Presença de Witmer e Singer indicaram altos níveis de sensação de presença e imersão para ambas tarefas (mediana de 128 e 143 pontos para SOIVET-Maze e SOIVET-Route, respectivamente (pontuação máxima de 154 pontos)). Ademais, todos os 22 itens do questionário apresentaram uma pontuação mediana acima de 5 numa escala Likert de 7 pontos, em ambas tarefas, onde 7 indica a maior sensação de presença e imersão. As pontuações de presença e imersão não diferiram quanto ao sexo e não apresentaram correlação significativa com a idade ou perfil de uso de tecnologia dos participantes, utilizando a correlação de Spearman. Os participantes que precisaram interromper a tarefa SOIVET-Maze por questões de tolerabilidade $(\mathrm{n}=2,6.25 \%$, pontuação no questionário de cybersickness de 16 e 24 pontos cada) foram excluídos da análise de sensação de presença e imersão. 
4.1.3 Usabilidade - Compreensão das instruções das tarefas e interação com o sistema

Todos os participantes foram capazes de compreender as instruções das tarefas e como interagir com o ambiente virtual utilizando o controle joystick. A maioria dos participantes solicitou uma segunda tentativa para a realizar a tarefa SOIVET-Maze e uma segunda rodada da fase de instrução da SOIVET-Route, devido ao viés atencional de distração gerado pela novidade do ambiente virtual nunca antes experimentado. Nenhum participante solicitou uma segunda tentativa para as fases de evocação imediata e tardia da SOIVET-Route. Além disso, o perfil de uso de tecnologia dos participantes, medido através do Questionário de Uso e Familiaridade com tecnologia não apresentou correlação com o desempenho nas tarefas, utilizando a correlação de Spearman.

\subsubsection{Desempenho nas tarefas}

O desempenho dos participantes nas tarefas SOIVET-Maze e SOIVET-Route foi extraído do sistema, conforme descrito nos itens 3.2.2.1 e 3.2.3.1. Levando em consideração que a maioria dos participantes solicitou uma segunda tentativa na tarefa SOIVET-Maze e na tarefa SOIVET-Route - devido ao viés atencional ocasionado pela novidade da tecnologia - foram selecionados para avaliação os resultados após estas segundas tentativas. Para avaliação inicial do desempenho nas tarefas, foram excluídos do total de 32 participantes, os dois que não conseguiram concluir a tarefa por graves sintomas de cybersickness, totalizando uma amostra de 30 participantes para a análise. 
Na tarefa SOIVET-Maze, houve importante variabilidade dos resultados. Dentre os 32 pontos de decisão no labirinto, a média de acertos, entre os 30 participantes, foi de 12,71 (DP 11,79), mediana de 8,0 e IQR 26,0. Quando analisamos a distribuição dos resultados em quartis, a média de acertos foi Q1 = 3,75, Q2 = 8, Q3 = 29,25 (Figura 8).

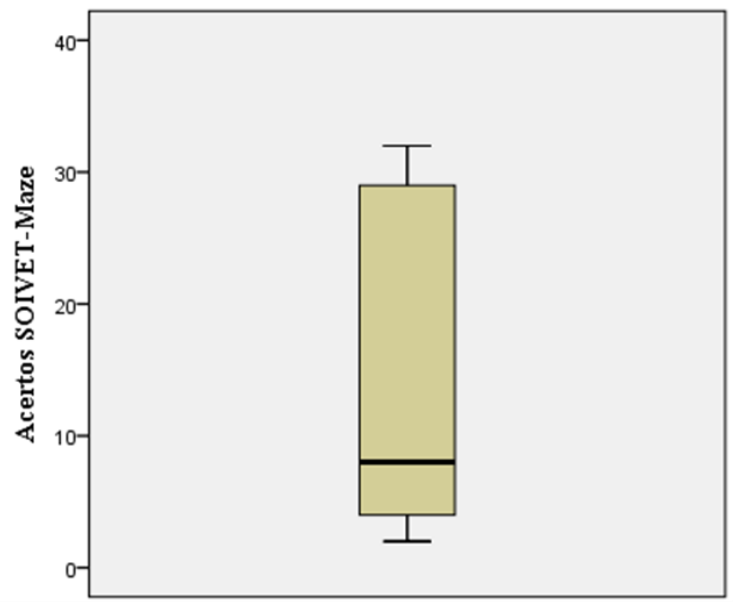

Figura 8. Desempenho dos participantes $(\mathrm{n}=30)$ na tarefa SOIVET-Maze

Além dos dois participantes excluídos dos resultados de desempenho por não terem conseguido realizar a tarefa por questões de tolerabilidade, mais outros três participantes realizaram a tarefa, porém a interromperam precocemente por este mesmo motivo (pontuação acima de 5 no questionário de cybersickness). Ao excluirmos estes participantes da análise, encontramos resultados levemente melhores, porém ainda com uma grande dispersão: média de acertos (n=27) de 13,89 (DP 11,91), divisão por quartis: $\mathrm{Q} 1=3, \mathrm{Q} 2=9, \mathrm{Q} 3=30$. Ao avaliarmos outros fatores que pudessem ter influenciado a variabilidade de desempenho na tarefa SOIVET-Maze, foi possível identificar uma clara influência do sexo nos resultados $(\mathrm{F}(2,24)=22,519, \mathrm{p}<0,001)$. Os homens apresentaram uma média de acertos bem superior à das mulheres, com média de 20,07 (DP 12,25) e valor mediano de 25,5 (IQR 23), enquanto que as mulheres tiveram média de 6,38 (DP 6,75) acertos e valor mediano de 4 (IQR 5) (Figura 9). Não foi encontrada uma influência 
significativa da idade, nem do perfil de uso de tecnologia no desempenho dos participantes.

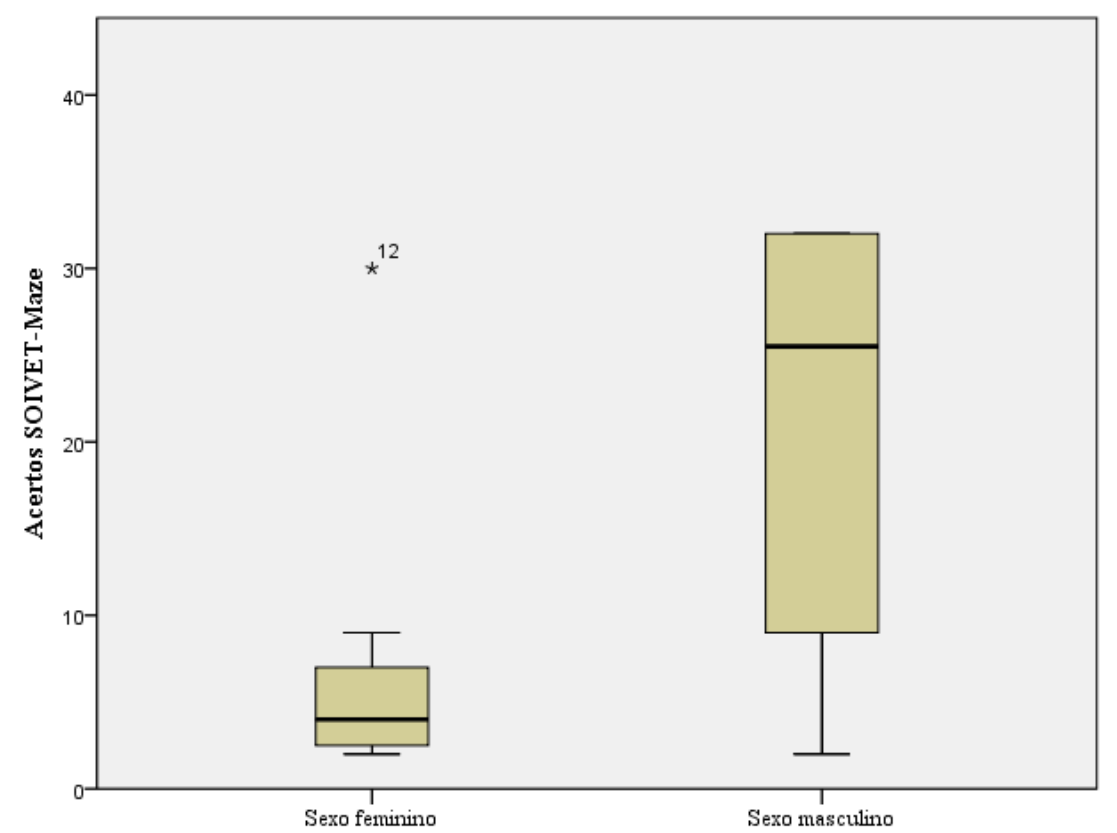

Figura 9. Desempenho dos participantes na tarefa SOIVET-Maze separado por sexo

Outro fator que influenciou esta grande variabilidade de resultados foi a complexidade da tarefa de orientação espacial. Foi observado que os participantes que declaravam ter dificuldade de orientação na vida real demonstravam maior dificuldade para realizar a tarefa SOIVET-Maze, enquanto aqueles que diziam ter um bom senso de direção desempenhavam melhor. De fato, o desempenho na tarefa SOIVET-Maze correlacionou-se significativamente com a pontuação total e também com muitos dos itens da Escala de Orientação de Santa Bárbara (SBSOD) (Tabela 2). 
Tabela 2. Correlação de Spearman entre o número de acertos na tarefa SOIVET-Maze e na tarefa tradicional MRMT e a pontuação em cada item da escala SBSOD e pontuação total $(n=30)$.

\begin{tabular}{|c|c|c|c|c|}
\hline \multirow{2}{*}{ Itens da escala SBSOD } & \multicolumn{2}{|c|}{ SOTVET-Maze } & \multicolumn{2}{|c|}{ MRMT } \\
\hline & $\mathbf{r}$ & $p$ & $\mathbf{r}$ & $p$ \\
\hline Eu sou muito bomboa em dar direções &,- 568 & $0,001 * *$ &,- 299 & 0,155 \\
\hline Eu tenho uma memória ruim de onde eu deixo as coisas. & ,388 & $0,037 *$ & 339 &, 072 \\
\hline Eu sou muito bomboa em estimar distâncias. &,- 304 & 0,108 &,- 366 & 051 \\
\hline Meu senso de direção é muito bom. &,- 375 & $0,045^{*}$ &,- 240 & 209 \\
\hline $\begin{array}{l}\text { Eu costumo pensar no ambiente em termos de pontos cardinais } \\
\text { (Norte, sul, leste, oeste) }\end{array}$ &,- 241 & 0,208 &,- 218 & 257 \\
\hline Eu me perco com facilidade em uma nova cidade. & 363 & 0,053 & ,322 & ,088 \\
\hline Eu gosto de ler mapas. &,- 481 & $0,008 * *$ &,- 166 & ,388 \\
\hline Eu tenho dificuldade para entender direções. & 452 & $0,014^{*}$ & 319 & 091 \\
\hline Eu sou muito bomboa em ler mapas. &,- 644 & $0,000 * *$ &,- 320 & 091 \\
\hline $\begin{array}{l}\text { Eu não me lembro muito bem dos caminhos quando estou de } \\
\text { carona como passageiro. }\end{array}$ & ,228 & 0,234 &,- 090 & ,641 \\
\hline Eu não gosto de dar direções. & 570 & $0,001^{* * *}$ &, 168 & ,385 \\
\hline Não é importante para mim me localizar onde estou. &, 216 & 0,260 &, 085 &, 661 \\
\hline $\begin{array}{l}\text { Eu geralmente deixo que outra pessoa se encarregue de fazer o } \\
\text { planejamento das rotas e caminhos em viagens mais longas. }\end{array}$ &, 451 & $0,014^{*}$ &, 228 &, 234 \\
\hline $\begin{array}{l}\text { Eu geralmente consigo me lembrar de um novo caminho depois } \\
\text { de ter percorrido ele uma vez. }\end{array}$ &,- 266 & 0,164 &,- 052 & ,787 \\
\hline Eu não tenho um bom "mapa mental" do ambiente a minha volta. &, 468 & $0,010^{*}$ &, 200 & 297 \\
\hline Pontuação Total &, 630 & $0,000^{* * *}$ & ,296 &, 119 \\
\hline
\end{tabular}

** Correlação significativa $\mathrm{p}<0,01$

* Correlação significativa $\mathrm{p}<0,05$

Por outro lado, o desempenho dos participantes na tarefa MRMT original em papel e caneta não apresentou grande variabilidade. A média de acertos no MRMT em papel (n=30) foi 29,57 (DP 3,04), mediana de 31 (IQR 4,0), divisão por quartis: Q1 = 28, Q2 = 31 e Q3 = 32. A pontuação de acertos no MRMT em papel correlacionou-se significativamente com o desempenho na tarefa SOIVET-Maze $(\mathrm{r}=0,537, \mathrm{p}=0,002) \mathrm{e}$ também foi encontrada uma significativa influência do sexo nos resultados $(F(2,27)=$ 11,642 p=0,002). É interessante ressaltar que o desempenho dos participantes no MRMT 
em papel não mostrou correlação significativa com nenhum item da SBSOD nem com a pontuação da SBSOD total $(r=-0,296, p=0,119)$.

A tarefa SOIVET-Route não mostrou grande variabilidade de resultados, mostrandose uma tarefa fácil para esta populaçao de adultos jovens. A média de acertos na tarefa SOIVET-Route imediata foi de 4,93 (DP 0,25), mediana de 5,0 (IQR 0,0) e na tarefa SOIVET-Route tardia foi de 4,97 (DP 0,18), mediana de 5,0 (IQR 0,0). A homogeneidade do desempenho entre os participantes pode ser verificada na Figura 10. O desempenho nestas tarefas não foi diferente entre o sexo masculino e o sexo feminino (Tabela 3) e não mostrou correlação com a idade $(r=0,062, p=0,745$ para imediata e $r=0,022, p=0,910$ para tardia), escolaridade $(\mathrm{r}=0,091, \mathrm{p}=0,632$ para imediato $\mathrm{e}=-0,207, \mathrm{p}=0,272$ para tardio) ou perfil de uso de tecnologia $(r=-0,263, p=0,160$ para imediato e $r=-0,290, p=$ 0,120 para tardio). Foi encontrada uma forte correlação entre os desempenhos na tarefa SOIVET-Route imediata e tardia $(\mathrm{r}=0,695, \mathrm{p}<0,001)$.

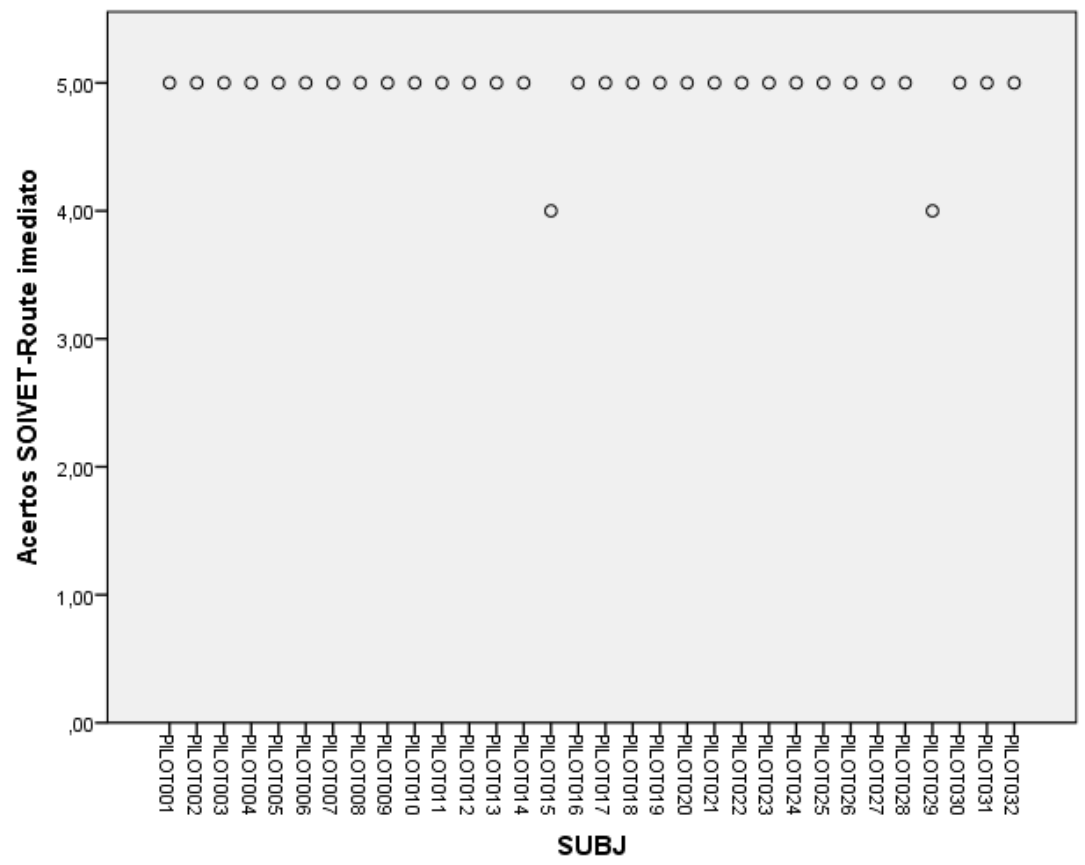

Figura 10. Distribuição da pontuação na tarefa SOIVET-Route imediata entre os voluntários do projeto piloto 
Tabela 3. Médias e medianas nas tarefas SOIVET-Maze, SOIVET-Route imediata e SOIVETRoute tardia separadas por sexo e comparação de grupos.

\begin{tabular}{|c|c|c|c|c|c|c|c|c|c|}
\hline & \multicolumn{4}{|c|}{$\begin{array}{c}\text { Homens } \\
n=14\end{array}$} & \multicolumn{4}{|c|}{$\begin{array}{c}\text { Mulheres } \\
n=16\end{array}$} & \multirow[b]{2}{*}{$U$} \\
\hline & Média & $\mathrm{DP}$ & Mediana & $\mathrm{IQR}$ & Média & DP & Mediana & IQR & \\
\hline SOIVET-Maze & 20,1 & 12,3 & 25,5 & 23,0 & 6,4 & 6,8 & 4,0 & 5,0 & $37,0^{\text {*** }}$ \\
\hline \multirow[t]{3}{*}{ MRMT } & 31,4 & 1,3 & 32,0 & 1,0 & 28,0 & 3,3 & 28,5 & 5,0 & $37,5^{* * *}$ \\
\hline & \multicolumn{4}{|c|}{$\mathrm{n}=15$} & \multicolumn{4}{|c|}{$\mathrm{n}=17$} & \\
\hline & Média & $\mathrm{DP}$ & Mediana & IQR & Média & DP & Mediana & $\mathrm{IQR}$ & $U$ \\
\hline SOIVET-Route imediata & 4,9 & 0,3 & 5,0 & 0,0 & 4,9 & 0,2 & 5,0 & 0,0 & 126,5 \\
\hline SOIVET-Route tardia & 4,9 & 0,3 & 5,0 & 0,0 & 5,0 & 0,0 & 5,0 & 0,0 & 119,0 \\
\hline
\end{tabular}

MRMT, Money Road Map Test. DP, Desvio Padrão, IQR, Intervalo interquartil. $U$, Teste de WilcoxonMann Whitney. ${ }^{* *} \mathrm{p}<0,01$.

\subsection{Avaliação com idosos}

\subsubsection{Fluxograma da coleta de dados}

Foram convidados a participar do estudo 38 idosos para o grupo controle e 24 idosos para o grupo CCL. A avaliação do rastreio cognitivo com a aplicação dos testes tradicionais e a aplicação das tarefas virtuais ocorreram geralmente em dias separados, dada a sobrecarga destas avaliações. O intervalo entre esses dias não foi superior a duas semanas. A avaliação cognitiva tradicional e o rastreio duraram em média uma hora e 30 minutos, enquanto a aplicação das tarefas virtuais durou em médias duas horas.

Ocorreu a mudança de grupo (do grupo controle para o grupo CCL) com três participantes, que apresentaram pontuação no ACE-R < 82. Foram excluídos do grupo controle seis participantes que não conseguiram realizar as tarefas (dropout) por motivo de tolerabilidade $(\mathrm{n}=4)$ ou por não concluírem o protocolo por outros motivos, 
como perda de contato e mudança de estado $(n=2)$. No grupo CCL, oito participantes foram excluídos por motivo de tolerabilidade $(n=4)$ ou outros motivos $(n=4)$, como perda de contato e desistência em participar. O número de dropouts no grupo controle não diferiu significativamente do grupo $\operatorname{CCL}(\chi 2=1,359 \mathrm{p}=0,243)$. Este fluxo de coleta pode ser visualizado na Figura 11. Adicionalmente, três voluntários do grupo controle e cinco voluntários do grupo CCL não realizaram avaliação neuropsicológica tradicional.

Grupo Controle

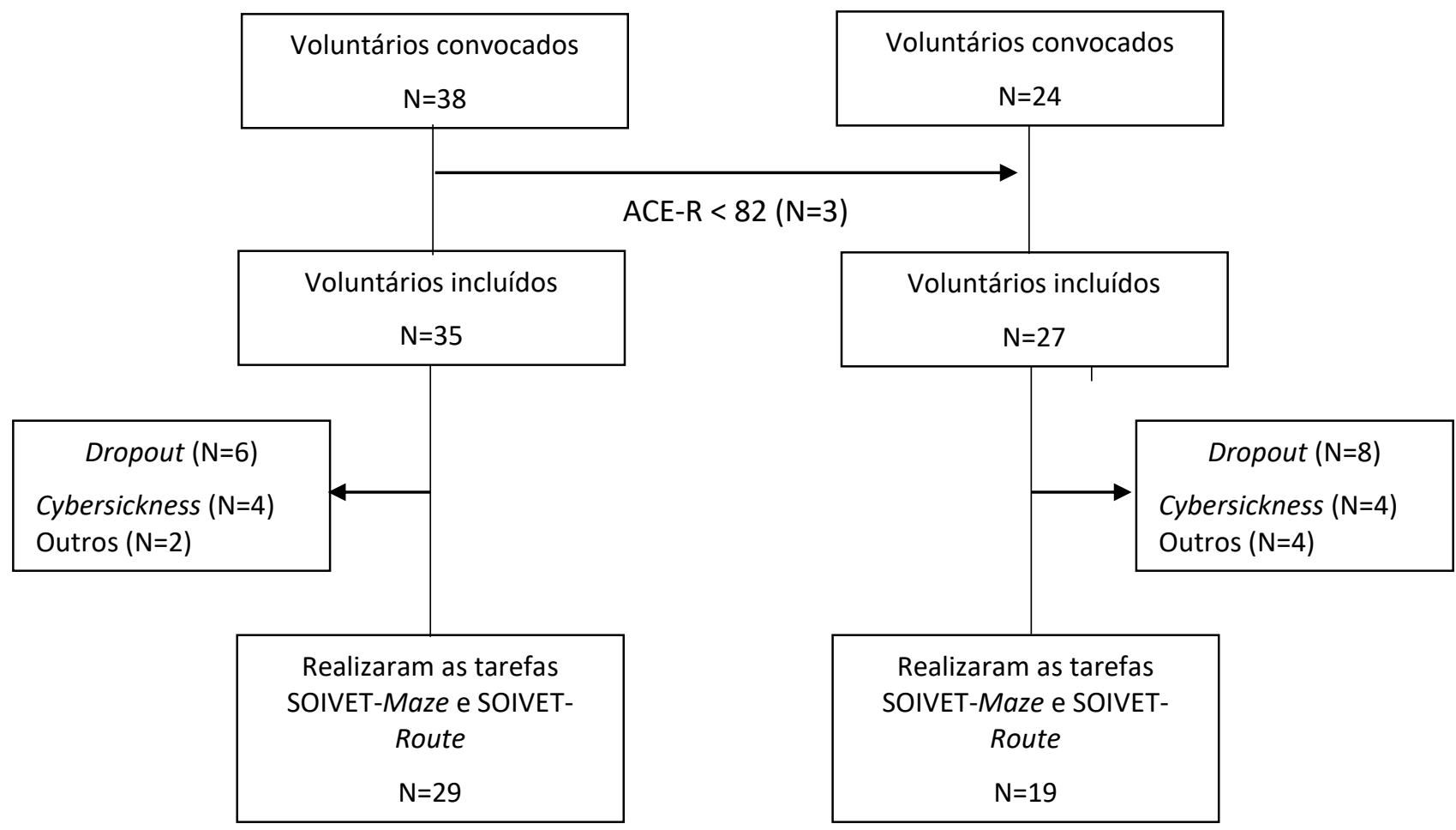

Figura 11. Fluxograma de coleta das tarefas virtuais, com dropouts por grupo. 


\subsubsection{Características da amostra}

Foram incluídos no grupo controle 29 participantes acima de 60 anos de idade com escolaridade mediana de 16 anos (IQR 4,0), sem queixa nem comprovação objetiva de comprometimento cognitivo verificada através de pontuação no ACER-R acima dos limites normativos de 82 pontos. Foram incluídos no grupo CCL 19 idosos acima de 60 anos, com escolaridade mediana de 12 anos (IQR 4,0). As características da amostra da etapa de avaliação com idosos estão descritas na tabela 4.

Tabela 4. Características da amostra da etapa de avaliação com idosos (n=48).

\begin{tabular}{|lcccccccc|}
\hline & \multicolumn{3}{c}{ Controle } & \multicolumn{3}{c|}{ CCL } \\
& \multicolumn{3}{c}{$(\mathrm{n}=29)$} & \multicolumn{3}{c|}{$(\mathrm{n}=19)$} & \\
\hline & Média & $\mathrm{dp}$ & Variação & Média & dp & Variação & $p$ \\
\hline Idade (anos) & 70.21 & 5.28 & $61-85$ & 72.53 & 6.50 & $64-92$ & 0,202 \\
Escolaridade (anos) & 14.54 & 2.49 & $9-16$ & 13.68 & 2.67 & $9-18$ & 0,245 \\
ACE-R & 93.35 & 4.18 & $84-99$ & 86.71 & 7.20 & $76-98$ & 0,001 \\
MMSE & 28.96 & 1.11 & $26-30$ & 27.43 & 2.24 & $24-30$ & 0.025 \\
Uso de Tecnologia & 18.24 & 8.34 & $3-32$ & 13.79 & 7.93 & $0-29$ & 0,11 \\
ICC & 0.40 & 0.71 & $0-3$ & 0.93 & 1.27 & $0-4$ & 0.251 \\
Homens n (\%) & & $9(31 \%)$ & & & $6(31.6 \%)$ & \\
\end{tabular}

ACE-R, Exame cognitivo de Addenbrooke - Revisado. MMSE, Mini Exame do Estado Mental. ICC, Índice de Comorbidade de Charlson. DP, Desvio padrão. Comparação entre grupo controle e grupo CCL utilizando teste $t$ para amostras independentes ou teste de Wilcoxon-Mann-Whitney. II Teste do Quiquadrado $\chi 2=0,0016, \mathrm{p}=0,968$

Os grupos controle e CCL não diferiram quanto à idade, escolaridade, proporção de homens, perfil de uso de tecnologia e comorbidades. Os grupos diferiram significativamente quanto à pontuação no ACE-R e MMSE (Tabela 4). 


\subsubsection{Correlação com testes neuropsicológicos tradicionais}

A análise de correlação entre a pontuação na tarefa SOIVET-Maze e os testes tradicionais sem separação por grupos $(n=40)$ revelou uma correlação significativa com o MRMT, com o teste de Torre de Londres, com o teste das Linhas de Benton e com a pontuação total do ACE-R. Não foi encontrada correlação significativa com o teste de Blocos de Corsi, ordem direta ou inversa, nem com o Mini Exame do Estado Mental. A matriz de correlação entre todos os testes está detalhada na tabela 5.

Tabela 5. Matriz de correlação entre a tarefa SOIVET-Maze e os testes neuropsicológicos tradicionais.

Correlação entre médias (rô de Spearman) para a tarefa SOIVET-Maze

\begin{tabular}{|c|c|c|c|c|c|c|c|c|}
\hline & $\begin{array}{c}\text { SOIVET- } \\
\text { Maze }\end{array}$ & MRMT & $\begin{array}{c}\text { Corsi } \\
\text { (Direto) }\end{array}$ & $\begin{array}{c}\text { Corsi } \\
\text { (Inverso) }\end{array}$ & TOL & $\begin{array}{c}\text { Linhas de } \\
\text { Benton }\end{array}$ & MMSE & ACE-R \\
\hline SOIVET-Maze & - & & & & & & & \\
\hline MRMT & $.345^{*}$ & - & & & & & & \\
\hline Corsi (Direto) & .236 & .262 & - & & & & & \\
\hline Corsi (Inverso) & .196 & .130 & $.327^{*}$ & - & & & & \\
\hline Torre de Londres & $.350 *$ & .283 & $.514^{* * *}$ & .223 & - & & & \\
\hline Linhas de Benton & $.428^{* * * *}$ & $.504^{* * *}$ & $.463^{* * *}$ & $.400^{*}$ & .270 & - & & \\
\hline MMSE & .243 & $.461^{* * *}$ & .177 & -.068 & $.427^{\text {*** }}$ & .244 & - & \\
\hline ACE-R & $.368^{*}$ & $.523^{* * *}$ & .217 & .099 & $.474^{* * *}$ & .311 & $.688^{* * *}$ & - \\
\hline
\end{tabular}

MRMT, Money Road Map Test. Linhas de Benton, Teste de orientação de linhas de Benton, MMSE, Mini Exame do Estado Mental ACE-R, Exame cognitivo de Addenbrooke - Revisado. Correlação de Spearman $(\mathrm{n}=40) . * * \mathrm{p}<0,01 . * \mathrm{p}<0,05$

Adicionalmente, ao separarmos a pontuação no ACE-R em suas subcategorias 1) atenção e orientação; 2) memória; 3) Fluência; 4) Linguagem e 5) Visuoespacial, encontramos uma correlação significativa entre a pontuação na tarefa SOIVET-Maze e a subcategoria memória $(\mathrm{r}=0.480, \mathrm{p}=0.002)$ e visuoespacial $(\mathrm{r}=0.317, \mathrm{p}=0.046) . \mathrm{O}$ desempenho na tarefa SOIVET-Maze não mostrou correlação com a idade $(\mathrm{r}=0.013$, 
$\mathrm{p}=0.932)$, escolaridade $(\mathrm{r}=0.200, \mathrm{p}=0.177)$ ou perfil de uso de tecnologia $(\mathrm{r}=0.111$, $\mathrm{p}=0.500)$.

A análise de correlação entre a pontuação na tarefa SOIVET-Route e os testes tradicionais sem separação por grupos $(n=40)$ revelou uma correlação significativa entre a pontuação na SOIVET-Route imediata e a pontuação na SOIVET-Route tardia ( $\mathrm{r}=.511$, p<0.001), o MRMT (r=.392, p=0.006) e a pontuação total no ACE-R (r=.396, p=0.011). A pontuação na tarefa SOIVET-Route tardia não mostrou correlação significativa com nenhum teste neuropsicológico tradicional. Ademais, as pontuações obtidas pela rota percorrida em ambiente real no quinto andar do Instituto Central do Hospital das Clínicas de São Paulo ("Caminho") tanto imediata quanto tardia não se correlacionaram com nenhum teste tradicional. A matriz de correlação entre todos os testes está detalhada na tabela 6.

Tabela 6. Matriz de correlação entre a tarefa SOIVET-Route imediata e tardia, o caminho percorrido no mundo real (reprodução imediata e tardia) e os testes neuropsicológicos tradicionais.

Correlação entre médias (rô de Spearman) paraa tarefa SOIVET-Route

\begin{tabular}{|c|c|c|c|c|c|c|c|c|c|c|c|}
\hline & $\begin{array}{l}\text { SOIVET- } \\
\text { Route I. }\end{array}$ & $\begin{array}{l}\text { SOIVET- } \\
\text { Route T. }\end{array}$ & $\begin{array}{c}\text { Caminho } \\
\text { HC I. }\end{array}$ & $\begin{array}{c}\text { Caminho } \\
\text { HC T. }\end{array}$ & MRMT & $\begin{array}{c}\text { Corsi } \\
\text { (Direto) }\end{array}$ & $\begin{array}{c}\text { Corsi } \\
\text { (Inverso) }\end{array}$ & TOL & $\begin{array}{c}\text { Linhas de } \\
\text { Benton }\end{array}$ & MMSE & ACE-R \\
\hline SOIVET-Route I. & - & & & & & & & & & & \\
\hline SOIVET-Route T. & $.511^{\text {*** }}$ & - & & & & & & & & & \\
\hline "Caminho" HC I. & .026 & .100 & - & & & & & & & & \\
\hline "Caminho" HC T. & -.030 & .036 & $.853^{\text {**** }}$ & - & & & & & & & \\
\hline MRMT & $.392^{* * * *}$ & .071 & -.029 & .006 & - & & & & & & \\
\hline Corsi (Direto) & .245 & -.080 & -.197 & -.110 & .262 & - & & & & & \\
\hline Corsi (Inverso) & .281 & .228 & .188 & .114 & .130 & $.327^{*}$ & - & & & & \\
\hline Torre de Londres & .304 & .078 & .041 & .119 & .283 & $.514^{* * *}$ & .223 & - & & & \\
\hline Linhas de Benton & .188 & .128 & -.107 & -.068 & $.504^{* * *}$ & $.463^{* * *}$ & $.400 *$ & .270 & - & & \\
\hline MMSE & .305 & .095 & .165 & .134 & $.461^{* * *}$ & .177 & -.068 & $.427^{* * *}$ & .244 & - & \\
\hline ACE-R & $.398^{*}$ & .308 & .064 & .083 & $.523^{* * *}$ & .217 & .099 & $.474^{* * * *}$ & .311 & $.688^{* * *}$ & - \\
\hline
\end{tabular}

SOIVET-Route I, imediata. SOIVET-Route T, tardia. Caminho HC, rota percorrida no mundo real (I, imediata e T, tardia). MRMT, Money Road Map Test. MMSE, Mini Exame do Estado Mental ACE-R, Exame cognitivo de Addenbrooke - Revisado. Correlação de Spearman $(n=40) . * * p<0,01 .{ }^{*} p<0,05$. 
Ademais, ao investigarmos a correlação da tarefa SOIVET-Route imediata e tardia com as subcategorias do ACE-R, encontramos uma correlação significativa entre a pontuação SOIVET-Route imediata e a subcategoria memória $(\mathrm{r}=0.341, \mathrm{p}=0.031)$ e visuoespacial $(\mathrm{r}=0.319, \mathrm{p}=0.045)$. A pontuação SOIVET-Route tardia se correlacionou apenas com a subcategoria memória $(\mathrm{r}=0.394, \mathrm{p}=0.012)$. As pontuações na rota percorrida em ambiente real ("Caminho" imediato e tardio) não se correlacionaram com nenhuma subcategoria do ACE-R.

$\mathrm{Na}$ análise de correlação entre idade, escolaridade e perfil de uso de tecnologia, identificamos que apenas a escolaridade mostrou correlação tanto com a pontuação SOIVET-Route imediata $(\mathrm{r}=0.442, \mathrm{p}=0.002)$ quanto tardia $(\mathrm{r}=0.410, \mathrm{p}=0.004) . \mathrm{O}$ desempenho dos participantes nas tarefas virtuais, bem como nos testes neuropsicológicos tradicionais pode ser visualizado na tabela 7 . 
Tabela 7. Desempenho dos participantes, separado por grupo (controle e CCL), nas tarefas virtuais e nos testes neuropsicológicos tradicionais

\begin{tabular}{|c|c|c|c|c|c|c|}
\hline \multirow{3}{*}{ SOIVET-Maze } & \multicolumn{3}{|c|}{$\begin{array}{c}\text { Controle } \\
(\mathrm{n}=29)\end{array}$} & \multicolumn{3}{|c|}{$\begin{array}{c}\text { CCL } \\
(n=19)\end{array}$} \\
\hline & Média & DP & Variação & Média & DP & Variação \\
\hline & 6,72 & 2,68 & $1-13$ & 4,84 & 1,98 & $2-7$ \\
\hline MRMT & 25,06 & 4,92 & $16-32$ & 22,84 & 3,90 & $18-32$ \\
\hline SOIVET-Route imediato & 4,48 & 0,83 & $3-5$ & 3,37 & 1,64 & $0-5$ \\
\hline \multirow[t]{3}{*}{ SOIVET-Route tardio } & 4,65 & 0,72 & $3-5$ & 3,95 & 1,43 & $1-5$ \\
\hline & \multicolumn{3}{|c|}{$(n=26)$} & \multicolumn{3}{|c|}{$(n=14)$} \\
\hline & Média & DP & Variação & Média & DP & Variação \\
\hline Caminho imediato & 4,60 & 0,82 & $3-5$ & 4,71 & 0,61 & $3-5$ \\
\hline Caminho tardio & 4,68 & 0,75 & $3-5$ & 4,71 & 0,73 & 3-5 \\
\hline Corsi (Direto) & 7,35 & 1,52 & $5-11$ & 7,07 & 1,54 & $5-10$ \\
\hline Corsi (Inverso) & 6,58 & 1,64 & $4-9$ & 6,54 & 1,45 & $5-10$ \\
\hline Torre de Londres & 31,85 & 3,00 & $25-36$ & 29,57 & 3,70 & $21-36$ \\
\hline Linhas de Benton & 20,19 & 4,32 & $11-30$ & 19,72 & 5,51 & $10-28$ \\
\hline
\end{tabular}

MRMT, Money Road Map Test. Caminho (imediato e tardio), reprodução da rota em ambiente real no Hospital das Clínicas de São Paulo. Corsi, Teste dos Blocos de Corsi (direto e inverso). Linhas de Benton, Teste da Orientação das Linhas de Benton. ACE-R, Exame Cognitivo de Addenbrooke Revisado e suas subcategorias. DP, desvio padrão.

\subsubsection{Comparação entre grupos}

$\mathrm{Na}$ análise da comparação entre os grupos houve diferença para a SOIVET-Maze, enquanto na tarefa em papel-caneta (MRMT) não foi observada diferença estatisticamente significativa. A pontuação na tarefa SOIVET-Maze foi capaz de diferenciar significativamente o grupo controle do grupo CCL ( $U=151,500, p=0.008)$, enquanto a pontuação no MRMT não apresentou diferença estatisticamente significativa ( $\mathrm{U}=190,00, \mathrm{p}=0,071$ ) (Figura 12). A exclusão dos três participantes incluídos no grupo CCL pela pontuação no teste de rastreio do ACE-R abaixo do limiar de corte não 
modificou a direção dos resultados e a significância da tarefa SOIVET-Maze na diferenciação dos grupos se manteve, bem como o resultado não significativo da MRMT.
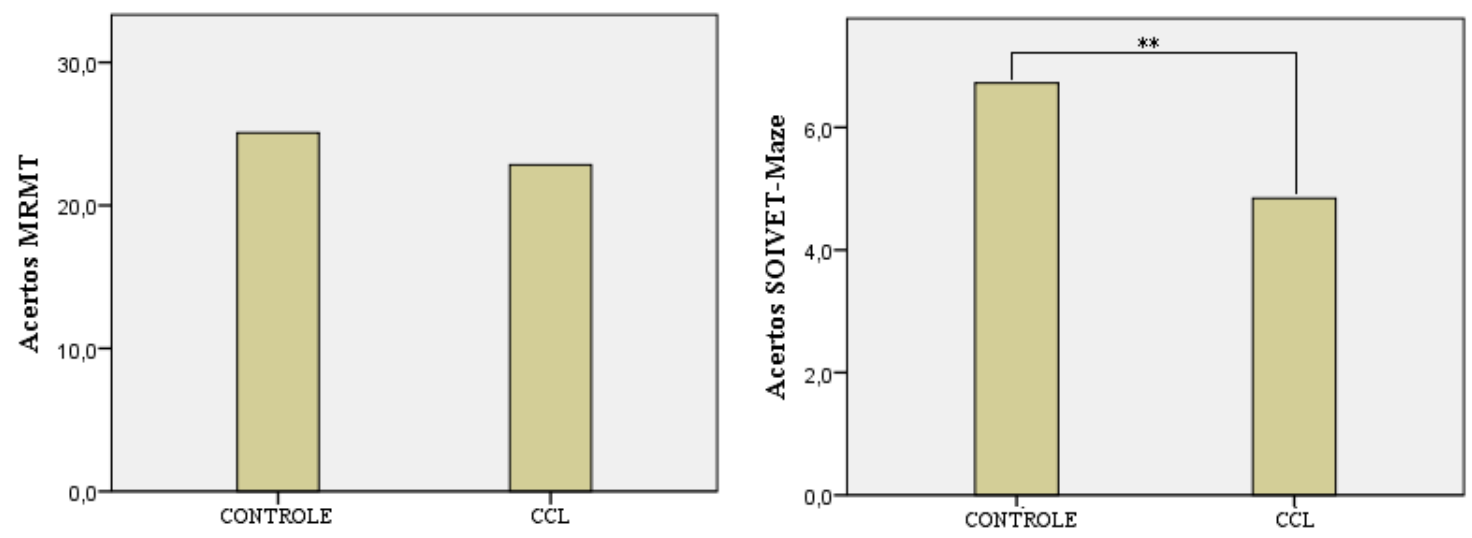

Figura 12. Média de acertos nas tarefas MRMT e SOIVET-Maze por grupo. **p<0.01

As médias das pontuações nas tarefas SOIVET-Route imediata e tardia, bem como no “Caminho" percorrido em ambiente real (reprodução imediata e tardia) também foram obtidas para comparação de grupos. A tarefa SOIVET-Route reprodução imediata e tardia foi significamente diferente entre grupos $(\mathrm{U}=164,50 ; \mathrm{p}=0,009$ para SOIVET-Route imediata e U=197,00; $\mathrm{p}=0,044$ para SOIVET-Route tardia) (Figura 13). As pontuações das reproduções imediata e tardia do caminho percorrido em ambiente real não foram capazes de diferenciar os grupos $(\mathrm{U}=172,50 ; \mathrm{p}=0,917$ e $\mathrm{U}=172,00 ; \mathrm{p}=0,888$ respectivamente) (Tabela 8). A exclusão dos três participantes que passaram do grupo controle para o grupo CCL após o teste de rastreio com o ACE-R também não modificou a direção dos resultados encontrados. 

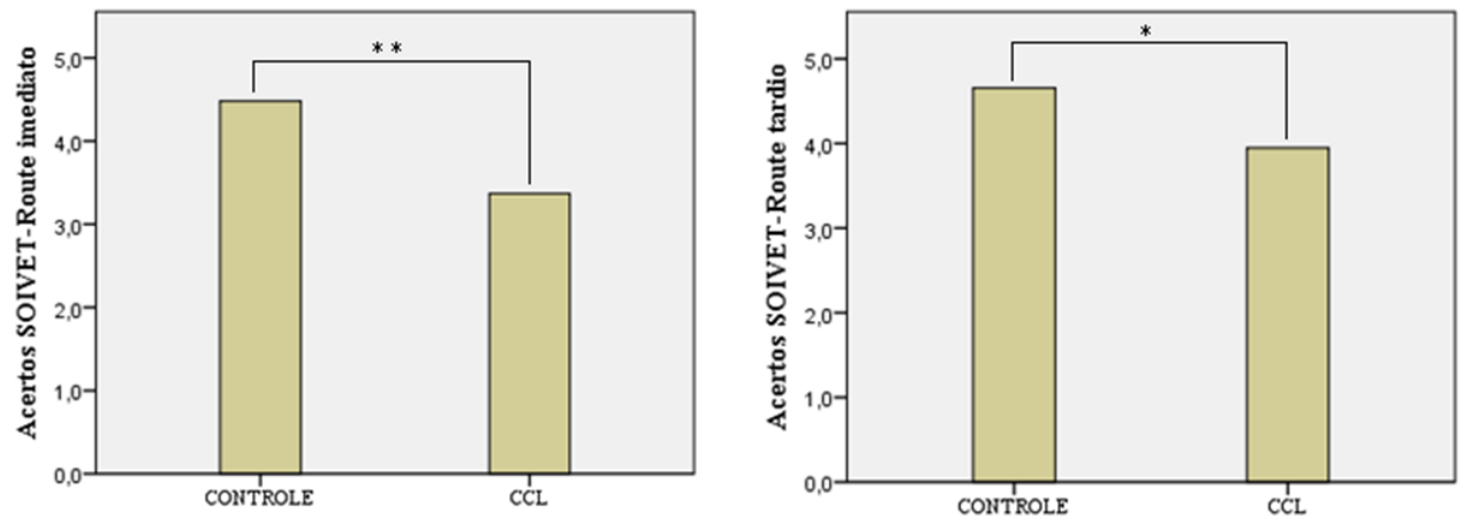

Figura 13. Média de acertos nas tarefas SOIVET-Route imediata e tardia, por grupo. **p<0,01*p<0,05

Tabela 8. Médias e medianas obtidas nas tarefas SOIVET-Maze, SOIVET-Route imediata e tardia e "Caminho" imediato e tardio e comparação de grupos.

\begin{tabular}{|c|c|c|c|c|c|c|c|c|c|}
\hline & & & $\begin{array}{l}\text { trole } \\
=29 \text { ) }\end{array}$ & & & & $\begin{array}{l}\mathbf{C L} \\
=19)\end{array}$ & & \\
\hline & Média & DP & Mediana & IQR & Média & DP & Mediana & IQR & $U$ \\
\hline SOIVET-Maze & 6,7 & 2,7 & 7,0 & 3,0 & 4,8 & 2,0 & 5,0 & 5,0 & $151,5^{* *}$ \\
\hline MRMT & 25,1 & 4,9 & 25,0 & 8,0 & 22,8 & 3,9 & 22,0 & 4,0 & 190,0 \\
\hline SOIVET-Route imediata & 4,5 & 0,8 & 5,0 & 1,0 & 3,4 & 1,6 & 4,0 & 3,0 & $164,5^{* *}$ \\
\hline SOIVET-Route tardia & 4,7 & 0,7 & 5,0 & 0,0 & 3,9 & 1,4 & 5,0 & 2,0 & $197,0^{*}$ \\
\hline "Caminho" imediato & 4,6 & 0,8 & 5,0 & 0,0 & 4,7 & 0,6 & 5,0 & 0,0 & 172,50 \\
\hline "Caminho" tardio & 4,7 & 0,7 & 5,0 & 0,0 & 4,7 & 0,7 & 5,0 & 0,0 & 172,00 \\
\hline
\end{tabular}

MRMT, Money Road Map Test. CCL, Grupo com comprometimento cognitivo leve. DP, Desvio padrão. IQR, Intervalo interquartil. $U$, Teste Wilcoxon-Mann-Whitney. $* p<0,05 * * p<0,01$

\subsubsection{Análise de acurácia (curva ROC)}

A análise de acurácia utilizou a curva ROC, construída locando-se a taxa de verdadeiros positivos (sensibilidade) contra a taxa de falso-positivos (1-especificidade). Foram consideradas as pontuações nas tarefas SOIVET-Maze, SOIVET-Route imediata e SOIVET-Route tardia para identificação do grupo CCL em comparação com o grupo controle (Tabela 9). Evidenciou-se acurácia moderada para as tarefas SOIVET-Maze e SOIVET-Route imediata para o diagnóstico de CCL (Figura 14). 


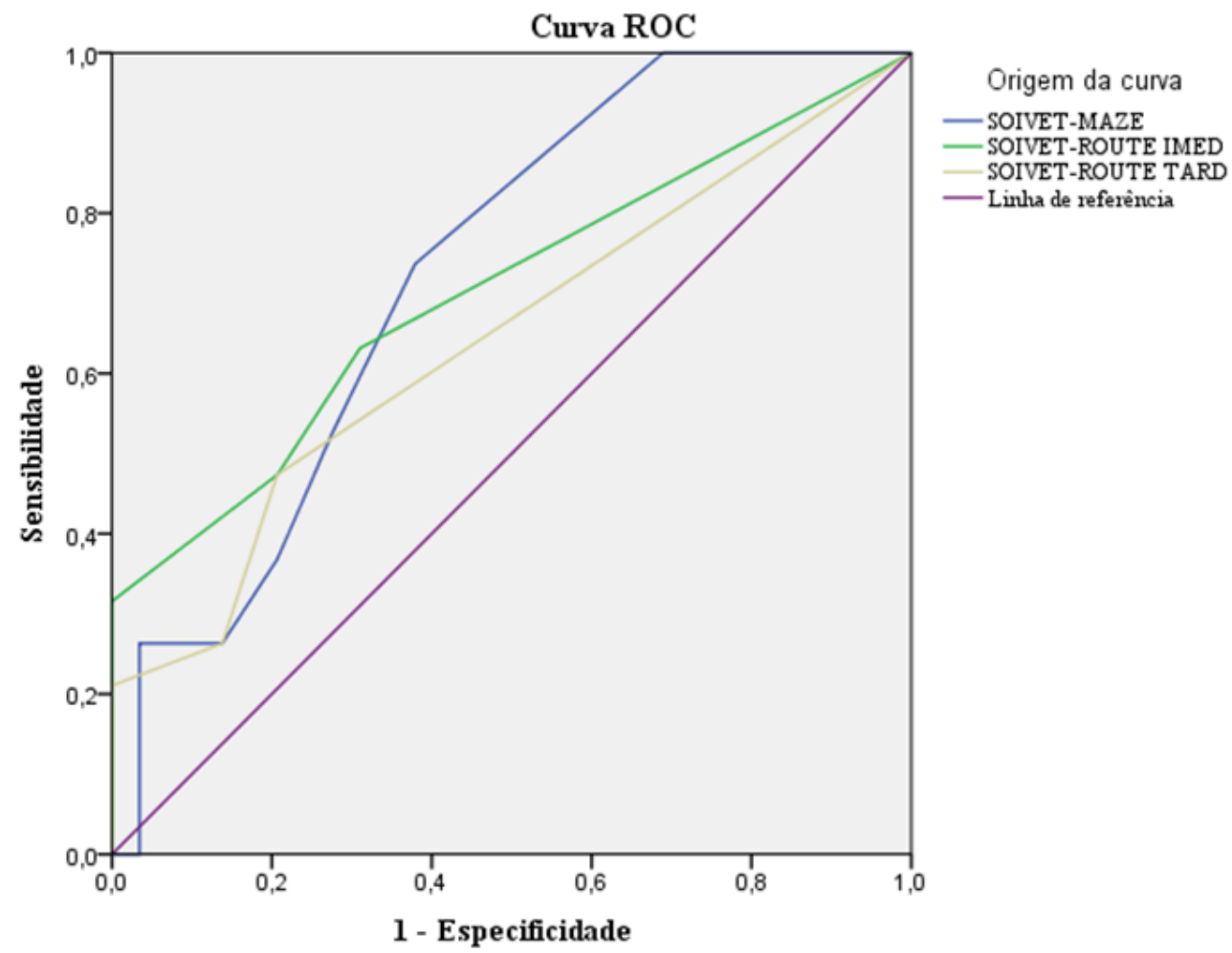

Figura 14. Curvas ROC das tarefas SOIVET-Maze, SOIVET-Route imediata e SOIVET-Route tardia

Os valores de sensibilidade e especificidade foram obtidos através do index $\mathrm{J}$ de Youden, para o ponto de corte ideal em cada tarefa. Os resultados da análise de sensibilidade e especificidade estão detalhados na tabela 9. Em seguida podem ser observados os valores de sensibilidade e especificidade para diferentes pontos de corte (Tabela 10). A escolha do ponto de corte pode ser realizada considerando-se a priorização na capacidade de detecção (sensibilidade) ou na especificidade. 
Tabela 9. Resultados da análise de sensibilidade e especificidade para as tarefas SOIVET-Maze, SOIVET-Route imediata e SOIVET-Route tardia.

\begin{tabular}{|lcccc|}
\hline & SOIVET-Maze & SOIVET-Route Imed & SOIVET-Route Tard \\
\cline { 2 - 3 } AUC & 0,725 & 0,701 & 0,642 \\
IC $(95 \%)$ & $0,577-0,844$ & $0,552-0,825$ & $0,491-0,776$ \\
Sensibilidade $(\%)$ & 73,7 & 63,2 & 47,4 \\
Especificidade $(\%)$ & 62,1 & 69,0 & 79,3 \\
Ponto de Corte & $\leq 6$ & $\leq 4$ & $\leq 4$ \\
\hline
\end{tabular}

Nota: Dados obtidos através da curva ROC e do índice J de Youden. AUC, área sob a curva. IC, Intervalo de confiança de $95 \%$.

Tabela 10. Pontos de corte propostos para as tarefas SOIVET-Maze, SOIVET-Route imediata e tardia e os diferentes valores de sensibilidade e especificidade.

\begin{tabular}{|ccccccccccc|}
\hline \multicolumn{3}{|c}{ SOIVET-Maze } & & \multicolumn{3}{c}{ SOIVET-Route imed. } & & \multicolumn{3}{c|}{ SOIVET-Route tard. } \\
\cline { 1 - 1 } $\begin{array}{c}\text { Ponto de } \\
\text { corte }\end{array}$ & Sens. & Espec. & $\begin{array}{c}\text { Ponto de } \\
\text { corte }\end{array}$ & Sens. & Espec. & $\begin{array}{c}\text { Ponto de } \\
\text { corte }\end{array}$ & Sens. & Espec. \\
$\leq 2$ & 26,3 & 96,5 & & $\leq 0$ & 0 & 100 & & $\leq 1$ & 0 & 100 \\
$\leq 3$ & 26,3 & 86,2 & & $\leq 2$ & 31,6 & 100 & & $\leq 2$ & 21,1 & 100 \\
$\leq 4$ & 36,8 & 79,3 & & $\leq 3$ & 4,4 & 79,3 & & $\leq 3$ & 26,3 & 86,2 \\
$\leq 5$ & 52,6 & 72,4 & & $\leq 4$ & 63,2 & 69,0 & & $\leq 4$ & 47,4 & 79,3 \\
$\leq 6$ & 73,7 & 62,1 & & $\leq 5$ & 100 & 0 & & $\leq 5$ & 100 & 0 \\
$\leq 7$ & 100 & 31,0 & - & - & - & & - & - & - \\
\hline
\end{tabular}

SOIVET-Route imed, SOIVET-Route imediata. SOIVET-Route tard, SOIVET-Route tardia. Sens, sensibilidade. Espec, especificidade. 


\section{Discussão}

Os resultados encontrados no presente estudo demonstram em primeiro lugar a viabilidade da aplicação das tarefas de realidade virtual imersiva em adultos e também em idosos com idade entre 61 e 92 anos, com e sem CCL. Os participantes apresentaram diferentes graus de escolaridade, perfis de uso de tecnologia e capacidade cognitiva global, o que não interferiu na capacidade de compreender e utilizar o sistema proposto. As tarefas SOIVET-Maze e SOIVET-Route imediata mostraram correlação com testes neuropsicológicos tradicionais e puderam diferenciar o grupo de idosos controle do grupo CCL, com acurácia moderada para identificação do grupo CCL.

Uma etapa importante no desenvolvimento de novas tarefas, em especial quando se utiliza uma nova tecnologia, é a avaliação da interação do sistema proposto com os usuários, de forma a se obter uma melhor compreensão das características negativas das tarefas e maneiras de refiná-las. A capacidade do ambiente virtual imersivo de reproduzir percepções sensoriais semelhantes ao mundo real traz vantagens para a avaliação de processos cognitivos que, dessa forma, se tornam mais semelhantes aos recrutados no diaa-dia $(118,119)$. Entretanto, para obter tal engajamento cognitivo, é importante assegurar que os participantes tenham vivenciado uma significativa sensação de presença e imersão.

Em primeiro lugar, o projeto piloto deste estudo foi capaz de demonstrar que as instruções das tarefas e a interação com os ambientes virtuais foram de fácil compreensão. 
Em segundo lugar, foi demonstrado que as tarefas SOIVET-Maze e SOIVET-Route produziram uma forte sensação de presença e imersão, cruciais quando se objetiva uma tarefa ecológica.

A tecnologia de realidade virtual imersiva vem aumentando seu campo de atuação em diferentes contextos relacionados à saúde do idoso, como na reabilitação postural $(120,121)$, treinamento cognitivo $(122,123)$, reabilitação pós isquemia cerebral $(124,125)$ e até na educação contra abuso e negligência do idoso (126). Apesar de ainda existir um questionamento quanto à aceitação deste grupo frente a novas tecnologias, estudos recentes têm demonstrado que mesmo aqueles idosos sem experiência com a tecnologia não se mostraram resistentes à sua utilização, inclusive com atitudes positivas após a primeira experiência $(86,127)$. Em especial no que tange à aceitação entre idosos com CCL ou demência, o estudo de Manera et al. evidenciou que estes demonstraram satisfação e interesse pelas tarefas de realidade virtual, com poucos sintomas de desconforto do tipo cybersickness (128). Além disso, os participantes relataram preferência pelas tarefas virtuais em comparação às tarefas tradicionais em papel e caneta utilizadas pelos pesquisadores (128). No estudo do nosso grupo de pesquisa, houve uma boa aceitação dos participantes idosos frente à tecnologia imersiva, com boa compreensão da usabilidade do sistema.

Outro aspecto importante foi a tolerabilidade do sistema entre os participantes idosos, questão potencialmente limitante para estudos com realidade virtual imersiva. A incidência de dropouts por questões de tolerabilidade foi de 11,4\% no grupo controle e 14,8\% no grupo CCL, uma incidência baixa em relação às taxas de cybersickness de 30 a $80 \%$ relatadas em outros estudos (129). O projeto piloto havia evidenciado questões relevantes de tolerabilidade que precisaram ser aperfeiçoadas antes de se prosseguir para 
a aplicação do sistema em idosos, visando minimizar o desconforto e a perda de participantes no estudo (dropouts). A mudança na forma do deslocamento das tarefas após a etapa piloto, tornando-as obrigatoriamente vinculadas ao posicionamento da cabeça e a troca de equipamento para o Oculus Rift que possui maior capacidade de processamento visual, melhoraram consideravelmente a tolerabilidade do sistema para a população alvo, os idosos. Outro ponto importante foi a pré-seleção de participantes sem histórico de labirintopatias, que se mostrou relacionada à maior incidência de cybersickness na etapa piloto. Estes resultados favoráveis de tolerabilidade poderão servir de base para outros estudos de realidade virtual imersiva que venham a recrutar idosos como população alvo.

Um achado relevante da etapa piloto foi a correlação entre o desempenho na tarefa SOIVET-Maze e o questionário de auto relato da Escala de Orientação de Santa Bárbara (SBSOD). Este foi o primeiro resultado em direção ao entendimento da capacidade desta tarefa de avaliar a orientação espacial dos participantes. Conforme defendido por autores como Morganti et al. (2016) e Hegarty et al. (2006), a perspectiva survey, ou vista de cima num mapa, pouco se assemelha ao processo cognitivo envolvido na orientação de um indivíduo no espaço $(81,82)$. Os ambientes virtuais, por outro lado, permitem a perspectiva em ampla escala, com a reprodução da consciência corporal do participante, mais próxima do funcionamento no mundo real $(81,130)$. Em concordância com esta afirmativa, verificou-se também que o desempenho dos participantes adultos no MRMT em papel, de fato não se correlacionou com nenhum item da Escala de Orientação de Santa Bárbara, nem com sua pontuação total.

Outro achado consistente com a literatura foi a influência do sexo no desempenho dos participantes da etapa piloto. Diversos estudos têm demonstrado que em geral, os homens 
apresentam melhor desempenho nas tarefas de orientação espacial em comparação às mulheres (131-134). Os resultados de desempenho na tarefa SOIVET-Maze em adultos jovens claramente demonstram este efeito. É de se esperar também que a idade influencie nestes resultados, uma vez que o envelhecimento notoriamente influencia as habilidades espaciais (135). Em concordância com esta tendência descrita, foi possível verificar uma média de acertos maior entre os adultos jovens do que entre os idosos cognitivamente saudáveis, especialmente na tarefa SOIVET-Maze. A tarefa SOIVET-Route se mostrou de fácil realização e um provável efeito teto foi atingido na população adulta jovem, mas a média de acertos entre os idosos cognitivamente saudáveis também se mostrou levemente inferior à dos adultos jovens nesta tarefa.

Em avaliação cognitiva, frequentemente há um ou mais testes utilizados amplamente que são conhecidos como "padrão-ouro" para a avaliação de determinado domínio cognitivo, como a memória, a atenção ou as funções executivas. Entretanto, conforme exposto anteriormente, não há até o momento um padrão-ouro para a avaliação da orientação espacial, o que dificulta a verificação da validade com base na relação com variáveis externas (37). Ademais, os tradicionais testes em "papel e caneta" utilizados tradicionalmente para a avaliação da orientação espacial pouco se aproximam da investigação direta dos processos cognitivos envolvidos nesta função $(82,136)$. A capacidade de se orientar no mundo real exige o engajamento dos processos de orientação egocêntrica e alocêntrica e a integração entre eles (81). Ao realizar uma tarefa de orientação no papel, por outro lado, é comum que sejam engajados os processos de memória visual, atenção e capacidade visuoconstrutiva e, em certo grau, de funções executivas (mais especificamente o planejamento). Por esse motivo foram selecionados para a validade de construto testes que avaliam esses aspectos individualmente. A correlação da pontuação na tarefa SOIVET-Maze com os testes neuropsicológicos 
tradicionais demonstraram que esta tarefa apresentou uma correlação fraca, porém significativa com a tarefa original em papel e caneta (MRMT), com a capacidade de planejamento medida pelo teste da Torre de Londres e com a categoria visuoespacial do ACE-R. A tarefa apresentou correlação moderada e significativa com a capacidade de visuopercepção e rotação mental medida pelo Teste da orientação das linhas de Benton e com a categoria memória do ACE-R. Era esperada uma correlação ao menos moderada da pontuação na SOIVET-Maze com as tarefas de visuopercepção e com a tarefa original em papel e caneta. De fato, os resultados dos participantes adultos na tarefa SOIVETMaze demonstraram uma correlação moderada com a tarefa MRMT, mas entre os participantes idosos a correlação se mostrou fraca. Isso indica possivelmente a influência de outros fatores no desempenho da SOIVET-Maze nesta população, como por exemplo a capacidade cognitiva global. Outro aspecto a ser considerado é a característica mais ecológica e próxima da orientação requerida na vida real e na tarefa em $\mathrm{RV}$ em comparação aos simples testes de papel e caneta. Estes últimos não apresentam a complexidade e as múltiplas possibilidades que se revelam no teste ecológico. A correlação com o teste das linhas de Benton e a torre de Londres denota a tomada de decisão nesta tarefa, uma vez que o sujeito sempre escolhe entre possibilidades: como na escolha de determinada linha no teste das linhas de Benton ou no planejamento e tomada de atitudes para resultados futuros na torre de Londres.

No estudo de Morganti (2018), foi encontrada uma correlação moderada entre o MRMT em papel e a versão computadorizada não imersiva em 3D desta tarefa em uma amostra com participantes de 30 a 80 anos (137). A mesma autora em 2013 utilizou esta versão computadorizada com idosos cognitivamente saudáveis e idosos com DA leve. Com esta amostra, foi encontrada uma correlação fraca porém significativa da tarefa computadorizada em $3 D$ com o MMSE e os Blocos de Corsi, mas não foi descrita uma 
correlação com o MRMT (56). Diferente dos resultados encontrados no presente estudo, Morganti et al. não encontraram correlação do labirinto computadorizado com o teste das Linhas de Benton, nem com a Torre de Londres. Uma importante diferença entre as duas tarefas virtuais é a não imersão da tarefa de Morganti et al. Outra diferença importante foi a forma como o caminho no mapa era fornecido: no estudo de 2013 os participantes seguravam o mapa em papel original, fora do ambiente computadorizado e no presente estudo, o mapa estava visível dentro do ambiente virtual com a possibilidade de acompanhamento da progressão da rota pelo ponto verde.

Um aspecto interessante foi a correlação da pontuação na SOIVET-Maze com a categoria memória do ACE-R, com correlação inclusive superior à categoria visuoespacial. Este achado pode ser explicado primeiramente pela inclusão dos participantes CCL amnésticos que naturalmente apresentavam pontuação inferior nesta categoria em comparação aos idosos cognitivamente saudáveis. Outra possível explicação seria a convergência de domínios cognitivos - orientação alocêntrica e memória mediados pela mesma região, o hipocampo. Estudos anteriores demonstraram que participantes CCL com comprometimento de memória do tipo hipocampal apresentavam desempenho pior em tarefas de orientação alocêntrica comparado aos CCL amnésticos não hipocampais $(62,138,139)$. Ademais, tarefas de orientação alocêntrica parecem envolver regiões específicas do hipocampo comuns à memória episódica (140), embora uma lateralização da cognição espacial à direita e da memória episódica à esquerda seja descrita (45). Estudos demonstraram que as memórias topográficas, dependentes do hipocampo, representam a relação espacial entre a localização de objetos e permitem o reconhecimento de um local mesmo após uma mudança na perspectiva (141-143). O hipocampo parece integrar informações espaciais provenientes de outras regiões cerebrais (como o córtex parietal e parahipocampal) e recrutar informações da memória episódica 
na formação de um mapa cognitivo. Esta integração utiliza aspectos espaciais e temporais a todo momento durante o processo de navegação: "me lembro de ter virado à direita depois de passar pela ponte" $(144,145)$, o que coloca o hipocampo como um node central na rede de navegação $(45,145)$.

A correlação fraca e significativa com o teste da Torre de Londres indica algum grau de envolvimento da capacidade de planejamento na tarefa SOIVET-Maze, o que era esperado por se tratar de uma tarefa com labirinto. Embora necessário, o planejamento não é capaz de determinar o desempenho nesta tarefa como um todo. A tarefa exige substancialmente uma capacidade de rotação mental e transposição entre a perspectiva alocêntrica para a egocêntrica a cada virada. Este resultado vai ao encontro dos achados de Serino et al. (2018), que demonstraram a relação do planejamento com a capacidade de orientação alocêntrica, mas não com a capacidade de integração entre a orientação egocêntrica e a alocêntrica. O trabalho destes autores diferenciou as etapas de uma tarefa de realidade virtual entre o reconhecimento puramente alocêntrico da posição de um objeto e este mesmo reconhecimento com a interferência da orientação egocêntrica. Foi evidenciado que a etapa alocêntrica esteve relacionada à capacidade de planejamento mensurada pelo teste da Torre de Londres, mas não a etapa de integração. Esta última teve relação apenas com o teste de Trilhas A e B, defendido pelos autores como medida de atenção e multitarefas (146). A tarefa SOIVET-Maze inclui um componente importante de orientação alocêntrica e reconhecimento do mapa, assim como a tarefa de Serino et al. Por outro lado, há também a influência importante do posicionamento do indivíduo a cada virada (orientação egocêntrica). Deste modo, a correlação fraca e significativa com o teste da Torre de Londres parece condizer com algum grau de planejamento na tarefa, sem entretanto ser capaz de justificar todo o desempenho. 
A correlação moderada com o teste de orientação das linhas de Benton indica a maior influência do julgamento visuoperceptivo nesta tarefa. Interessante notar que as tarefas que envolvem memória operacional visuoespacial e atenção (Blocos de Corsi direto e indireto e categoria atenção e orientação do ACE-R) não mostraram correlação com o desempenho na SOIVET-Maze. Isto indica possivelmente a pouca influência destes domínios cognitivos na realização da tarefa.

Outro dado importante foi a influência da capacidade cognitiva global (medida através da pontuação total do ACE-R). Por se tratar de uma tarefa difícil e que necessita da transposição entre dois tipos de orientação a cada virada no mapa, é compreensível que quanto melhor a capacidade cognitiva global, melhor o desempenho do participante. $\mathrm{O}$ estudo de Oliveira et al. encontrou este mesmo resultado: o desempenho numa tarefa virtual de avaliação visuoespacial mostrou forte correlação com a capacidade cognitiva global, mensurada pela Avaliação Cognitiva de Montreal (MoCA). Os autores também demonstraram que o desempenho no teste virtual foi capaz de explicar um terço da variabilidade do MoCA. Interessante ressaltar que os autores não encontraram correlação da tarefa virtual com nenhum outro teste cognitivo tradicional utilizado. Defenderam, portanto, que o processo cognitivo envolvido em tarefas virtuais ecológicas é amplo e difícil de isolar pelos testes cognitivos tradicionais (147).

A transposição entre os dois tipos de orientação, bem como a integração com o posicionamento do corpo e o movimento no labirinto podem levar à intepretação de que a tarefa SOIVET-Maze se trata de uma dupla-tarefa. A habilidade para realização de dupla-tarefas, por sua vez, é sabidamente influenciada pela capacidade cognitiva global (148) e pela idade (149) e está comprometida na DA (150). De fato parece ser difícil isolar com precisão os domínios cognitivos envolvidos em tarefas virtuais, que são dependentes 
da capacidade cognitiva global e podem ser defendidos como dupla-tarefas. Por outro lado, essa complexidade parece ser uma vantagem, ao menos no que se refere ao estudo da cognição espacial $(130,151)$.

A ausência de influência da idade, escolaridade e perfil de uso de tecnologia é um achado importante da tarefa SOIVET-Maze, visto que favorece a sua utilização por diferentes populações. A idade e a escolaridade costumam influenciar muitas tarefas de avaliação cognitiva $(152,153)$. No estudo de Humphreys et al. mais da metade da casuística era de participantes com baixa escolaridade ( $\leq 7$ anos) (152), enquanto no estudo de Beaufils et al. a média de escolaridade dos idosos foi de 12 anos (153). Em nosso estudo a escolaridade dos participantes variou entre 9 e 18 anos, com uma média de 12 e 13 anos de escolaridade em cada grupo, semelhante ao estudo de Beaufils et al. Uma tarefa ecológica que identifique um grupo de maior risco de conversão para DA e que não seja influenciada por estes fatores é definitivamente uma vantagem. O perfil de uso de tecnologia também não mostrou correlação com o desempenho na tarefa SOIVETMaze, o que reforça o entendimento de que a habilidade de orientação espacial teve maior influência sobre o desempenho e não a familiaridade ou facilidade de uso com a tecnologia.

A tarefa SOIVET-Route demonstrou menor relação com as tarefas cognitivas tradicionais. A tarefa SOIVET-Route imediata apresentou correlação fraca porém significativa com a tarefa MRMT, com as categorias memória e visuoespacial do ACE$\mathrm{R}$ e uma correlação moderada com a pontuação SOIVET-Route tardia. Estes resultados indicam a relação desta tarefa com alguns dos domínios cognitivos envolvidos na orientação espacial, como rotação mental, memória e visuoconstrução, mas não com outros domínios como planejamento e visuopercepção. A tarefa SOIVET-Route tardia 
por sua vez não mostrou correlação com praticamente nenhum domínio cognitivo avaliado por outros testes (a não ser a subcategoria memória do ACE-R), o que limita o entendimento do construto avaliado por esta tarefa e a utilidade de sua aplicação. Parece haver uma influência da memória no desempenho desta etapa da tarefa Route, o que era esperado, mas não de outros domínios que compõem a orientação espacial. Esta discrepância entre os resultados imediato e tardio, com favorecimento da SOIVET-Route imediata para a avaliação da orientação espacial, apontam para uma provável influência da habilidade de aprendizagem de rotas, em detrimento da memória visuoespacial pensada inicialmente. De fato, as tarefas de aprendizagem de rotas têm ganhado espaço no estudo da orientação espacial e se mostrado sensíveis para identificação do envelhecimento patológico $(51,71,154)$. O recurso da criação de uma rota para avaliação da orientação espacial já foi utilizado em diferentes estudos tanto de avaliação ecológica em ambiente real quanto em ambiente virtual (51,155-157). As tarefas do subitem “Caminho" do TCMR, embora utilizem também a memória, necessitam que o paciente recrute outras funções cognitivas como a orientação espacial e o reconhecimento de marcos topográficos no ambiente. Em uma situação cotidiana, se os locais utilizados forem mais afastados e complexos, como um jornaleiro, uma cantina ou um determinado prédio, é natural que o esforço cognitivo para um paciente com desorientação espacial refazer esse caminho seja maior. Levando isso em consideração, como o TCMR permite a adaptação com outros locais que não os 5 propostos dentro da sala de atendimento, objetivou-se a adequação da curta sequência de marcos do TCMR para um ambiente maior, como o quinto andar do Instituto Central do HCFMUSP. Desta forma, a tarefa permitiu a reprodução de processos cognitivos que são engajados quando nos orientamos e aprendemos novos caminhos no nosso dia-a-dia. 
Diversos estudos demonstraram que idosos com CCL apresentavam pior desempenho nas tarefas de aprendizagem de rotas em comparação a idosos cognitivamente saudáveis $(51,63,158,159)$. O estudo de Benke et al. (2014) evidenciou a relação da tarefa de aprendizagem de rotas com tarefas tradicionais de memória episódica verbal, sem a influência da idade, escolaridade ou sexo (63). O estudo de Peter et al. (2018), por outro lado, não identificou relação entre a tarefa de aprendizagem de rotas e testes de capacidade visuoconstrutiva simples como o teste do relógio. Neste mesmo estudo, foi descrito que a tarefa de aprendizagem de rotas correlacionou-se apenas com a evocação tardia da figura complexa de Rey, tarefa esta que envolve não só memória, mas também capacidade visuoconstrutiva de material complexo (51). Adicionalmente, os resultados de correlação da tarefa SOIVET-Route (imediata e tardia) demonstraram a influência da escolaridade dos participantes no desempenho, mas não da idade, nem da familiaridade com a tecnologia.

De acordo com a hipótese inicial do presente estudo, as tarefas SOIVET-Maze, SOIVET-Route imediata e SOIVET-Route tardia foram capazes de diferenciar o grupo controle do grupo CCL. Interessante observar que a tarefa original em papel, MRMT, não foi capaz dessa diferenciação. Estudos anteriores demonstraram que esta tarefa foi capaz de diferenciar pacientes com DA de idosos cognitivamente saudáveis $(160,161)$, mas não idosos com CCL de idosos cognitivamente saudáveis (162). Esta última diferenciação, entretanto, seria mais útil na prática clínica. Muitos testes de diferentes domínios cognitivos são capazes de identificar a demência estabelecida, mas poucos conseguem diferenciar grupos de maior risco de conversão (163).

Os resultados encontrados no presentes estudo favorecem a ideia de que as avaliações ecológicas das funções cognitivas são vantajosas para a detecção precoce do declínio 
cognitivo em fases mais leves (164-166). Particularmente, as avaliações ecológicas da orientação espacial (seja em ambiente virtual ou ambiente real) têm-se mostrado úteis na diferenciação do envelhecimento normal do patológico $(167,168)$, na detecção de grupos CCL de maior risco de conversão $(67,72,169)$ e mesmo na identificação de indivíduos clinicamente saudáveis com biomarcadores da patologia da DA $(163,168,170)$.

Um aspecto importante a se estudar quando são propostas tarefas para identificação de um grupo diagnóstico é a análise de acurácia. Os resultados indicaram acurácia moderada das tarefas SOIVET-Maze e SOIVET-Route imediata para detecção do grupo CCL. A tarefa SOIVET-Maze demonstrou maior sensibilidade $(73,7 \%)$, enquanto a tarefa SOIVET-Route tardia maior especificidade $(79,3 \%)$. Por outro lado, esta última apresentou AUC menor que 0,7, o que indica uma acurácia fraca para esta tarefa como um todo. Os resultados encontrados neste estudo favorecem a utilização da tarefa SOIVET-Maze e SOIVET-Route imediata como parte da avaliação cognitiva de idosos, de modo a buscar indícios de um possível envelhecimento patológico. Para isso, pontuações abaixo de seis acertos na SOIVET-Maze e quatro acertos na SOIVET-Route imediato podem ser considerados como pontos de corte. Pontos de corte abaixo desses valores (como cinco acertos na SOIVET-Maze e três acertos na SOIVET-Route) se mostraram mais sensíveis na detecção do grupo CCL, porém perderam em especificidade. Estes resultados vão ao encontro de um crescente porém ainda pequeno número de estudos que investigaram a acurácia de tarefas de orientação espacial para o diagnóstico de CCL. O estudo de Tarnanas et al. (2012) por exemplo, diferenciou a sensibilidade e a especificidade dos componentes alo e egocêntrico de sua tarefa virtual, ambos apresentando sensibilidade acima de 90\%, mas com vantagem do componente alocêntrico quanto à especificidade(171). No estudo de Howett et al. (2019) foi encontrado que a tarefa de orientação espacial virtual aumentava seu poder de acurácia quando a presença 
de biomarcadores era levada em consideração (169). De uma maneira geral, os estudos que utilizaram tarefas de orientação espacial (em sua maioria ecológicas mas também algumas não ecológicas) encontraram acurácias moderadas a altas para identificação de CCL (172). Embora ainda escassos, esses resultados contribuem para a percepção de que a inclusão de tarefas de orientação espacial devem fazer parte da avaliação cognitiva do idoso, com grande potencial para identificação de grupos de risco.

\subsection{Limitações}

O estudo em questão apresenta algumas limitações, que devem ser consideradas na interpretação dos resultados, a saber: 1) Na tarefa SOIVET-Maze, os participantes realizaram a tarefa em papel e caneta (MRMT) sempre antes da tarefa virtual. Isso ocorreu para facilitar a compreensão dos participantes para a tarefa virtual, de forma que pudessem compreender fora do sistema imersivo a exigência de rotação mental requerida pelo mapa do MRMT e, consequentemente, na tarefa SOIVET-Maze. Este fluxo de realização das tarefas não foi, portanto, randomizado e pode ter exercido influência sobre o desempenho na tarefa virtual; 2) embora o diagnóstico de CCL tenha sido estabelecido em outro momento, com a utilização de diferentes testes cognitivos e seguindo os critérios de Petersen ou Jak \& Bondi, não foram utilizados biomarcadores para confirmação da patologia da DA. Portanto, apesar do diagnóstico de CCL amnéstico ser indicativo de um

processo patológico subjacente, a confirmação dos indivíduos com maior risco de conversão demandaria acompanhamento; 3) três participantes do grupo CCL foram incluídos neste grupo provenientes do grupo controle após o rastreio cognitivo global indicar pontuação abaixo do limiar da normalidade. Embora o teste de rastreio não tenha 
sido utilizado na análise de comparação de grupos, estes participantes podem diferir dos outros participantes incluídos no grupo CCL e que foram diagnosticados com outros critérios. Por outro lado, a exclusão destes três participantes não modificou a direção dos resultados, o que enfraquece o entendimento de que a capacidade cognitiva global destes participantes possa ter influenciado na diferença de grupos.

\subsection{Implicações clínicas e considerações para estudos futuros}

O uso da tecnologia de realidade virtual para avaliação cognitiva apresenta vantagens, como a já mencionada capacidade de reprodução de situações e contextos cognitivos bem próximos aos do mundo real. Além disso, a facilidade de aplicação com redução da necessidade de pessoal especializado, menor tempo de aplicação, menor interferência sociocultural e até mesmo linguística e o maior engajamento dos participantes também são vantagens importantes. Algumas considerações e potenciais para melhoria do sistema SOIVET podem ser pontuados para etapas futuras e novos estudos. Entre os potenciais de melhoria do sistema, podemos destacar: 1) uma etapa de treino do labirinto poderia ser padronizada e realizada de forma progressiva, de modo que o participante perceba com clareza o que é considerado "acerto" e "erro" pelo sistema e o que lhe é esperado em termos de rotação mental: Isso evitaria a necessidade da realização da tarefa MRMT em papel antes da tarefa SOIVET-Maze, que foi utilizada com o intuito desta explicação e familiarização. Neste sentido, a etapa de treino da SOIVET-Maze permitiria que o participante só conclua o treino após acertar uma sequência progressiva e prédeterminada de viradas e compreender bem a tarefa; 2) o refinamento do ponto que identifica a posição e a progressão na tarefa SOIVET-Maze ("ponto verde"): Este foi um 
aspecto que pareceu confundir alguns participantes e poderia ser melhorado. A facilitação da identificação da posição do participante no mapa, permitindo que esta identificação aconteça em "tempo real” poderia ser considerada, ao invés de apenas identificar o último ponto de virada. A visualização mais intuitiva do caminho já percorrido, diferenciando os trechos já percorridos daqueles ainda por vir com um sistema de cores (trechos já percorridos em cinza mais claro por exemplo) também poderia facilitar a compreensão da tarefa; 3) a divisão do mapa em etapas, como "fases" de um jogo progressivamente mais difícil poderia ser considerada como parte de uma gamificação.

Gamificação (do inglês gamification) é o termo utilizado quando se aplicam elementos dos jogos (games) aos contextos não relacionados aos jogos de entretenimento, estudando os elementos que fazem dos games tão atrativos para o ser humano e como transportá-los para as tarefas comuns do dia a dia A gamificação visa afetar o comportamento e a motivação dos usuários por meio de experiências remanescentes utilizadas em jogos e tem sido amplamente utilizada no contexto da saúde, melhorando o engajamento dos participantes e a adesão aos tratamentos de reabilitação digital (173).

Na tarefa SOIVET-Maze, ao invés do mapa ser apresentado de forma completa desde o início da tarefa, este poderia ser subdividido em etapas (de 5 ou mais pontos de virada por exemplo), de modo que o participante possa visualizar trechos menores do caminho por vez e possa avançar no mapa conforme conclua satisfatoriamente as etapas anteriores; 4) a transposição das tarefas em realidade virtual imersiva para um aparelho tablet com sensor de rotação poderia ser uma alternativa para aqueles que não conseguem utilizar a tecnologia por questões de tolerabilidade. A utilização de um tablet com sensor de rotação permitiria manter a forma de locomoção no ambiente vinculada ao movimento do corpo e da cabeça (recrutando assim a informação sensorial egocêntrica de posicionamento do 
corpo em relação ao ambiente). Isto ampliaria a aplicabilidade destas tarefas para diferentes contextos e para diferentes participantes, não só pelas questões de tolerabilidade mas também pela redução significativa no custo e na complexidade operacional do sistema; por fim 5) a utilização do posicionamento da mensagem e do livro na tarefa SOIVET-Route como medida de path integration. O processo de integração de caminho (ou path integration em inglês) é a capacidade de identificar e retornar a um local visitado anteriormente. Este processo é dependente da integração contínua de pistas multissensoriais (visual, proprioceptiva e vestibular) que fornecem a informação da posição atual e a direção do local anterior (174). A capacidade de integração de caminho não é dependente de marcos topográficos (orientação alocêntrica) e parece ser mediada pelo córtex entorrinal $(175,176)$. O comprometimento do processo de integração de caminhos parece comprometido no CCL e sua avaliação foi capaz de diferenciar indivíduos CCL com e sem biomarcadores para DA de forma superior a testes neuropsicológicos tradicionais $(74,169)$. A tarefa SOIVET-Route reproduziu os componentes da mensagem e do livro presentes no TCMR original mas não os utilizou como medida de avaliação. A solicitação para que os participantes apontassem para onde foi deixada a mensagem ou o livro em determinado local da rota poderia constituir uma avaliação do processo de integração de rotas, adicionalmente à avaliação da reprodução imediata do caminho na SOIVET-Route. Por se tratar de uma avaliação promissora da cognição espacial de idosos com CCL, o acréscimo de uma etapa de integração de caminho poderia se mostrar vantajosa.

Além das questões operacionais do sistema, outros pontos importantes para novos estudos seriam o acompanhamento desses participantes por maior período de tempo, de modo a identificar quais destes evoluíram para a patologia estabelecida da DA (ou outras patologias) e se o desempenho nas tarefas seria capaz de identificar aqueles que 
converteram. A utilização de biomarcadores também seria interessante, de modo a verificar se as tarefas SOIVET-Maze e SOIVET-Route imediata também conseguiriam diferenciar aqueles com e sem biomarcadores da DA, como já evidenciado em outros estudos. Ademais, a verificação da confiabilidade teste-reteste, intra e interexaminador, bem como outras características da validação do sistema proposto também se mostram necessárias. 


\subsection{Conclusão}

Em conclusão, o sistema de realidade virtual imersiva para avaliação da orientação espacial, sistema SOIVET, se mostrou viável para aplicação em adultos e na população idosa com diferentes níveis de escolaridade, familiaridade com tecnologia e comprometimento cognitivo. Em especial, as tarefas SOIVET-Maze e SOIVET-Route imediata demonstraram correlação com testes cognitivos tradicionais que apontam para a avaliação da integração alo e egocêntrica e de aprendizagem de rotas respectivamente. Estas tarefas foram capazes de diferenciar o grupo de idosos controle do grupo CCL e mostraram acurácia moderada na identificação do grupo CCL. Estes resultados apoiam a inclusão de tarefas de orientação espacial na avaliação cognitiva de idosos, bem como indicam as vantagens de tarefas de realidade virtual na reprodução de processos cognitivos complexos. Este estudo abre caminho para que futuras pesquisas possam refinar a usabilidade do sistema e ampliar sua utilização, bem como para confirmação de aspectos da validação das tarefas. Adicionalmente, a utilização das tarefas propostas poderia ser considerada em estudos futuros para a investigação de pacientes com biomarcadores da DA e até mesmo em outras patologias em que a avaliação da orientação espacial possa contribuir para o seu entendimento. 


\section{Anexo A}

Teste dos Blocos de Corsi: Este teste foi descrito na década de 70a , para investigação da memória operacional visuoespacial, ou seja, a capacidade de armazenamento de informações em um curto período de tempo. Nesta tarefa, são dispostos nove cubos (blocos) do mesmo tamanho em uma tábua de madeira e numerados de 1 a 9 (Figura A1). A numeração dos blocos só é visível para o examinador e não para o participante a ser testado. Durante a avaliação, o examinador toca com o dedo indicador uma sequência de blocos, numa taxa de um bloco por segundo e, logo em seguida, o participante deve apontar os blocos na mesma ordem em que foram apontados pelo examinador. A dificuldade é aumentada progressivamente, aumentando-se o número de blocos tocados em cada série. A tarefa é interrompida após dois erros consecutivos em uma mesma quantidade de blocos e a capacidade de memória operacional visuoespacial (também conhecida como span) é determinada pela extensão da maior série repetida corretamente.

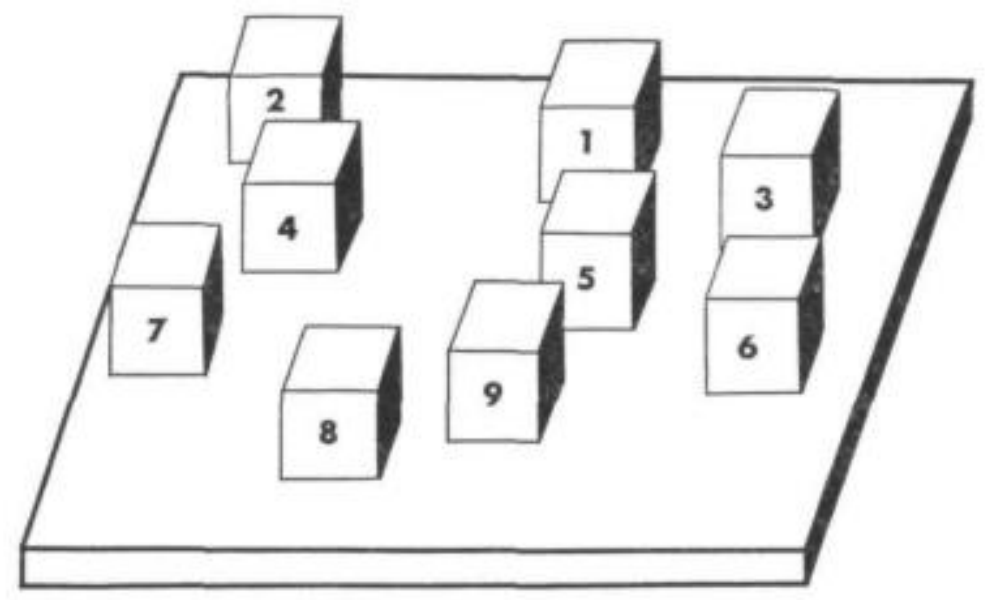

Figura A1. Teste dos Blocos de Corsi, visão do examinador.

Teste da Torre de Londres: Adaptado de um outro teste, a Torre de Hanoi, o teste da Torre de Londres foi descrito na década de $80^{\mathrm{b}}$ como uma forma de avaliação das funções executivas de alta ordem, ou seja, da parte mais refinada e complexa do processamento cognitivo. Esta tarefa foi desenvolvida para avaliar a capacidade de planejamento através do posicionamento de três esferas coloridas em três pinos de comprimentos diferentes (Figura A2). Partindo sempre da mesma posição inicial, a cada problema o participante deve mover as esferas para uma configuração final no menor número de movimentos. Quatro problemas requerem dois a três movimentos, quatro requerem quatro movimentos e quatro requerem cinco movimentos. $\mathrm{O}$ grau de planejamento exigido aumenta de acordo com o número de movimentos para a resolução de cada problema. 

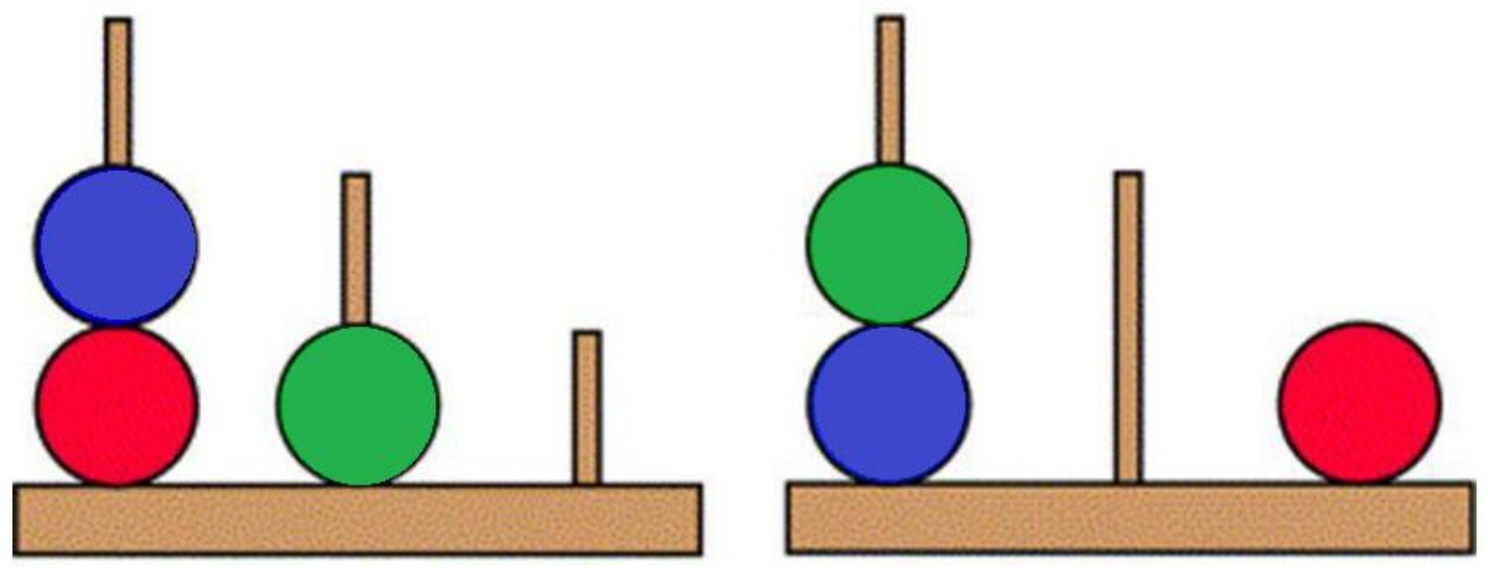

Figura A2. Exemplos da posição inicial e a configuração final de um problema

Teste da Orientação das Linhas de Benton: Descrito por Arthur Benton em $1978^{c}$ para detecção de pacientes com lesão em hemisfério cerebral direito, comumente envolvido na capacidade de percepção viuoespacial. Esta tarefa envolve o julgamento da orientação da direção das linhas, de acordo com o ângulo a que correspondem (Figura A3). Com esta tarefa, Benton tinha o objetivo de mensurar "da forma mais pura possível” o raciocínio espacial, ou seja, com o mínimo de interferência de outros aspectos da cognição (como visuoconstrução ou rotação mental). Durante a avaliação, são apresentados aos participantes 30 itens (páginas) contendo um par de linhas em diferentes posições na parte superior e uma sequência de linhas numeradas em ângulos de igual proporção na parte inferior. O participante deve indicar a qual linha numerada cada linha do par apresentado corresponde.
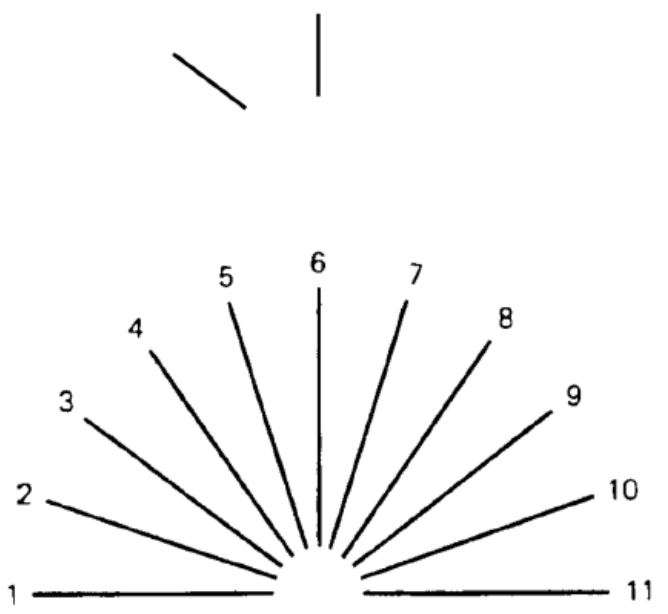

Figura A3. Exemplo de um item do Teste de Orientação das Linhas de Benton 


\subsection{Referências:}

1. Portet F, Ousset PJ, Visser PJ, Frisoni GB, Nobili F, Scheltens P, et al. Mild cognitive impairment (MCI) in medical practice: a critical review of the concept and new diagnostic procedure. Report of the MCI Working Group of the European Consortium on Alzheimer's Disease. J Neurol Neurosurg Psychiatry. 2006 Jun ;77(6):714-8.

2. Petersen RC. Mild Cognitive Impairment. Contin Lifelong Learn Neurol. 2016 Apr;22(2, Dementia):404-18.

3. Petersen RC. Mild cognitive impairment as a diagnostic entity. J Intern Med. 2004 Sep;256(3):183-94.

4. Brucki SMD. Epidemiology of Mild Cognitive Impairment in Brazil. Dement Neuropsychol. 2013;7(4):363-6.

5. Godinho C, Camozzato AL, Onyszko D, Chaves ML. Estimation of the risk of conversion of mild cognitive impairment of Alzheimer type to Alzheimer's disease in a south Brazilian population-based elderly cohort: the PALA study. Int Psychogeriatr. 2012 Apr;24(4):674-81.

6. Chaves ML, Camozzato AL, Godinho C, Piazenski I, Kaye J. Incidence of mild cognitive impairment and alzheimer disease in southern Brazil. J Geriatr Psychiatry Neurol. 2009 Sep;22(3):181-7.

7. Tatsch MF, Bottino CM de C, Azevedo D, Hototian SR, Moscoso MA, Folquitto JC, et al. Neuropsychiatric symptoms in Alzheimer disease and cognitively impaired, nondemented elderly from a community-based sample in Brazil: prevalence and relationship with dementia severity. Am J Geriatr Psychiatry. 2006 May;14(5):438-45.

8. César KG, Brucki SMD, Takada LT, Nascimento LFC, Gomes CMS, Almeida MCS, et al. Prevalence of Cognitive Impairment Without Dementia and Dementia in Tremembé, Brazil. Alzheimer Dis Assoc Disord. 2016;30(3):264-71.

9. Lopes MA, Hototian SR, Bustamante SEZ, Azevedo D, Tatsch M, Bazzarella MC, et al. Prevalence of cognitive and functional impairment in a community sample in Ribeirão Preto, Brazil. Int J Geriatr Psychiatry. 2007;22(8):770-6.

10. Landau SM, Harvey D, Madison CM, Reiman EM, Foster NL, Aisen PS, et al. Comparing predictors of conversion and decline in mild cognitive impairment. Neurology. 2010 Jul 20;75(3):230-8.

11. Farias ST, Mungas D, Reed BR, Harvey D, deCarli C. Progression of Mild Cognitive Impairment to Dementia in Clinic- vs Community-Based Cohorts. Arch Neurol. 2009;66(9):1151-7.

12. Hu C, Yu D, Sun X, Zhang M, Wang L, Qin H. The prevalence and progression of mild cognitive impairment among clinic and community populations: a systematic review and meta-analysis. Int Psychogeriatrics. 2017 Oct;29(10):1595-608.

13. Jongsiriyanyong S, Limpawattana P. Mild Cognitive Impairment in Clinical Practice: A Review Article. Am J Alzheimer's Dis Other Dementias®. 2018 Dec;33(8):500-7.

14. Risacher SL, Saykin AJ, West JD, Shen L, Firpi H a, McDonald BC. Baseline MRI predictors of conversion from MCI to probable AD in the ADNI cohort. Curr Alzheimer Res. 2009 Aug;6(4):347-61.

15. Pozueta A, Rodríguez-Rodríguez E, Vazquez-Higuera JL, Mateo I, Sánchez-Juan P, 
González-Perez S, et al. Detection of early Alzheimer's disease in MCI patients by the combination of MMSE and an episodic memory test. BMC Neurol. 2011 Jan;11(1):78.

16. Ritchie C, Smailagic N, Noel-Storr AH, Takwoingi Y, Flicker L, Mason SE, et al. Plasma and cerebrospinal fluid amyloid beta for the diagnosis of Alzheimer's disease dementia and other dementias in people with mild cognitive impairment (MCI). Cochrane database Syst Rev. 2014 Jun;2014(6):CD008782.

17. Olsson B, Lautner R, Andreasson U, Öhrfelt A, Portelius E, Bjerke M, et al. CSF and blood biomarkers for the diagnosis of Alzheimer's disease: a systematic review and meta-analysis. Lancet Neurol. 2016 Jun;15(7):673-84.

18. Ma C, Wang J, Zhang J, Chen K, Li X, Shu N, et al. Disrupted Brain Structural Connectivity: Pathological Interactions Between Genetic APOE $\varepsilon 4$ Status and Developed MCI Condition. Mol Neurobiol. 2017 Nov;54(9):6999-7007.

19. Sörensen A, Blazhenets G, Rücker G, Schiller F, Meyer PT, Frings L, et al. Prognosis of conversion of mild cognitive impairment to Alzheimer's dementia by voxel-wise Cox regression based on FDG PET data. NeuroImage Clin. 2019;21:101637.

20. Counts SE, Ikonomovic MD, Mercado N, Vega IE, Mufson EJ. Biomarkers for the Early Detection and Progression of Alzheimer's Disease. Neurotherapeutics. 2017;14(1):3553.

21. Landau SM, Harvey D, Madison CM, Koeppe RA, Reiman EM, Foster NL, et al. Associations between cognitive, functional, and FDG-PET measures of decline in AD and MCI. Neurobiol Aging. 2011 Jul;32(7):1207-18.

22. Heister D, Brewer JB, Magda S, Blennow K, McEvoy LK. Predicting MCI outcome with clinically available MRI and CSF biomarkers. Neurology. 2011 Oct 25;77(17):1619-28.

23. Brien $\mathrm{CO}, \mathrm{Ph} \mathrm{D}$, Smith GE, Ivnik RJ, Boeve BF. Prediction of AD with MRI-Based Hippocampal volume in Mild Cognitive Impairment. Neurology. 2009;m(7):1397-403.

24. Ferreira LK, Diniz BS, Forlenza O V., Busatto GF, Zanetti M V. Neurostructural Predictors Of Conversion To Alzheimer'S Disease: A Meta-analysis Of Vbm Studies. Neurobiol Aging. 2011;32:1733-41.

25. Sperling RA, Aisen PS, Beckett LA, Bennett DA, Craft S, Fagan AM, et al. Toward defining the preclinical stages of Alzheimer's disease: Recommendations from the National Institute on Aging-Alzheimer's Association workgroups on diagnostic guidelines for Alzheimer's disease. Alzheimer's Dement. 2011 May;7(3):280-92.

26. Jack CR, Bennett DA, Blennow K, Carrillo MC, Dunn B, Haeberlein SB, et al. NIA-AA Research Framework: Toward a biological definition of Alzheimer's disease. Alzheimers Dement. 2018 Apr;14(4):535-562.

27. Knopman DS, Haeberlein SB, Carrillo MC, Hendrix JA, Kerchner G, Margolin R, et al. The National Institute on Aging and the Alzheimer's Association Research Framework for Alzheimer's disease: Perspectives from the Research Roundtable. Alzheimers Dement. 2018 Apr;14(4):563-575.

28. Knopman DS, Petersen RC, Jack CR. A brief history of "Alzheimer disease": Multiple meanings separated by a common name. Neurology. 2019 May 28;92(22):1053-1059..

29. Yanhong O, Chandra M, Venkatesh D. Mild cognitive impairment in adult: A neuropsychological review. Ann Indian Acad Neurol. 2013 Jul;16(3):310-8. 
30. Tabert MH, Manly JJ, Liu X, Pelton GH, Rosenblum S, Jacobs M, et al.

Neuropsychological prediction of conversion to Alzheimer disease in patients with mild cognitive impairment. Arch Gen Psychiatry. 2006 Aug;63(8):916-24.

31. Espinosa ANA, Boada M, Vinyes G, Valero S, Martínez-lage P, Peña-casanova J, et al. Ecological Assessment of executive functions in mild cognitive impairment and mild Alzheimer Disease. J Int Neuropsychol Soc. 2010;15(5):751-7.

32. Harvey PD. Clinical applications of neuropsychological assessment. Dialogues Clin Neurosci. 2012;14(1):91-9.

33. American Psychiatric Association. Diagnostic and statistical manual of mental disorders (5th ed.). American Journal of Psychiatry. 2013.

34. Irish M, Lawlor BA, Coen RF, Mara SMO. Everyday episodic memory in amnestic mild cognitive impairment : a preliminary investigation. BMC Neurosci. 2011;12(1):80.

35. Mapstone M, Steffenella TM, Duffy CJ. A visuospatial variant of mild cognitive impairment: getting lost between aging and AD. Neurology. 2003 Mar;60(5):802-8.

36. Chapman RM, Mapstone M, Mccrary JW, Gardner MN, Porsteinsson A, Sandoval TC, et al. Predicting conversion from Mild cognitive impairment to Alzheimer's Disease using neuropsychological test and multivariate methods. J Clin Exp Neuropsychol. 2012;33(2):187-99.

37. Lithfous S, Dufour A, Després O. Spatial navigation in normal aging and the prodromal stage of Alzheimer's disease: Insights from imaging and behavioral studies. Ageing Res Rev. 2013;12(1):201-13.

38. Langa KM, Levine DA. The diagnosis and management of mild cognitive impairment: A clinical review. Vol. 312, JAMA - Journal of the American Medical Association.

American Medical Association; 2014. p. 2551-61.

39. Lin JS, O'Connor E, Rossom C, Perdue LA, Eckstrom E. Screening for cognitive impairment in older adults: A systematic review for the U.S. preventive services task force. Vol. 159, Annals of Internal Medicine. 2013. p. 601-12.

40. Arevalo-Rodriguez I, Smailagic N, Roquéi Figuls M, Ciapponi A, Sanchez-Perez E, Giannakou A, et al. Mini-Mental State Examination (MMSE) for the detection of Alzheimer's disease and other dementias in people with mild cognitive impairment (MCI). Cochrane Database Syst Rev. 2015 Mar 5;(3):CD010783.

41. Belleville S, Fouquet C, Hudon C, Zomahoun HTV, Croteau J, Consortium for the Early Identification of Alzheimer's disease-Quebec. Neuropsychological Measures that Predict Progression from Mild Cognitive Impairment to Alzheimer's type dementia in Older Adults: a Systematic Review and Meta-Analysis. Neuropsychol Rev. 2017 Dec;27(4):328-53.

42. Aguirre GK, D'Esposito M. Topographical disorientation: A synthesis and taxonomy. Vol. 122, Brain. Oxford University Press; 1999. p. 1613-28.

43. Guariglia CC, Nitrini R. Topographical Disorientation in Alzheimer's Disease. Arq Neuropsiquiatria. 2009;67:967-72.

44. Iachini I, Iavarone A, Senese VP, Ruotolo F, Ruggiero G, Iachini T, et al. Visuospatial memory in healthy elderly, AD and MCI: A review. Curr Aging Sci. 2009 Mar;2(1):4359.

45. deIpolyi AR, Rankin KP, Mucke L, Miller BL, Gorno-Tempini ML. Spatial cognition 
and the human navigation network in AD and MCI. Neurology. 2007 Sep;69(10):98697.

46. Serino S, Cipresso P, Morganti F, Riva G. The role of egocentric and allocentric abilities in Alzheimer's disease: A systematic review. Ageing Res Rev. 2014 Jul;16:32-44.

47. Nedelska Z, Andel R, Laczó J, Vlcek K, Horinek D, Lisy J, et al. Spatial navigation impairment is proportional to right hippocampal volume. Proc Natl Acad Sci U S A. 2012;109(7):2590-4.

48. Moodley K, Minati L, Contarino V, Prioni S, Wood R, Cooper R, et al. Diagnostic differentiation of mild cognitive impairment due to Alzheimer's disease using a hippocampus-dependent test of spatial memory. Hippocampus. 2015;25(8):939-51.

49. Lim T-S, Iaria G, Moon SY. Topographical disorientation in mild cognitive impairment: a voxel-based morphometry study. J Clin Neurol. 2010;6(4):204-211.

50. Vlček K, Laczó J. Neural correlates of spatial navigation changes in mild cognitive impairment and Alzheimer's disease. Front Behav Neurosci. 2014;8:89.

51. Peter J, Sandkamp R, Minkova L, Schumacher L V, Kaller CP, Abdulkadir A, et al. Real-world navigation in amnestic mild cognitive impairment: The relation to visuospatial memory and volume of hippocampal subregions. Neuropsychologia. 2018 Jan;109:86-94.

52. Colombo D, Serino S, Tuena C, Pedroli E, Dakanalis A, Cipresso P, et al. Egocentric and allocentric spatial reference frames in aging: A systematic review. Neurosci Biobehav Rev. 2017 Sep;80:605-21.

53. Korthauer L., Nowak N., Frahmand M, Driscoll I. Cognitive correlates of spatial navigation: Associations between executive functioning and the virtual Morris Water Task. Behav Brain Res. 2017 Jan;317:470-8.

54. Lester AW, Moffat SD, Wiener JM, Barnes CA, Wolbers T. The Aging Navigational System. Neuron. 2017 Aug;95(5):1019-35.

55. Vann SD, Aggleton JP, Maguire EA. What does the retrosplenial cortex do? Nat Rev Neurosci. 2009 Nov;10(11):792-802.

56. Morganti F, Stefanini S, Riva G. From allo- to egocentric spatial ability in early Alzheimer's disease: a study with virtual reality spatial tasks. Cogn Neurosci. 2013;4:171-80.

57. Braak H, Braak E. Demonstration of amyloid deposits and neurofibrillary changes in whole brain sections. Brain Pathol. 1991 Apr;1(3):213-6.

58. Bird CM, Chan D, Hartley T, Pijnenburg YA, Rossor MN, Burgess N. Topographical short-term memory differentiates Alzheimer's disease from frontotemporal lobar degeneration. Hippocampus. 2010;20(10):1154-69.

59. Peters-Founshtein G, Peer M, Rein Y, Merhavi SK, Meiner Z, Arzy S. Mentalorientation: A new approach to assessing patients across the Alzheimer's disease spectrum. Neuropsychology. 2018;32(6):690-9.

60. Maguire EA, Gadian DG, Johnsrude IS, Good CD, Ashburner J, Frackowiak RSJ, et al. Navigation-related structural change in the hippocampi of taxi drivers. Proc Natl Acad Sci. 2000 Apr;97(8):4398-403.

61. Woollett K, Maguire EA. Acquiring "the Knowledge" of London's layout drives structural brain changes. Curr Biol. 2011 Dec ;21(24):2109-14. 
62. Laczo J, Vlcek K, Vyhnalek M, Vajnerova O, Ort M, Holmerova I, et al. Spatial navigation testing discriminates two types of amnestic mild cognitive impairment. Behav Brain Res. 2009 Sep;202(2):252-9.

63. Benke T, Karner E, Petermichl S, Prantner V, Kemmler G. Neuropsychological deficits associated with route learning in Alzheimer disease, MCI, and normal aging. Alzheimer Dis Assoc Disord. 2014;28(2):162-167.

64. Caffò AO, Lopez A, Spano G, Serino S, Cipresso P, Stasolla F, et al. Spatial reorientation decline in aging: the combination of geometry and landmarks. Aging Ment Heal. 2018;22(10):1372-83.

65. Mohammadi A, Kargar M, Hesami E, A. M, M. K, E. H. Using virtual reality to distinguish subjects with multiple- but not single-domain amnestic mild cognitive impairment from normal elderly subjects. Psychogeriatrics. 2018 Mar;18(2):132-42.

66. Qian J, Wolters FJ, Beiser A, Haan M, Ikram MA, Karlawish J, et al. APOE-related risk of mild cognitive impairment and dementia for prevention trials: An analysis of four cohorts. Miller BL, editor. PLOS Med. 2017 Mar;14(3):e1002254.

67. Laczó J, Andel R, Vlček K, Matoška V, Vyhnálek M, Martin T, et al. Spatial Navigation and APOE in Amnestic Mild Cognitive Impairment. Neurodegener Dis. 2011;8(4):16977.

68. Laczó J, Andel R, Vyhnalek M, Vlcek K, Nedelska Z, Matoska V, et al. APOE and spatial navigation in amnestic MCI: results from a computer-based test. Neuropsychology. 2014 Sep;28(5):676-84.

69. Hort J, Laczo J, Vyhnalek M, Bojar M, Bures J, Vlcek K, et al. Spatial navigation deficit in amnestic mild cognitive impairment. Proc Natl Acad Sci U S A. 2007 Mar;104(10):4042-7.

70. Cerman J, Ross A, Laczo J, Martin V, Zuzana N, Ivana M, et al. Subjective Spatial Navigation Complaints - A Frequent Symptom Reported by Patients with Subjective Cognitive Decline, Mild Cognitive Impairment and Alzheimer's Disease. Curr Alzheimer Res. 2018;15(3):219-28.

71. Mitolo M, Gardini S, Fasano F, Crisi G, Pelosi A, Pazzaglia F, et al. Visuospatial memory and neuroimaging correlates in mild cognitive impairment. J Alzheimer's Dis. 2013;35(1):75-90.

72. Laczó J, Andel R, Vyhnalek M, Vlcek K, Magerova H, Varjassyova A, et al. Human analogue of the morris water maze for testing subjects at risk of Alzheimer's Disease. Neurodegener Dis. 2010;7(1-3):148-52.

73. Weniger G, Ruhleder M, Lange C, Wolf S, Irle E. Egocentric and allocentric memory as assessed by virtual reality in individuals with amnestic mild cognitive impairment. Neuropsychologia. 2011;49(3):518-27.

74. Mokrisova I, Laczo J, Andel R, Gazova I, Vyhnalek M, Nedelska Z, et al. Real-space path integration is impaired in Alzheimer's disease and mild cognitive impairment. Behav Brain Res. 2016;307:150-8.

75. Mitolo M, Borella E, Meneghetti C, Carbone E. How to enhance route learning and visuo-spatial working memory in aging : a training for residential care home residents. Aging Ment Health. 2017 May;21(5):562-570

76. Rusconi ML, Suardi A, Zanetti M, Rozzini L, M.L. R, A. S, et al. Spatial navigation in elderly healthy subjects, amnestic and non amnestic MCI patients. J Neurol Sci. 
2015;359(1-2):430-7.

77. Money J, Alexander D, Walker H. A Standardized Road-Map Test of Direction Sense. Baltimore: Johns Hopkins Press; 1967.

78. Morganti F, Marrakchi S, Urban PP, Iannoccari G, Riva G. A virtual reality based tool for the assessment of " survey to route " spatial organization ability in elderly population : preliminary data. Cogn Neurosci. 2009;10(Suppl 2):257-9.

79. Oliveira R, Schmidt SL. Teste Comportamental de Memória de Rivermead: Manual da Versão Traduzida e Adaptada para o Brasil. Rio de Janeiro: Cognição; 1999.

80. Yassuda MS, Flaks MK, Viola LF, Pereira FS, Memória CM, Nunes PV, et al. Psychometric characteristics of the Rivermead Behavioural Memory Test (RBMT) as an early detection instrument for dementia and mild cognitive impairment in Brazil. Int Psychogeriatr. 2010 Sep;22(6):1003-11.

81. Morganti F. Embodied Space in Natural and Virtual Environments: Implications for Cognitive Neuroscience Research. In: Pervasive Computing Paradigms for Mental Health. 2016.

82. Hegarty M, Montello DR, Richardson AE, Ishikawa T, Lovelace K. Spatial abilities at different scales: Individual differences in aptitude-test performance and spatial-layout learning. Intelligence. 2006 Mar;34(2):151-76.

83. Morganti F, Riva G. Virtual reality as allocentric/egocentric technology for the assessment of cognitive decline in the elderly. In: Studies in Health Technology and Informatics. IOS Press; 2014. p. 278-84.

84. Riva G. Virtual reality: an experiential tool for clinical psychology. Br J Guid Counc. 2009 Aug;37(3):337-45.

85. Caffo AO, De Caro MF, Picucci L, Notarnicola A, Settanni A, Livrea P, et al. Reorientation deficits are associated with amnestic mild cognitive impairment. Am J Alzheimers Dis Other Demen. 2012 Aug;27(5):321-30.

86. Benoit M, Guerchouche R, Petit PD, Chapoulie E, Manera V, Chaurasia G, et al. Is it possible to use highly realistic virtual reality in the elderly? A feasibility study with image-based rendering. Neuropsychiatr Dis Treat. 2015;11:557-63.

87. Cogné M, Taillade M, N'Kaoua B, Tarruella A, Klinger E, Larrue F, et al. The contribution of virtual reality to the diagnosis of spatial navigation disorders and to the study of the role of navigational aids: A systematic literature review. Ann Phys Rehabil Med. 2017 Jun;60(3):164-76.

88. Garrett B, Taverner T, Gromala D, Tao G, Cordingley E, Sun C. Virtual Reality Clinical Research: Promises and Challenges. JMIR serious games. 2018 Oct;6(4):e10839.

89. Park MJ, Kim DJ, Lee U, Na EJ, Jeon HJ. A Literature Overview of Virtual Reality (VR) in Treatment of Psychiatric Disorders: Recent Advances and Limitations. Front psychiatry. 2019; 10:505.

90. Syed-Abdul S, Malwade S, Nursetyo AA, Sood M, Bhatia M, Barsasella D, et al. Virtual reality among the elderly: a usefulness and acceptance study from Taiwan. BMC Geriatr. 2019 Dec;19(1):223.

91. Huygelier H, Schraepen B, van Ee R, Vanden Abeele V, Gillebert CR. Acceptance of immersive head-mounted virtual reality in older adults. Sci Rep. 2019 Mar;9(1):4519.

92. Carvalho VA, Caramelli P, Carvalho VA, Caramelli P. Brazilian adaptation of the 
Addenbrooke's Cognitive Examination-Revised (ACE-R). Dement Neuropsychol. 2007 Jun;1(2):212-6.

93. Mioshi E, Dawson K, Mitchell J, Arnold R, Hodges JR. The Addenbrooke's Cognitive Examination Revised (ACE-R): a brief cognitive test battery for dementia screening. Int J Geriatr Psychiatry. 2006 Nov;21(11):1078-85.

94. César KG, Yassuda MS, Porto FHG, Brucki SMD, Nitrini R. Addenbrooke's cognitive examination-revised: normative and accuracy data for seniors with heterogeneous educational level in Brazil. Int Psychogeriatrics. 2017 Aug;29(8):1345-53.

95. Jak AJ, Bondi MW, Delano-Wood L, Wierenga C, Corey-Bloom J, Salmon DP, et al. Quantification of five neuropsychological approaches to defining mild cognitive impairment. Am J Geriatr Psychiatry. 2009;17(5):368-75.

96. Hegarty M, Richardson AE, Montello DR, Lovelace K, Subbiah I. Development of a self-report measure of environmental spatial ability. Intelligence. 2002;30(5):425-47.

97. Charlson ME, Pompei P, Ales KL, MacKenzie CR. A new method of classifying prognostic comorbidity in longitudinal studies: development and validation. J Chronic Dis. 1987;40(5):373-83.

98. Kennedy RS, Lane NE, Berbaum KS, Lilienthal MG. Simulator Sickness Questionnaire: An Enhanced Method for Quantifying Simulator Sickness. Int J Aviat Psychol. 1993 Jul;3(3):203-20.

99. Carvalho M, Costa R, Nardi A. Simulator Sickness Questionnaire: tradução e adaptação transcultural; Simulator Sickness Questionnaire: translation and cross-cultural adaptation. J bras Psiquiatr. 2011;60(4):247-52.

100. da Costa RQM, Pompeu JE, de Mello DD, Moretto E, Rodrigues FZ, Dos Santos MD, et al. Two new virtual reality tasks for the assessment of spatial orientation: Preliminary results of tolerability, sense of presence and usability. 2018;12(2):196-204.

101. Witmer BG, Singer MJ. Measuring Presence in Virtual Environments: A Presence Questionnaire. Presence: Teleoper Virtual Environ. 1998;7(3):225-40.

102. Slater M. Measuring Presence: A Response to the Witmer and Singer Presence Questionnaire. Presence Teleoperators Virtual Environ. 1999 Oct;8(5):560-5.

103. Schubert T, Friedmann F, Regenbrecht H. The Experience of Presence: Factor Analytic Insights. Presence Teleoperators Virtual Environ. 2001 Jun;10(3):266-81.

104. Vetter TR. Fundamentals of Research Data and Variables. Anesth Analg. 2017 Oct;125(4):1375-80.

105. Fay MP, Proschan MA. Wilcoxon-Mann-Whitney or t-test? On assumptions for hypothesis tests and multiple interpretations of decision rules. Stat Surv. 2010;4:1-39.

106. de Winter JCF, Gosling SD, Potter J. Comparing the Pearson and Spearman correlation coefficients across distributions and sample sizes: A tutorial using simulations and empirical data. Psychol Methods. 2016;21(3):273-90.

107. Pasquali L. Psicometria. Rev da Esc Enferm da USP. 2009;43:992-9.

108. American Educational Research Association, American Psychological Association, National Council on Measurement in Education. Standards for educational and psychological testing. American Psychological Association, editor. Washington, DC; 1999. 
109. Brown T. Construct validity: A unitary concept for occupational therapy assessment and measurement. Vol. 20, Hong Kong Journal of Occupational Therapy. 2010. p. 30-42.

110. Reichenheim ME, Moraes CL. Operacionalização de adaptação transcultural de instrumentos de aferição usados em epidemiologia. Rev Saude Publica. 2007;41(4):66573.

111. Perrochon A, Kemoun G, A. P, G. K. The walking trail-making test is an early detection tool for mild cognitive impairment. Clin Interv Aging. 2014;9:111-9.

112. Mitolo M, Gardini S, Caffarra P, Ronconi L, Venneri A, Pazzaglia F. Relationship between spatial ability, visuospatial working memory and self-assessed spatial orientation ability: a study in older adults. Cogn Process. 2015;16(2):165-76.

113. Benton AL, Varney NR, Hamsher K Des. Visuospatial Judgment: A Clinical Test. Arch Neurol. 1978;35(6):364-7.

114. Batista AX, Adda CC, Miotto EC, de Lúcia MCS, Scaff M. Torre de Londres e Torre de Hanói: contribuições distintas para avaliação do funcionamento executivo. J Bras Psiquiatr. 2007;56(2):134-9.

115. D. Johnson W, H. Burton J, A. Beyl R, E. Romer J. A Simple Chi-Square Statistic for Testing Homogeneity of Zero-Inflated Distributions. Open J Stat. 2015 Oct;05(06):48393.

116. Bamber D. The area above the ordinal dominance graph and the area below the receiver operating characteristic graph. J Math Psychol. 1975;12(4):387-415.

117. Youden WJ. Index for rating diagnostic tests. Cancer. 1950 Jan;3(1):32-5.

118. Garcia-Betances RI, Arredondo Waldmeyer MT, Fico G, Femanda Cabrera-Umpierrez M. A succinct overview of virtual reality technology use in Alzheimer's disease. Front Aging Neurosci. 2015 May 12;7:80.

119. Freeman D, Reeve S, Robinson A, Ehlers A, Clark D, Spanlang B, et al. Virtual reality in the assessment, understanding, and treatment of mental health disorders. Psychol Med. 2017 Mar;1-8.

120. Virk S, McConville KMV. Virtual Reality Applications in Improving Postural Control and Minimizing Falls. In: 2006 International Conference of the IEEE Engineering in Medicine and Biology Society. IEEE; 2006. p. 2694-7.

121. Bisson E, Contant B, Sveistrup H, Lajoie. Y. Functional Balance and Dual-Task Reaction Times in Older Adults Are Improved by Virtual Reality and Biofeedback Training. CyberPsychology Behav. 2007;10(1):16-23.

122. Optale G, Urgesi C, Busato V, Marin S, Piron L, Priftis K, et al. Controlling Memory Impairment in Elderly Adults Using Virtual Reality Memory Training: A Randomized Controlled Pilot Study. Neurorehabil Neural Repair. 2010 May;24(4):348-57.

123. García-Betances RI, Jiménez-Mixco V, Arredondo MT, Cabrera-Umpiérrez MF. Using Virtual Reality for Cognitive Training of the Elderly. Am J Alzheimer's Dis Other Dementiasr. 2015 Feb;30(1):49-54.

124. McEwen D, Taillon-Hobson A, Bilodeau M, Sveistrup H, Finestone H. Virtual Reality Exercise Improves Mobility After Stroke. Stroke. 2014;45(6):1853-5.

125. House G, Burdea G, Polistico K, Roll D, Kim J, Grampurohit N, et al. Integrative rehabilitation of residents chronic post-stroke in skilled nursing facilities: the design and evaluation of the BrightArm Duo. Disabil Rehabil Assist Technol. 2016 Nov;11(8):683- 
94.

126. Pickering CEZ, Ridenour K, Salaysay Z, Reyes-Gastelum D, Pierce SJ. EATI Island - A virtual-reality-based elder abuse and neglect educational intervention. Gerontol Geriatr Educ. 2018 Oct;39(4):445-63.

127. Huygelier H, Schraepen B, van Ee R, Vanden Abeele V, Gillebert CR. Acceptance of immersive head-mounted virtual reality in older adults. Sci Rep. 2019 Dec;9(1):4519.

128. Manera V, Chapoulie E, Bourgeois J, Guerchouche R, David R, Ondrej J, et al. A Feasibility Study with Image-Based Rendered Virtual Reality in Patients with Mild Cognitive Impairment and Dementia. Chao L, editor. PLoS One. 2016 Mar;11(3):e0151487.

129. Joseph J. LaViola Jr. A Discussion of Cybersickness in Virtual Environments. SIGCHI Bull. 2000;32(1).

130. Riva G. The neuroscience of body memory: From the self through the space to the others. Cortex. 2018 Jul;104:241-60.

131. Cushman L a, Duffy CJ, L.A. C, C.J. D. The sex specificity of navigational strategies in Alzheimer disease. Alzheimer Dis Assoc Disord. 2007;21(2):122-9.

132. Sneider JT, Hamilton DA, Cohen-Gilbert JE, Crowley DJ, Rosso IM, Silveri MM. Sex differences in spatial navigation and perception in human adolescents and emerging adults. Behav Processes. 2015 Feb

133. Yasen AL, Raber J, Miller JK, Piper BJ. Sex, but not Apolipoprotein E Polymorphism, Differences in Spatial Performance in Young Adults. Arch Sex Behav. 2015 Nov ;44(8):2219-26.

134. Liu I, Levy RM, Barton JJS, Iaria G. Age and gender differences in various topographical orientation strategies. Brain Res. 2011 Oct;1410:112-9.

135. Techentin C, Voyer D, Voyer SD. Spatial Abilities and Aging: A Meta-Analysis. Exp Aging Res. 2014 Aug;40(4):395-425.

136. Hegarty M, Waller D. A dissociation between mental rotation and perspective-taking spatial abilities. Intelligence. 2004 Apr;32(2):175-91.

137. Morganti F. Enacting space in virtual reality: A comparison between Money's Road Map test and its virtual version. Front Psychol. 2018 Dec 5;9:2410.

138. Dubois B, Albert ML. Amnestic MCI or prodromal Alzheimer's disease? Lancet Neurol. 2004 Apr;3(4):246-8.

139. Laczó J, Andel R, Vyhnalek M, Vlcek K, Magerova H, Varjassyova A, et al. From morris water maze to computer tests in the prediction of Alzheimer's disease. Neurodegener Dis. 2012;10(1-4):153-7.

140. Gazova I, Vlcek K, Laczó J, Nedelska Z, Hyncicova E, Mokrisova I, et al. Spatial navigation - a unique window into physiological and pathological aging. Front Aging Neurosci. 2012 Jun;4:16.

141. King JA, Burgess N, Hartley T, Vargha-Khadem F, O'Keefe J. Human hippocampus and viewpoint dependence in spatial memory. Hippocampus. 2002;12(6):811-20.

142. Hartley T, Bird CM, Chan D, Cipolotti L, Husain M, Vargha-Khadem F, et al. The hippocampus is required for short-term topographical memory in humans. Hippocampus . 2007;17(1):34-48. 
143. Muffato V, Hilton C, Meneghetti C, De Beni R, Wiener JM. Evidence for age-related deficits in object-location binding during place recognition. Hippocampus. 2019 Oct;29(10):971-979

144. O'Keefe J, Nadel L. The Hippocampus as a cognitive map. OXFORD UNIVERSITY PRESS, editor. Oxford; 1978.

145. Lisman J, Buzsáki G, Eichenbaum H, Nadel L, Ranganath C, Redish AD. Viewpoints: how the hippocampus contributes to memory, navigation and cognition. Nat Neurosci. 2017 Nov;20(11):1434-47.

146. Serino S, Morganti F, Colombo D, Pedroli E, Cipresso P, Riva G. Disentangling the contribution of spatial reference frames to executive functioning in healthy and pathological aging: An experimental study with virtual reality. Sensors (Switzerland). 2018;18(6).

147. Oliveira J, Gamito P, Alghazzawi DM, Fardoun HM, Rosa PJ, Sousa T, et al. Performance on naturalistic virtual reality tasks depends on global cognitive functioning as assessed via traditional neurocognitive tests. Appl Neuropsychol. 2018;25(6):555-61.

148. Hirsch P, Nolden S, Koch I. Higher-order cognitive control in dual tasks: Evidence from task-pair switching. J Exp Psychol Hum Percept Perform. 2017;43(3):569-80.

149. Korotkevich Y, Trewartha KM, Penhune VB, Li KZH. Effects of age and cognitive load on response reprogramming. Exp Brain Res. 2015 Mar;233(3):937-46.

150. Camicioli R, Howieson D, Lehman S, Kaye J. Talking while walking: The effect of a dual task in aging and Alzheimer's disease. Neurology. 1997 Apr;48(4):955-8.

151. Coutrot A, Schmidt S, Coutrot L, Pittman J, Hong L, Wiener JM, et al. Virtual navigation tested on a mobile app is predictive of real-world wayfinding navigation performance. PLoS One. 2019 Mar;14(3).

152. Humphreys GW, Duta MD, Montana L, Demeyere N, McCrory C, Rohr J, et al. Cognitive Function in Low-Income and Low-Literacy Settings: Validation of the TabletBased Oxford Cognitive Screen in the Health and Aging in Africa: A Longitudinal Study of an INDEPTH Community in South Africa (HAALSI). J Gerontol B Psychol Sci Soc Sci. 2017 Jan;72(1):38-50.

153. Beaufils E, Hommet C, Brault F, Marqué A, Eudo C, Vierron E, et al. The effect of age and educational level on the cognitive processes used to comprehend the meaning of pictograms. Aging Clin Exp Res. 2014;26(1):61-5.

154. Pengas G, Patterson K, Arnold RJ, Bird CM, Burgess N, Nestor PJ. Lost and found: Bespoke memory testing for Alzheimer's disease and semantic dementia. J Alzheimer's Dis. 2010;21(4):1347-65.

155. Allison S, Head D. Route repetition and route reversal: Effects of age and encoding method. Psychol Aging. 2017 May 1;32(3):220-31.

156. Farrell MJ, Arnold P, Pettifer S, Adams J, Graham T, MacManamon M. Transfer of Route Learning from Virtual to Real Environments. J Exp Psychol Appl. 2003 Dec;9(4):219-27.

157. Richardson AE, Montello DR, Hegarty M. Spatial knowledge acquisition from maps and from navigation in real and virtual environments. Mem Cogn. 1999;27(4):741-50.

158. Rusconi ML, Suardi A, Zanetti M, Rozzini L, M.L. R, A. S, et al. Spatial navigation in elderly healthy subjects, amnestic and non amnestic MCI patients. J Neurol Sci . 2015 
Dec;359(1-2):430-7.

159. Boccia M, Di Vita A, Diana S, Margiotta R, Imbriano L, Rendace L, et al. Is Losing One's Way a Sign of Cognitive Decay? Topographical Memory Deficit as an Early Marker of Pathological Aging. J Alzheimer's Dis]. 2019;68(2):679-93.

160. Flicker C, Ferris SH, Crook T, Reisberg B, Bartus RT. Equivalent spatial-rotation deficits in normal aging and alzheimer's disease. J Clin Exp Neuropsychol. 1988 Aug;10(4):387-99.

161. Rainville C, Marchand N, Passini R. Performances of patients with a dementia of the Alzheimer type in the Standardized Road-Map test of Direction Sense.

Neuropsychologia. $2002 ; 40(5): 567-73$.

162. Serino S, Morganti F, Di Stefano F, Riva G. Detecting early egocentric and allocentric impairments deficits in Alzheimer's disease: an experimental study with virtual reality. Front Aging Neurosci. 2015 May; 7:88.

163. Allison SL, Rodebaugh TL, Johnston C, Fagan AM, Morris JC, Head D. Developing a Spatial Navigation Screening Tool Sensitive to the Preclinical Alzheimer Disease Continuum. Arch Clin Neuropsychol. 2019 Oct 24;34(7):1138-1155

164. Plancher G, Tirard A, Gyselinck V, Nicolas S, Piolino P. Using virtual reality to characterize episodic memory profiles in amnestic mild cognitive impairment and Alzheimer's disease: Influence of active and passive encoding. Neuropsychologia. 2012 Apr;50(5):592-602.

165. Bessi V, Mazzeo S, Padiglioni S, Piccini C, Nacmias B, Sorbi S, et al. From Subjective Cognitive Decline to Alzheimer's Disease: The Predictive Role of Neuropsychological Assessment, Personality Traits, and Cognitive Reserve. A 7-Year Follow-Up Study. J Alzheimer's Dis. 2018 May;63(4):1523-35.

166. Weakley A, Schmitter-Edgecombe M. Naturalistic assessment of task interruption in individuals with mild cognitive impairment. Neuropsychology. 2019 Jan;33(1):1-12.

167. Konishi K, Joober R, Poirier J, MacDonald K, Chakravarty M, Patel R, et al. Healthy versus Entorhinal Cortical Atrophy Identification in Asymptomatic APOE4 Carriers at Risk for Alzheimer's Disease. J Alzheimers Dis. 2018;61(4):1493-507.

168. Coughlan G, Coutrot A, Khondoker M, Minihane A-M, Spiers H, Hornberger M. Toward personalized cognitive diagnostics of at-genetic-risk Alzheimer's disease. Proc Natl Acad Sci U S A. 2019;116(19):9285-92.

169. Howett D, Castegnaro A, Krzywicka K, Hagman J, Marchment D, Henson R, et al. Differentiation of mild cognitive impairment using an entorhinal cortex-based test of virtual reality navigation. Brain. 2019 Jun;142(6):1751-66.

170. Allison S, Babulal G, Stout S, Barco P, Carr D, Fagan A, et al. Alzheimer Disease Biomarkers and Driving in Clinically Normal Older Adults. Alzheimer Dis Assoc Disord. 2018;32(2):101-6.

171. Tarnanas I, Laskaris N, Tsolaki M. On the comparison of VR-responses, as performance measures in prospective memory, with auditory P300 responses in MCI detection. Stud Health Technol Inform. 2012;181:156-61.

172. da Costa RQM, Viveiro LAP, Pompeu JE, Brucki SMD. Spatial orientation tasks show moderate to high accuracy for the diagnosis of Mild Cognitive Impairment. Artigo submetido para publicação. 2019 
173. Sardi L, Idri A, Fernández-Alemán JL. A systematic review of gamification in e-Health. Vol. 71, Journal of Biomedical Informatics. Academic Press Inc.; 2017. p. 31-48.

174. Etienne AS, Jeffery KJ. Path integration in mammals. Vol. 14, Hippocampus. 2004. p. $180-92$.

175. McNaughton BL, Battaglia FP, Jensen O, Moser EI, Moser MB. Path integration and the neural basis of the "cognitive map." Nat Rev Neurosci. 2006 Aug;7(8):663-78

176. Wolbers T, Wiener JM, Mallot HA, Büchel C. Differential recruitment of the hippocampus, medial prefrontal cortex, and the human motion complex during path integration in humans. J Neurosci. 2007 Aug;27(35):9408-16. 


\section{Apêndice 1}

Exame Cognitivo de Addenbrooke, versão revisada (ACE-R)

\section{EXAME COGNITIVO DE ADDENBROOKE - VERSÃO REVISADA}

Titulo original: Addenbrooke's Cognitive Examination - Revised (ACE-R)

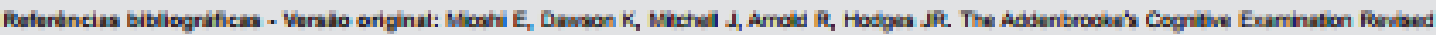

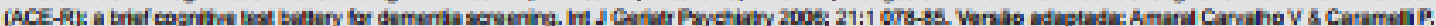

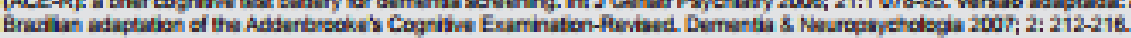

\section{Nome:}

Data de nascimento:

Nome do Hospital:
Data da avaliaçăo:........................

Nome do examinador:

Escolaridade:

Profissẫ:

Dominância manual:,

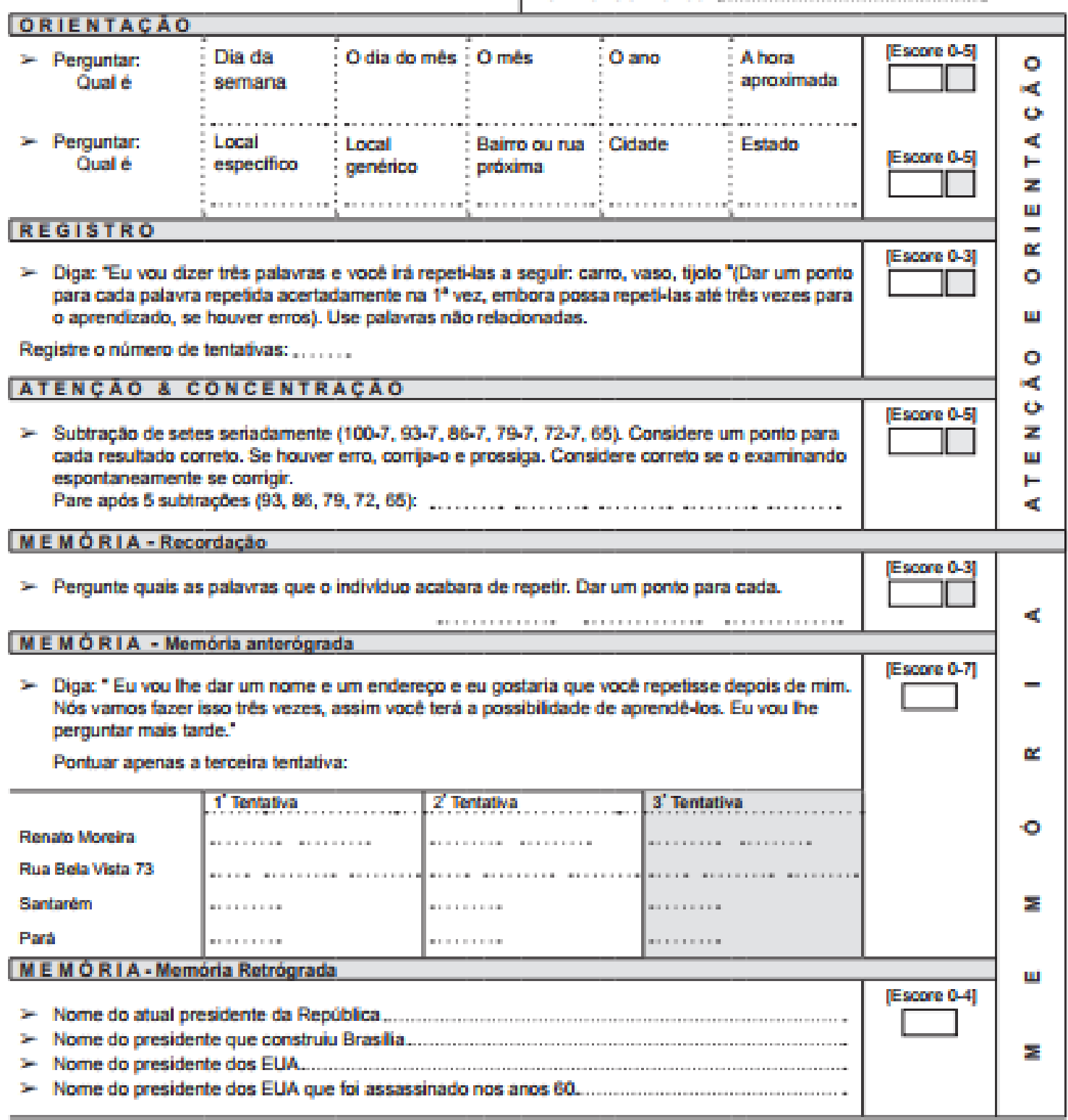


- Letras

Diga: "Eu vou the dizer uma letra do alfabeto e eu gostaria que voct dissesse o maior número de palavras que puder começando com a letra, mas nsto diga nomes de pessoas ou lugares. Vocte esta peonto(a) ? Vocé tem um minuto e a letra é "p".
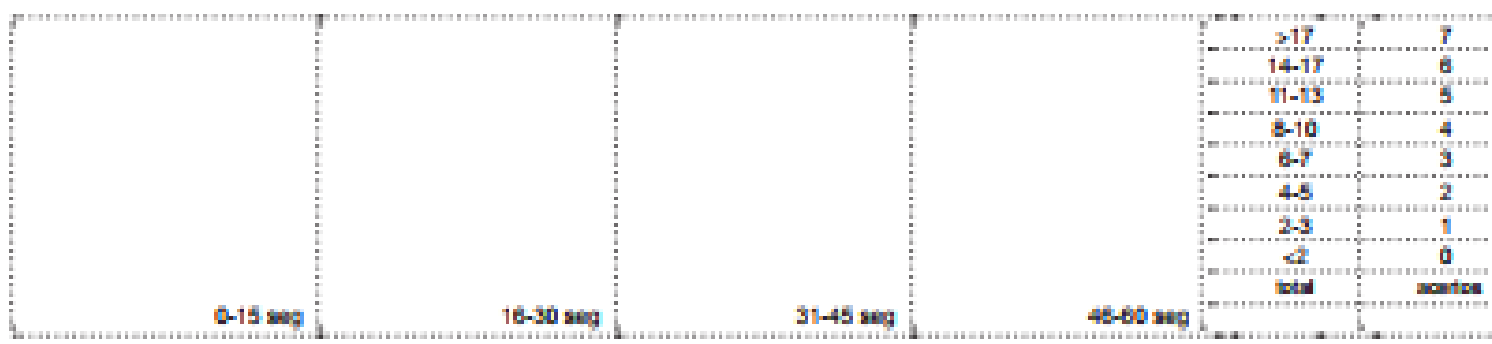

- Animais

Digax "Agora vocé poderia dizer o maior nümero de animais que conseguir, começando com qualquer letra?
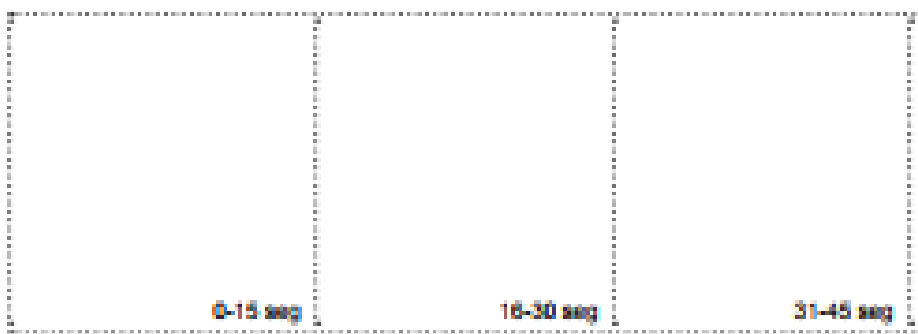

[Esoore 0-7]

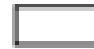

[Escore 0.7]

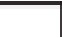

\section{LINGUAGEM. Compreensio}

- Mostrar a instruçlo escrita e pedir ao individuo para fazer o que esta sendo mandado (nso auxilie se ele pedir ajuda ou se so ler a frase sem realizar o comando):

Comando:

"Pegue este papel com a mào direita, dobre-o ao meio e coloque -o no cháo." Dar um ponto para cada acerto. Se o individuo pedir ajuda no meio da tarefa nsto de dicas.

- Peça so individuo para escrever uma frase: Se nto compreender o significado, ajude com: alguma frase que tenha começo, meio e fim, alguma covisa que aconteceu haje: alguma coisa que queira dizer. Para a correçto nato sto considerados erros gramaticais ou ortográficos. Dar um ponta. 


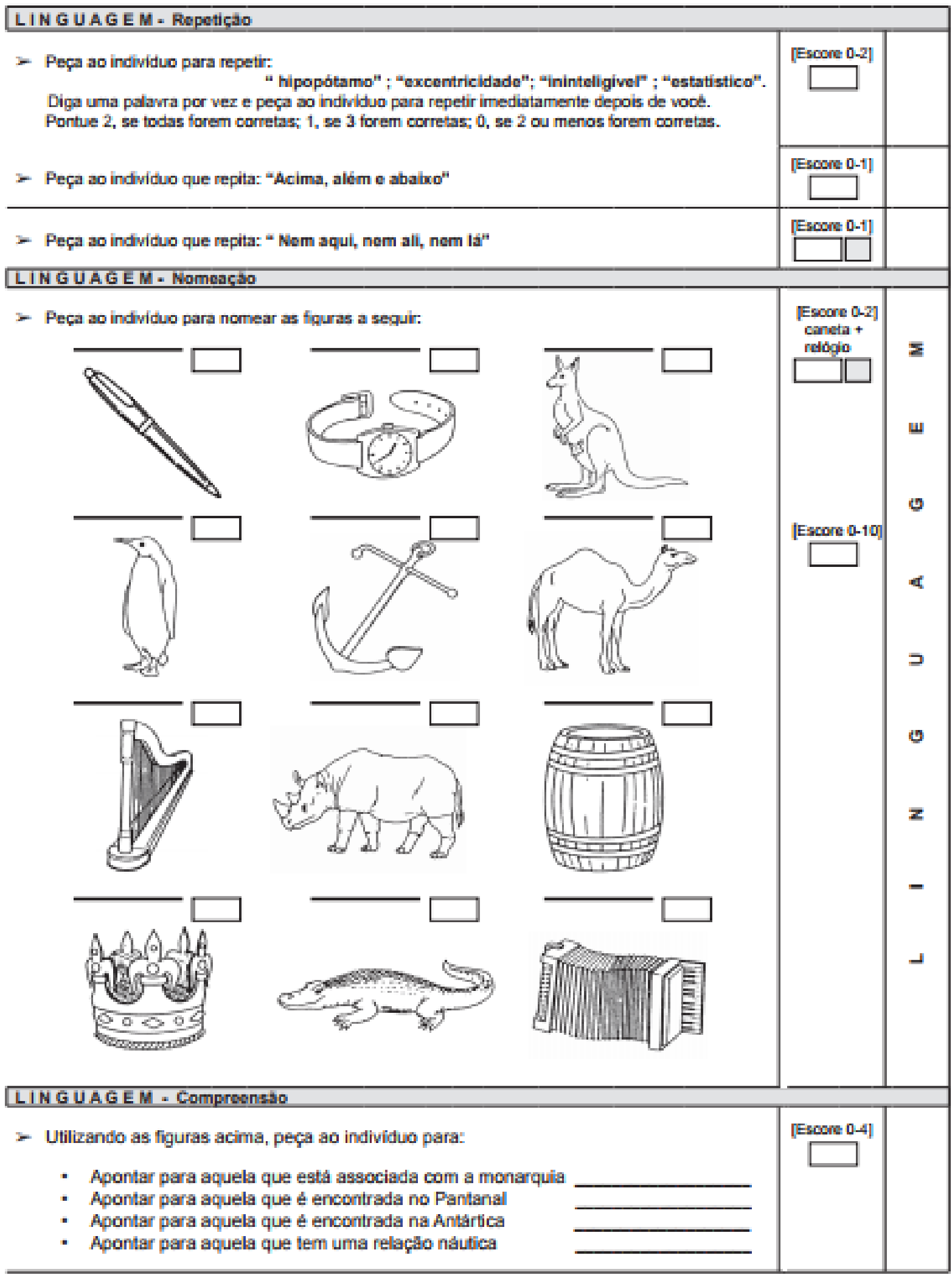


EXANE COGNITIVO DE ADOENBROOKE - VERSÄO REVISADA

\section{LINGUAGEM-Leitura}

- Peça ao individuo para ler as seguintes palavras: [Pontuar com 1, se todas estiverem corretas]

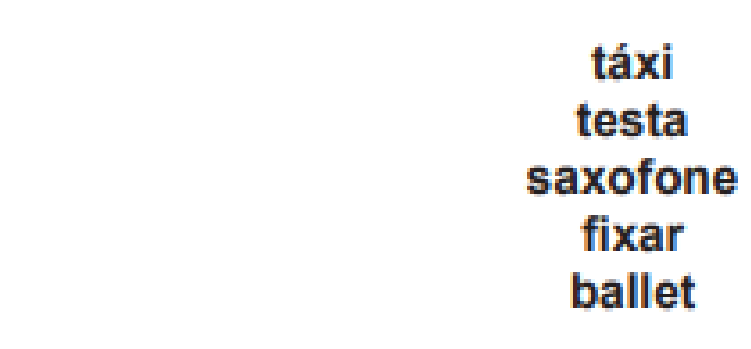

HABILIDADES VISUAIS.ESPACIAIS

- Pentágonos sobrepostos: Peça so individuo para capiar o desenho e para fazer o melhor possfivel.

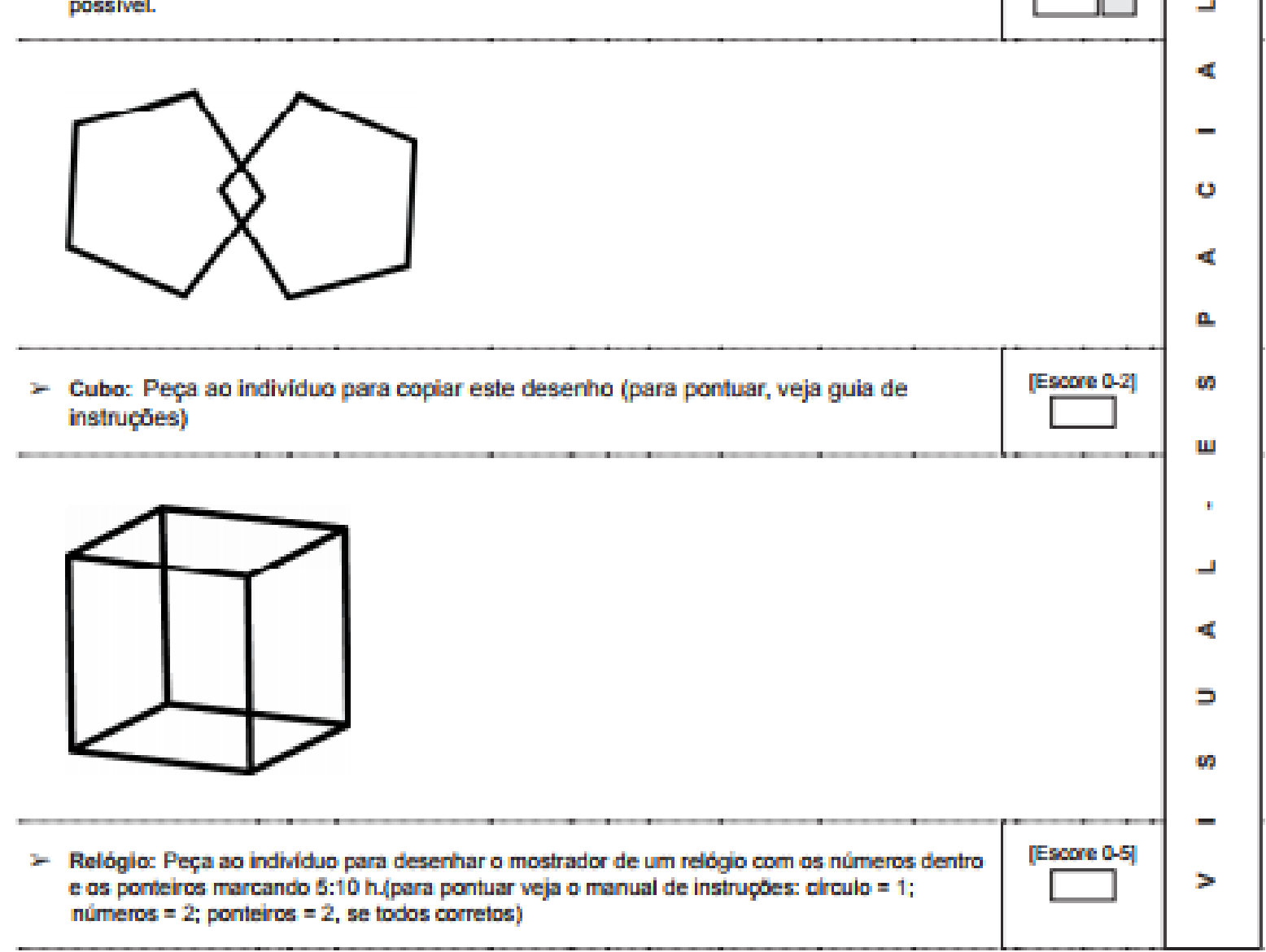


EXANE COGNITIVO DE ADOENBROOKE - VERSÄO REVIBADA

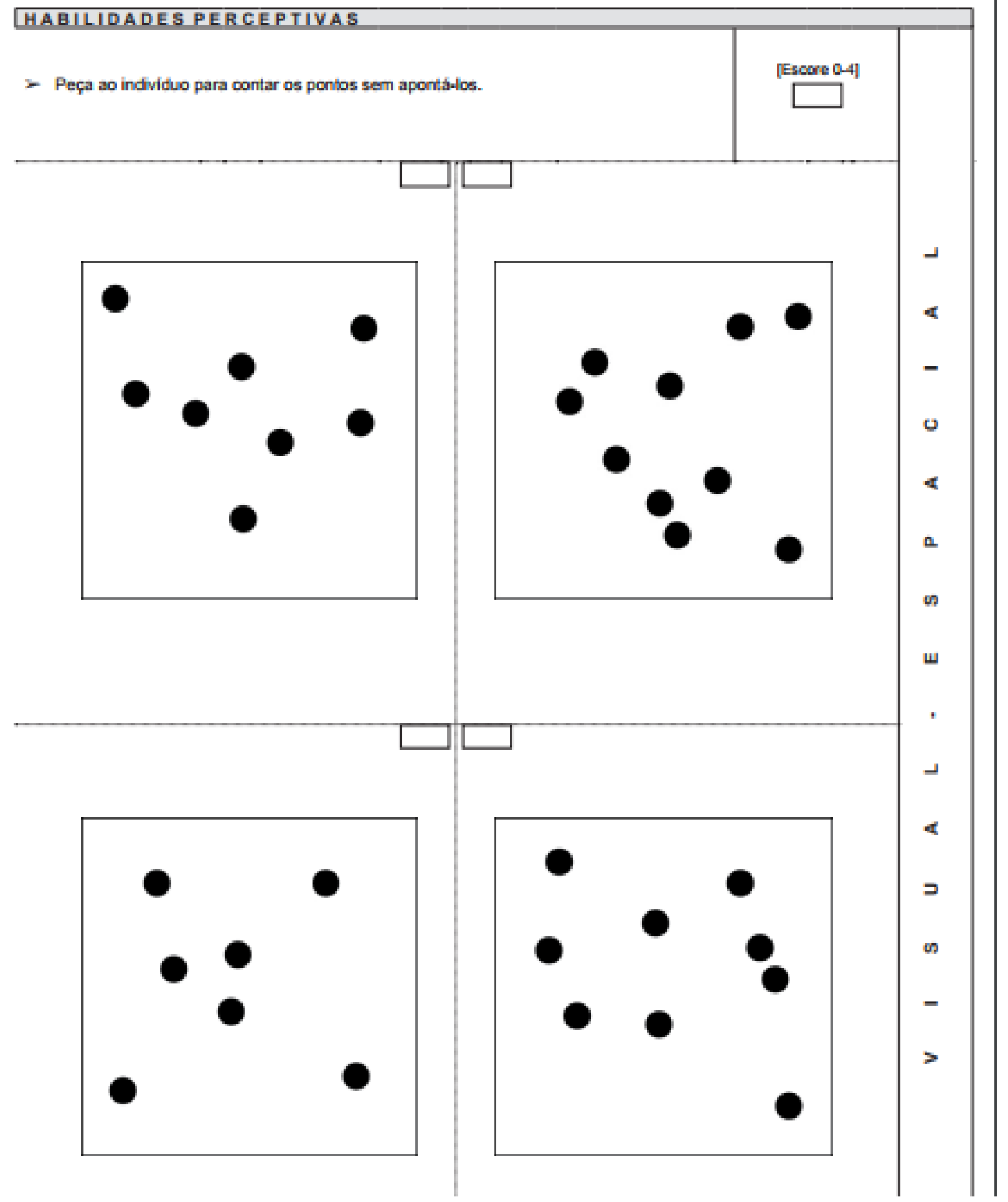


EXAME COGNITIVO DE ADOENBROOKE - VERSÄO REVISADA

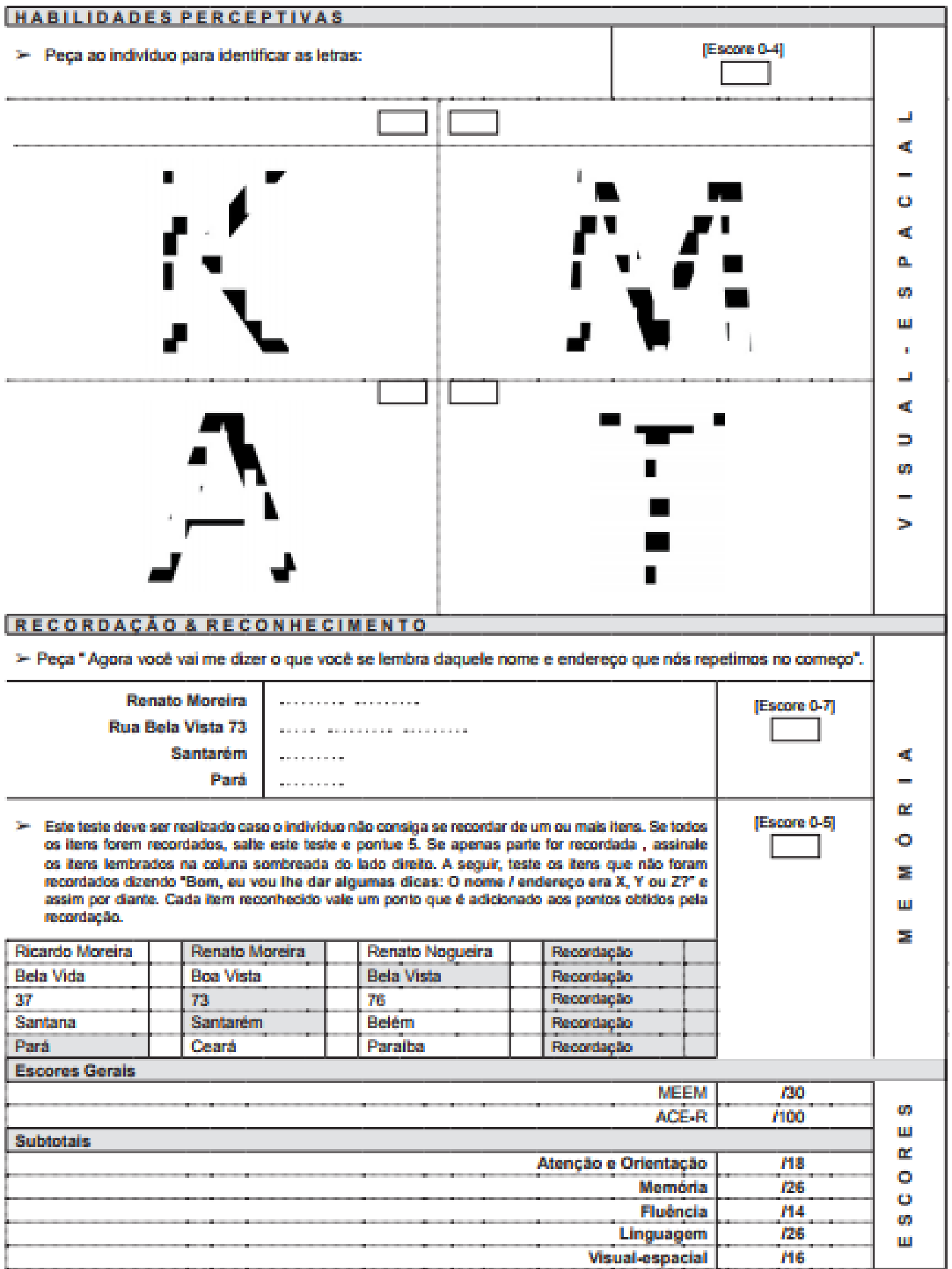




\section{Apêndice 2}

Escala de Orientação de Santa Bárbara

ESCALA DE ORIENTAÇAO DE SAHTA BARBARA

Home:

Data:

Sex: $F$ M Idade:

Nes te ques tionário você veráuma série de afirmativas relacionadas à sua orientação es pecial, capacidade de navegação, preferências e experiências . A pós cada afirmativa, você deve circularo rúmero que indica o seu grau de concordância com a frase. Circule " 1 " se você concorda totalmente que a afimativa se aplica a você e 7 se você dis corda totalmente, ou então algum rúmero entre es ses dois, se você conconda ou dis corda parcialmente. Circule 4 se você nem concorda nem discorda.

1. Eu sou ruito bomboaem dar direções .

Concordo totalmente $1 \quad 2 \quad 3 \quad 4 \quad 5 \quad 5 \quad 6 \quad 7$ Discordo totalmente

\section{Eu tenho uma memória ruim de onde eu deixo as coisas.}

\section{Concordo totalmente $1 \quad 2 \quad 3 \quad 3 \quad 4 \quad 5 \quad 6 \quad 7$ Discordo totalmente}

3. Eu sou rouito bomboa em es timar dis tâncias.

Concordo totalmente $1 \quad 2 \quad 3 \quad 4 \quad 5 \quad 5 \quad 6 \quad 7$ Discordo|totalmente

4. Meu serso de direção é rruito bom.

Concordo totalmente $1 \quad 2 \quad 3 \quad 4 \quad 4 \quad 5 \quad 6 \quad 7$ Discordo totalmente

5. Eu cos tumo pens ar no amb iente em termos de pontos cardinais (Norte, sul, les te, oes te)

Concordo totalmente $1 \quad 2 \quad 3 \quad 4 \quad 5 \quad 5 \quad 6 \quad 7$ Discordo totalmente

\section{Eu me perco com facilidade em uma nova cidade}

Concordo totalmente $1 \quad 2 \quad 3 \quad 3 \quad 4 \quad 5 \quad 6 \quad 7$ Discordo totalmente

7. Eu gos to de ler mapas.

Concordo totalmente $1 \quad 2 \quad 3 \quad 3 \quad 4 \quad 5 \quad 6 \quad 7$ Discordo totalmente 
8. Eu tenho dificuldade para entender direçŏes.

Concordo totalmente $1 \quad 2 \quad 3 \quad 4 \quad 4 \quad 5 \quad 6 \quad 7$ Discordo totalmente

9. Eu sou nouito bomboaem ler mapas.

Concordo totalmente $1 \quad 2 \quad 3 \quad 4 \quad 5 \quad 6 \quad 7$ Discordo totalmente

10. Eu năo me lembro muito bem dos caminhos quando estoude carona como passageiro.

Concordo totalmente $1 \quad 2 \quad 3 \quad 3 \quad 4 \quad 5 \quad 6 \quad 7$ Discordo totalmente

11. Eu năo gosto de dar direçŏes.

Concordo totalmente $1 \quad 2 \quad 3 \quad 4 \quad 5 \quad 6 \quad 7$ Discordo totalmente

12. Năo é inportante para mim me bcalizar onde estou

Concordo totalmente $1 \quad 2 \quad 3 \quad 3 \quad 4 \quad 5 \quad 6 \quad 7$ Discordo totalmente

13. Eu gerabmente deico que outra pessoa se encarregue de faxer o planejamento das rotas e caminhos em viagens mais bngas.

Concordo totalmente $1 \quad 2 \quad 3 \quad 4 \quad 5 \quad 5 \quad 7$ Discordo totalmente

14. Eu geralmente cons izo me lemb rar de um novo caminho depois de ter percorrido ele uma vez.

Concordo totalmente $1 \quad 2 \quad 3 \quad 4 \quad 4 \quad 5 \quad 6 \quad 7$ Discordo totalmente

15. Eu năo tenho un bom "mapa mentaF" do ambiente a minha volta.

Concordo totalmente $1 \quad 2 \quad 3 \quad 4 \quad 4 \quad 5 \quad 6 \quad 7$ Discordo totalmente

As perguntas com pontuação invertidas es tăo emnegrito. 


\section{Apêndice 3}

Questionário de Cybersickness

Questionário de desconforto após ambiente virtual

Por favor, circule o grau em que você sentiu qualquer um dos sintomas abaixo:

\begin{tabular}{|l|l|l|l|l|}
\hline \multicolumn{1}{|c|}{ NEM UM POUCO UM POUCO } & & & \\
\hline Desconforto Geral & & & & \\
\hline Cansaço & & & & \\
\hline Dor de cabeça & & & & \\
\hline Cansaço na vista & & & & \\
\hline Aumento da salivação & & & & \\
\hline Suor & & & & \\
\hline Náusea & & & & \\
\hline Dificuldade de se concentrar & & & & \\
\hline Taquicardia & & & & \\
\hline Visão borrada & & & & \\
\hline Tontura (com os olhos fechados) & & & & \\
\hline Tontura (com os olhos abertos) & & & & \\
\hline Confusão mental & & & & \\
\hline Vertigem & & & & \\
\hline Desconforto abdominal & & & & \\
\hline Refluxo & & & & \\
\hline
\end{tabular}




\begin{abstract}
Apêndice 4
Questionário de Desconforto e Rastreio para Cinetose

Questionário de rastreio para desconforto antes da realidade virtual
\end{abstract}

1. Você está sentindo algum desconforto neste momento?

$\square \operatorname{Sim} \square$ Não

Descreva:

2. Você teve episódios de vômito ou enjôo hoje ou nos últimos dias?

$\square \operatorname{Sim} \square$ Não

3. Você tem histórico de enjôo relacionado a algum meio de trasnporte?

$\square \operatorname{sim} \square$ Não

Se sim, por favor descreva onde (carro, em barcos, trens, avião) e quando (recentemente vs há muito tempo ou na infância):

4. Você já sentiu tonturas ou náuseas enquanto assistia a um filme em uma tela grande (e.x. cinema)?

$\square \operatorname{Sim} \square$ Não

Descreva:

5. Você sente enjôo ou tontura quando lê em um carro ou ônibus em movimento?

$\square \operatorname{sim} \square$ Não

6. Você prefere ser o motorista ao invés do passageiro, porque senão você sente tonturas ou náuseas?

$\square \operatorname{sim} \square$ Não 


\begin{abstract}
Apêndice 5
Questionário de Presença de Witmer \& Singer (Perguntas 1 a 5)
\end{abstract}

Descreva sua experiência neste ambiente virtual, marcando um "X" na escala de 7 pontos abaixo, de acordo com o conteúdo da pergunta e as respostas apresentadas.

Por favor, considere toda a escala ao fazer suas respostas, inclusive os niveis intermediários, se aplicáveis. Sinta-se à vontade para responder às perguntas independentemente da ordem em que aparecem. Não pule nenhuma pergunta.

\title{
Em relação ao experimento do CAMINHO NO INSTITUTO CENTRAL:
}

1. 0 quanto você sentiu que podia controlar os eventos?

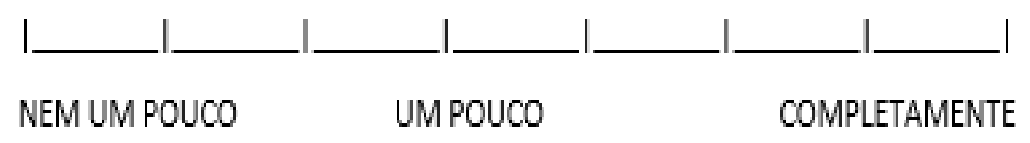

2. Você achou que 0 ambiente respondeu às ações que você fez?

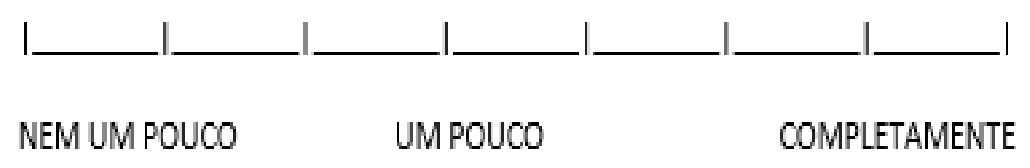

3. Como você acha que foi a sua interação com o ambiente?

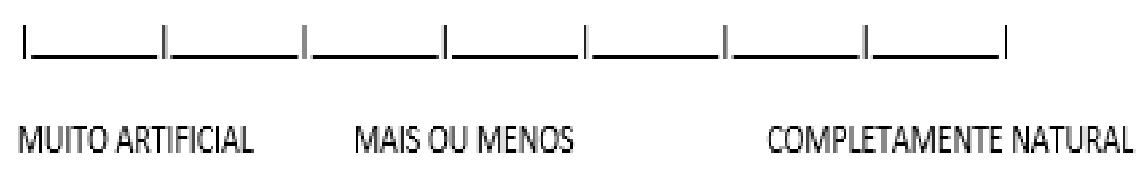

4. 0 quanto você acha que os aspectos visuais do ambiente te envolveram?

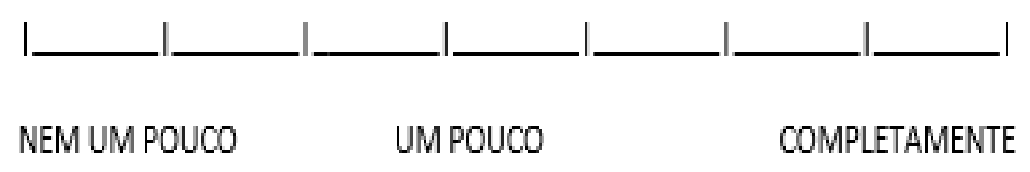

5. 0 que você achou do mecanismo que controlava o seu movimento dentro do ambiente?

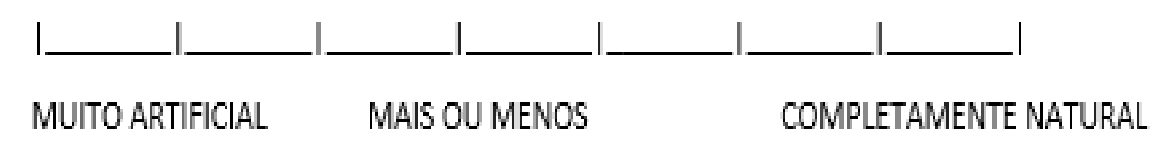




\section{Apêndice 6}

Questionário de Uso e Familiaridade com Tecnologia

Nome:

Data:

Descreve sua experiência com o uso da tecnologia. Por favor, considere toda a escala ao fazer suas respostas, inclusive os níveis intermediários, se aplicáveis. Sinta-se à vontade para responder às perguntas independentemente da ordem em que aparecem. Não pule nenhuma pergunta.

1. Com que frequência você utiliza o computador?

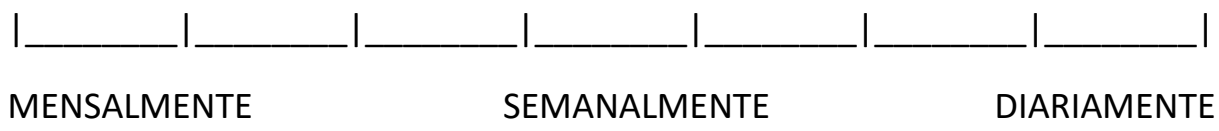

2. O seu celular é "smartphone" ou "iPhone"?

$\operatorname{Sim} \quad \square \quad$ Não

3. O seu celular tem acesso à internet?

$\operatorname{Sim} \quad \square \quad$ Não

4. Com que frequência você utiliza a internet do celular?

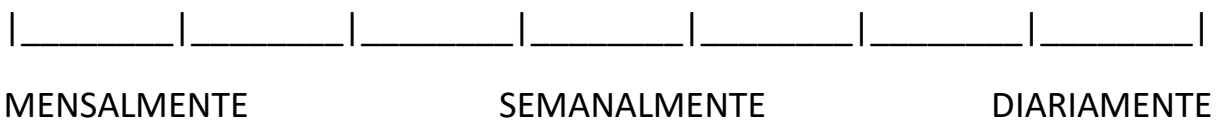

3. Você tem familiaridade com a tecnologia touchscreen?

Sim

Não

5. Você joga algum jogo no celular ou tablet?

Sim $\square$ Não

6. Com que frequência você joga no celular ou tablet?

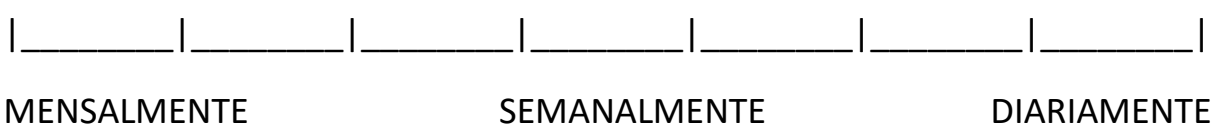

7. Você joga algum jogo de videogame?

Sim

Não

8. Com que frequência você joga videogame?

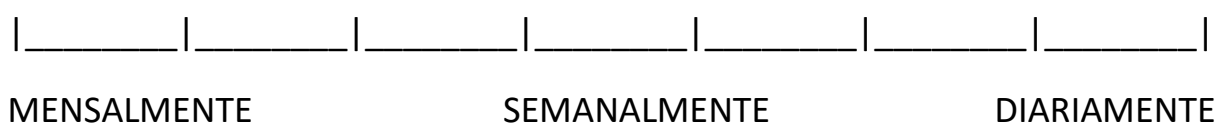

9. Você costuma utilizar o GPS ou aplicativos como Google Maps ou Waze?

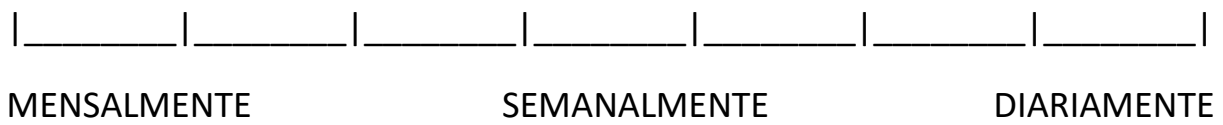

